\title{
ADVANCED MEMBRANE SEPARATION TECHNOLOGIES FOR ENERGY RECOVERY FROM INDUSTRIAL PROCESS STREAMS
}

\author{
January 14, 2013
}

\author{
Prepared by \\ James R. Keiser, ORNL, Principle Investigator \\ Dexin Wang, Gas Technology Institute \\ Brian Bischoff, ORNL \\ Rich Ciora, Media and Process Technology \\ Balasubramaniam Radhakrishnan, ORNL \\ Sarma B. Gorti, ORNL
}

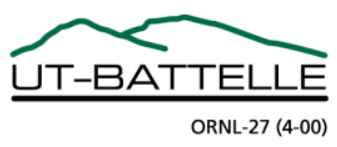




\section{DOCUMENT AVAILABILITY}

Reports produced after January 1, 1996, are generally available free via the U.S. Department of Energy (DOE) Information Bridge.

Web site http://www.osti.gov/bridge

Reports produced before January 1, 1996, may be purchased by members of the public from the following source.

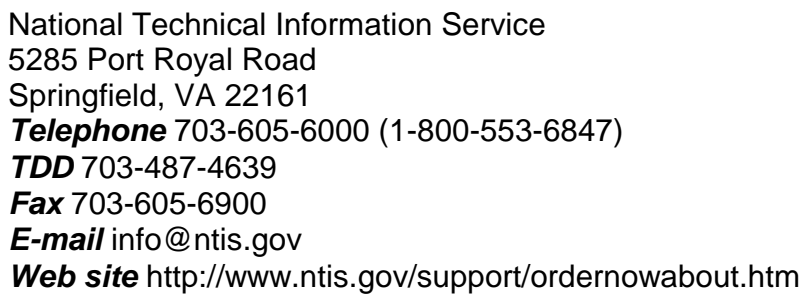

Reports are available to DOE employees, DOE contractors, Energy Technology Data Exchange (ETDE) representatives, and International Nuclear Information System (INIS) representatives from the following source.

Office of Scientific and Technical Information

P.O. Box 62

Oak Ridge, TN 37831

Telephone 865-576-8401

Fax 865-576-5728

E-mail reports@osti.gov

Web site http://www.osti.gov/contact.html

This report was prepared as an account of work sponsored by an agency of the United States Government. Neither the United States Government nor any agency thereof, nor any of their employees, makes any warranty, express or implied, or assumes any legal liability or responsibility for the accuracy, completeness, or usefulness of any information, apparatus, product, or process disclosed, or represents that its use would not infringe privately owned rights. Reference herein to any specific commercial product, process, or service by trade name, trademark, manufacturer, or otherwise, does not necessarily constitute or imply its endorsement, recommendation, or favoring by the United States Government or any agency thereof. The views and opinions of authors expressed herein do not necessarily state or reflect those of the United States Government or any agency thereof. 
Advanced Manufacturing Office

\title{
ADVANCED MEMBRANE SEPARATION TECHNOLOGIES FOR ENERGY RECOVERY FROM INDUSTRIAL PROCESS STREAMS
}

\author{
Authors: \\ James R Keiser, ORNL \\ Dexin Wang, Gas Technology Institute \\ Brian Bischoff, ORNL \\ Rich Ciora, Media and Process Technology \\ Balasubramaniam Radhakrishnan, ORNL \\ Sarma B. Gorti, ORNL
}

Date Published: January 14, 2013

Prepared by

OAK RIDGE NATIONAL LABORATORY

Oak Ridge, Tennessee 37831-6283

managed by

UT-BATTELLE, LLC

for the

U.S. DEPARTMENT OF ENERGY

under contract DE-AC05-00OR22725 



\section{CONTENTS}

LIST OF FIGURES

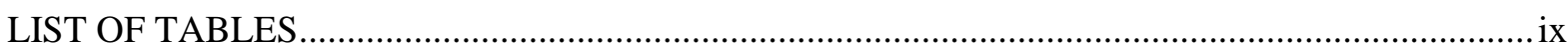

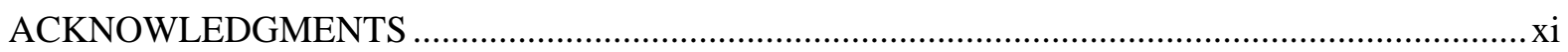

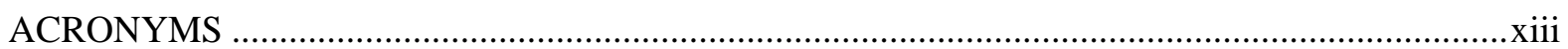

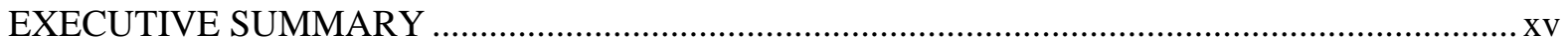

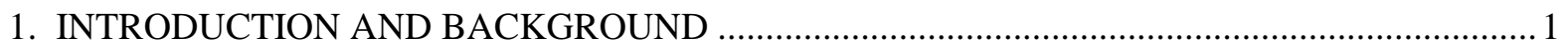

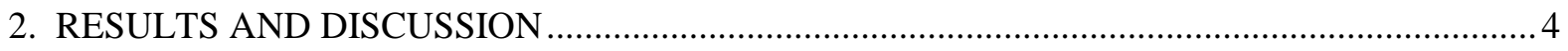

2.1. TASK 1 - IDENTIFY TARGET ENVIRONMENTS AND DESIRED REMOVAL

EFFICIENCIES

2.2 TASK 2 - DEFINE MATERIAL AND MEMBRANE MODULE DEVELOPMENT

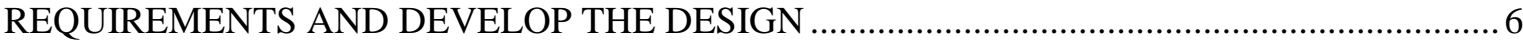

2.2.1. Morphological Description of Fouling Constituents ................................................... 7

2.2.2. Fouling Mechanism in Filtration via MF/UF ................................................................ 7

2.2.3. Fouling That Results from Pore Penetration and Clogging/Plugging by Dissolved Organic

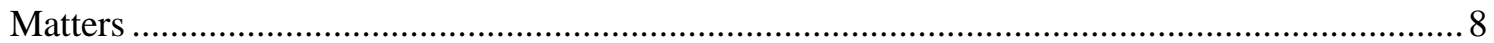

2.2.4. Fouling Due to Surface Interaction with DOM and Formation of Stagnant Cake Layer.... 10

2.2.5. Flux Loss due to the Concentration Polarization (CP) Layer Formation and the

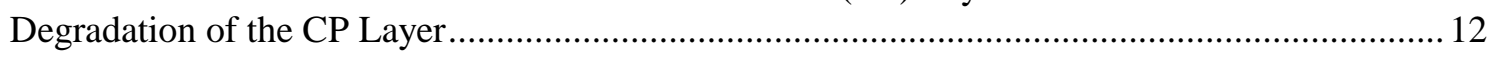

2.2.6. Proposed Technical Approach to Overcome Barriers .......................................................... 13

2.3. TASK 3 - SELECT CANDIDATE MATERIALS FOR MEMBRANE AND SUBSTRATE

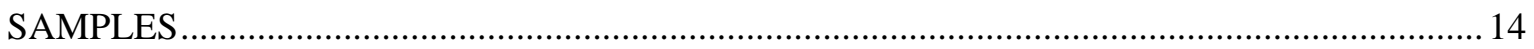

2.4. TASK 4 - FABRICATE MEMBRANES FROM CANDIDATE MATERIALS ..................... 15

2.5. TASK 5 - EVALUATE MEMBRANES UNDER LABORATORY CONDITIONS .............. 18

2.6. TASK 6 - FABRICATE PROTOTYPE TMCS FROM THE MOST PROMISING

CANDIDATES

2.7. TASK 7 - CONDUCT BENCH-SCALE TESTING OF PROTOTYPE TMC MODULES .... 34

2.8 TASK 8 - PERFORM CFD SIMULATION OF TMC FOR WATER VAPOR AND HEAT

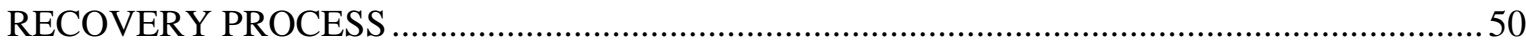

2.9 TASK 9 - CONDUCT COMMERCIAL SCALE PROTOTYPE TESTING ….......................62

2.10 TASK 10 - CONDUCT PRODUCT OPTIMIZATION STUDIES, ECONOMIC ANALYSIS

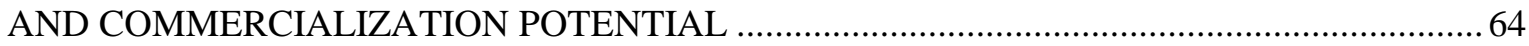

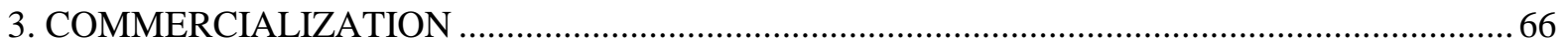

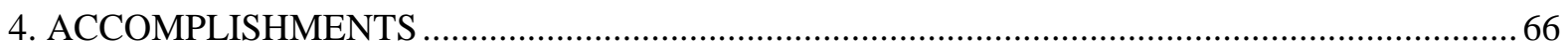

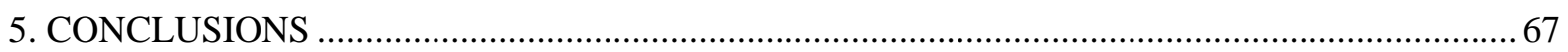

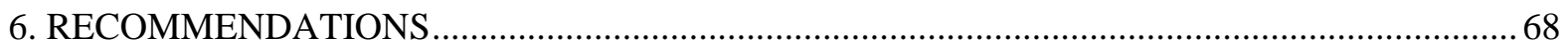

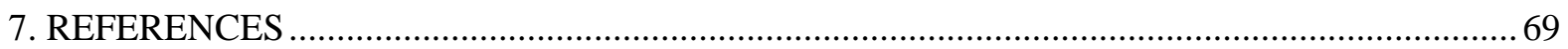





\section{LIST OF FIGURES}

Figure 1. Depiction of the original GTI transport membrane condenser technology with water flow on

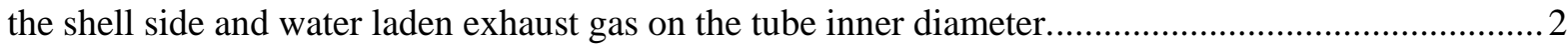

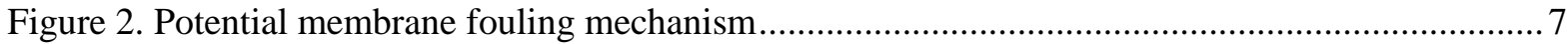

Figure 3. Effect of pore size on membrane permeance decay during filtration of Allegheny River water at a very low TMP. Significant flux loss from pore plugging/penetration was observed for the $50 \mathrm{~nm}$ but not for 10 and $4 \mathrm{~nm}$ (see expanded view in Figure 4) pore size membranes.

Figure 4. Expanded view of Fig. 3 showing the effect of pore size (4 and $10 \mathrm{~nm})$ on membrane permeance decay during filtration of Allegheny River water. Unlike the $50 \mathrm{~nm}$ pore size membrane, the permeance shows a rapid drop (due to rapid CP layer formation and surface interaction) followed by a steady state permeance, indicative of little or no irreversible pore plugging/penetration.

Figure 5. Effect of membrane rinsing and backpulsing on flux permeance recovery for a $50 \mathrm{~nm}$ M\&PT ceramic membrane treating Allegheny River water. TMP is $68 \mathrm{kPa}$. Rinsing and backpulsing was effective, but not completely restoring the original clean water flux. Rinsing and backpulsing effectiveness declined significantly in the following cycling. The permeance flux declined continuously throughout the 1 st and 2 nd cycles due to the pore plugging/penetration of the membrane with a large pore size $(50 \mathrm{~nm}$.).

Figure 6. Effectiveness of membrane rinsing and backpulsing for a modified (sulfonic acid) and unmodified M\&PT alumina $(50 \mathrm{~nm})$ membrane at TMP=68 kPa. Significant permeance flux recovery is noted after rinsing for the alumina membrane. The modified membrane regains little or no permeance via membrane rinsing, although its permeance is higher than the unmodified membrane. This indicates that the fouling in the unmodified membrane partially results from interaction with the membrane surface.

Figure 7. Effects of transmembrane pressure on membrane permeance during filtration of Allegheny

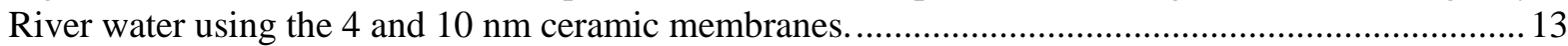
Figure 8. Pore size distribution of M\&PT ceramic membranes. ....................................................... 13 Figure 9. SEM photomicrographs of the TMC membrane elements (ORNL modified ORNL substrate) showing defects that yield bubbles in water bubble testing.

Figure 10. Weight change versus exposure time for ferritic alloys with different chromium content (wt $\%$ ) exposed to aqueous solution containing $600 \mathrm{ppm}$ sulfur dioxide at $90^{\circ} \mathrm{C}$.

Figure 11. TMC membrane element (ORNL ceramic layer on ORNL stainless substrate) clean water

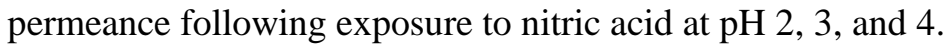

Figure 12. TMC membrane element (MPT ceramic layer on M\&PT ceramic substrate) clean water permeance following exposure to sulfurous acid at $\mathrm{pH} 2,3$, and 4 for up to 20 days.

Figure 13. SEM photomicrographs of the TMC membrane elements (ORNL modified ORNL substrate) showing original membrane (left) and membrane after 55 days in nitric acid at $\mathrm{pH} 2$ and $85^{\circ} \mathrm{C}$ (right).

Figure 14. SEM photomicrographs of the TMC membrane elements (M\&PT modified M\&PT substrate) following exposure to $\mathrm{pH} 2$ and 3 and compared with the virgin (control) membrane. Intermediate substrate is clearly visible through the heavily damaged $\mathrm{pH} \sim 2$ exposed part in the 4,420X micrograph.

Figure 15. Flow-weighted pore size distribution of metallic supported membranes coated by M\&PT heated at two temperatures.

Figure 16. Cumulative flow starting at large pore sizes versus pore size for metal supported membranes coated by M\&PT in two steps.

Figure 17. Flow weighted pore size distribution of membranes coated by ORNL in a single step and treated at $300^{\circ} \mathrm{C}$

Figure 18. Cumulative flow versus pore size for membranes coated by ORNL in a single step at 
Figure 19. Flow weighted pore-size distribution of ORNL prepared membranes treated at $950^{\circ} \mathrm{C} . \ldots 27$ Figure 20. Cumulative flow versus pore size for membranes coated by ORNL in a single step treated at $950^{\circ} \mathrm{C}$.

Figure 21. Electron micrograph showing cross section of aluminum oxide ooxide layer on surface of

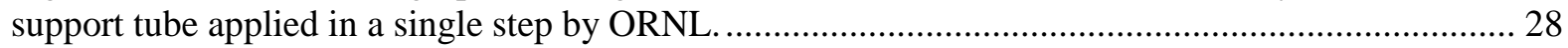
Figure 22. Electron micrograph showing enlarged area where aluminum oxide penetrates into the gap between the support tube particles. 28 Figure 23. Electron micrograph showing layer of fine stainless steel on surface of support tube taken at $500 \mathrm{X}$......

Figure 24 Electron micrograph showing layer of fine stainless steel on surface of support tube taken at 2000X.

Figure 25. Electron micrograph showing layer of fine nickel on surface of support tube taken at 500X.

Figure 26. Electron micrograph showing layer of fine nickel on surface of support tube taken at 2000X.

Figure 27. Electron micrograph taken at an angle showing how layer of fine nickel improves smoothness of surface. Large particles from support can be seen sticking through nickel layer. ........ 31 Figure 28. SEM micrographs of the surface and cross section of the typical finished full length tube with a stainless steel substrate and ceramic intermediate and outer layers. 32 Figure 29. Dimensional consistency of the stainless steel substrates; Maximum OD and Maximum OD-Minimum OD for 192 tubes are characterized.

Figure 30. SEM photomicrographs of the surface of the Batch \#2 membranes at 500x following exposure to $\mathrm{SO}_{2}$ laden combustion gas. There is no evidence of membrane cracking or pinholing. The


Figure 31. SEM photomicrographs of the surface of the Batch \#2 membranes at 1,500x and 5,000x following exposure to $\mathrm{SO}_{2}$ laden combustion gas. There is no evidence of membrane cracking or pinholing. The stripes in the part are scratches likely due to handling. .....

Figure 32. SEM photomicrographs of the surface of the M\&PT TMC membrane elements exposed to $\mathrm{pH} \sim 2$ of sulfuric acid in tests described in Table 8 after 100 and 1,300 hours of exposure at $85^{\circ} \mathrm{C} \ldots 40$ Figure 33. SEM photomicrographs of the surface of the M\&PT TMC membrane elements exposed to $\mathrm{pH} \sim 3$ of sulfuric acid in tests described in Table 8 after 100 and 1,300 hours of exposure at $85^{\circ} \mathrm{C} . \ldots 41$ Figure 34. SEM photomicrographs of the surface of the M\&PT TMC membrane elements exposed to $\mathrm{pH} \sim 4$ of sulfuric acid in tests described in Table 8 after 100 and 1,300 hours of exposure at $85^{\circ} \mathrm{C} . \ldots 42$ Figure 35. SEM photomicrographs of the cross section of the M\&PT TMC membrane elements exposed to $\mathrm{pH} \sim 2$ and $\sim 4$ of sulfuric acid in tests described in Table 8 after 100 and 1,300 hours of exposure at $85^{\circ} \mathrm{C}$.

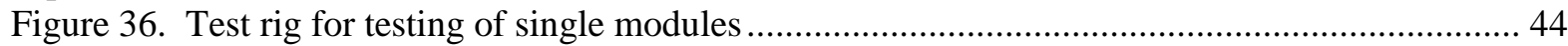

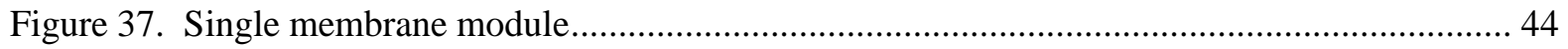

Figure 38. Flue gas inlet temperature effect on TMC water transfer rate. ....................................... 45

Figure 39. Water inlet temperature effect on TMC water transfer rate .......................................... 45

Figure 40. Water inlet flow rate effect on TMC water transfer rate .............................................. 46

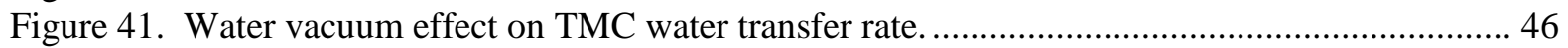

Figure 42. ID and OD membrane coating effect on TMC water transfer rate. .................................. 47

Figure 43. Different membrane pore sizes effect on TMC water transfer rate. ................................ 47

Figure 44. Flue gas high moisture content effect on TMC water transfer rate. ................................ 48

Figure 45. Flue gas high moisture content effect on TMC heat recovery rate................................ 48

Figure 46. Water transfer rate for metallic and ceramic substrate membrane tubes ........................... 49

Figure 47. Heat recovery rate for metallic andceramic substrate membrane tubes ............................ 50

Figure 48. Schematic of the CFD condensation/evaporation and transportation models. ................... 51 
Figure 49. CFD simulation compared with test results for the 200 HP TMC.

Figure 50. CFD simulation suggests a 3-pass TMC new design.

Figure 51. Mesh for the finite element model to study heat transfer in a single tube showing a section of the tube near the inlet.

Figure 52. Temperature distribution $\left[{ }^{\circ} \mathrm{C}\right]$ from heat transfer analysis of single tube near the tube outlet.

Figure 53. Schematic representation of the water meniscus at the top (outer) surface of the membrane for the case of a cylindrical pore.

Figure 54. Temperature of the water (red) and $\mathrm{CO}_{2}$ (green) molecules during the $350 \mathrm{~K}$ run. .58 Figure 55. Initial distribution (left) and final distribution (right) of the water molecules (green and blue) and $\mathrm{CO}_{2}$ molecules (red and yellow) showing clustering of water molecules for the $300 \mathrm{~K}$ run. Similar trend was observed for the $350 \mathrm{~K}$ also.

Figure 56. GCMS simulations showing capillary condensation of water in a rectangular cavity, (a) temperature $=0.4$, pore size $=5.0 ;$ (b) temperature $=0.5$, pore size $=5.0 ;(\mathrm{c})$ temperature $=0.4$, pore size $=8.0$. Increasing the temperature at constant pore size or increasing pore size at constant temperature lead to reduction in the amount of capillary condensation.

Figure 57. Variation of condensed water content in the pore as a function of chemical potential of water (proportional to the relative humidity). Sudden increase in the fraction condensed indicates filling of pores by capillary condensation.

Figure 58. Comparison condensation curves for bulk and a pore of reduced radius of 4.0. The reduced temperature is 0.40 .

Figure 59. Bulk condensation as a function of reduced temperature with an activity level of -1.8 . Condensed water appears below a reduced temperature of 0.38 and becomes significant at much lower reduced temperatures.

Figure 61. Effect of average water temperature on water and heat recovery....

Figure 62. Water and heat recovery performance for metallic-tube modules and ceramic-tube modules. 



\section{LIST OF TABLES}

Table 1. Industrial environments with high moisture content as proposed by project participants ......... 5

Table 2. Candidate substrate alloys and relevant properties of each .............................................. 15

Table 3. Properties of Supports Fabricated from 434L Stainless Steel ............................................ 16

Table 4. Thermal conductivity of potential membrane components ................................................... 19

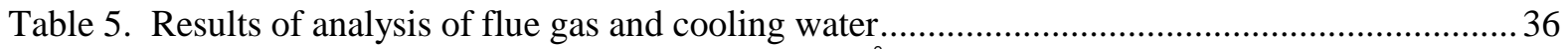

Table 6 . Batch \#1 fouling test results: Permeance of $100 \AA$ pore M\&PT ceramic membranes before and after fouling tests conducted at the GTI test facility following exposure to combustion gas from a natural gas burner for 100 hours. Permeance is in liters $/ \mathrm{m} 2 / \mathrm{hr} / \mathrm{bar}$. Testing was conducted with distilled water prefiltered to $80 \AA$. Water permeance tests were conducted at about $22^{\circ} \mathrm{C}$ and $10 \mathrm{psig}$

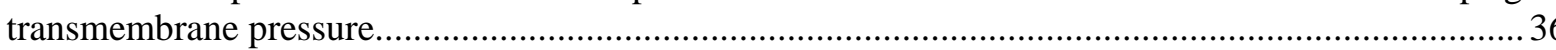

Table 7. Batch \#1 fouling test results: Permeance of $100 \AA$ pore M\&PT ceramic membranes before and after fouling tests conducted at the GTI test facility following exposure for 100 hours to combustion gas from a natural gas burner spiked with $300 \mathrm{ppm} \mathrm{SO}$. Permeance is in liters $/ \mathrm{m} 2 / \mathrm{hr} / \mathrm{bar}$. Testing was conducted with distilled water prefiltered to $80 \AA$. Water permeance tests were conducted at about $22^{\circ} \mathrm{C}$ and $10 \mathrm{psig}$ transmembrane pressure. 36 Table 8. Water permeance of ceramic based TMC membrane elements following exposure to sulfuric acid spiked water at $\mathrm{pH}=2,3$, and 4 for the times shown at room temperature and $85^{\circ} \mathrm{C}$. Test solutions were prepared with distilled water. Water permeance testing was conducted with distilled water prefiltered at $80 \AA \AA$. Water permeance tests were conducted at about $22^{\circ} \mathrm{C}$ and $10 \mathrm{psig}$ transmembrane pressure. No permeance testing was conducted with the ceramic layer modified

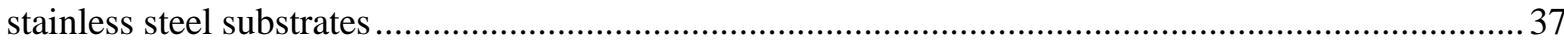

Table 9: Key parameters of the two TMC modules and the small OD module as reference.................49

Table 10. Comparison of the CFD and the test data ....................................................................52 Table 11. Comparison of the capital cost and energy cost savings of a typical $300 \mathrm{Hp}$ steam boiler operating at a base case of $80 \%$ efficiency with a (i) standalone high pressure economizer and (ii) high pressure economizer with TMC and integral low pressure economizer. Assumes 8,400 annual operating hours and natural gas at $\$ 8.50 / \mathrm{MCF}$. 



\section{ACKNOWLEDGMENTS}

This project was funded by the US Department of Energy (DOE), Office of Energy Efficiency and Renewable Energy (EERE) Advanced Manufacturing Office (AMO). This material project was managed as CPS Agreement Number: 14953 under CPS Project Number: 18737 and was conducted from 09/01/2006 through 09/30/2011. The lead organization was the Oak Ridge National Laboratory (ORNL). Other project partners included:

Gas Technology Institute - Subcontractor and Cost Share Partner

Media and Process Technology Inc - Subcontractor and Cost Share Partner

University of Tennessee-Knoxville - Subcontractor

Alcoa Aluminum - Cost Share Partner

Cleaver Brooks - Cost Share Partner

Domtar Inc - Cost Share Partner

Dow Chemical - Cost Share Partner

Meadwestvaco - Cost Share Partner

Weyerhaeuser Company - Cost Share Partner 


\section{ACRONYMS}

\begin{tabular}{ll} 
AMO & Advanced Manufacturing Office \\
CBW & Cannon Boiler Works \\
CFD & Computational Fluid Dynamics \\
CP & Concentration Polarization \\
DOE & Department of Energy \\
DOM & Dissolved Organic Matter \\
EERE & Office of Energy Efficiency and Renewable Energy \\
EPM & Elementary Physical Model \\
GCMC & Grand Canonical Monte Carlo \\
GPM & Gallons Per Minute \\
GTI & Gas Technology Institute \\
HP & Horse Power \\
Lmhb & liters/m²/hr/bar \\
ID & Inner Diameter \\
MF & Microfiltration \\
MMBtu & Million (thousand thousand) British Thermal Units \\
M\&PT & Media and Process Technology \\
NOM & Natural Organic Matter \\
OD & Outer Diameter \\
ORNL & Oak Ridge National Laboratory \\
ppm & Parts per million \\
psi & Pounds per square inch \\
psig & pounds per square inch gage \\
QA/QC & Quality Assurance/Quality Control \\
R\&D & Research and Development \\
SCFH & Standard Cubic Feet Per Hour \\
SEM & Scanning Electron Microscope \\
SMM & Surface Modified Membrane \\
SS & Suspended Solid \\
TMC & Transport Membrane Condenser \\
TMP & Transmembrane Pressure \\
UF & Ultrafiltration \\
US & United States \\
VOC & Volatile Organic Carbons \\
& \\
\hline
\end{tabular}


xiv 


\section{EXECUTIVE SUMMARY}

Recovery of energy from relatively low-temperature waste streams is a goal that has not been achieved on any large scale. Heat exchangers do not operate efficiently with low-temperature streams and thus require such large heat exchanger surface areas that they are not practical. Condensing economizers offer one option for heat recovery from such streams, but they have not been widely implemented by industry.

A promising alternative to these heat exchangers and economizers is a prototype ceramic membrane system using transport membrane technology for separation of water vapor and recovery of heat. This system was successfully tested by the Gas Technology Institute (GTI) on a natural gas fired boiler where the flue gas is relatively clean and free of contaminants. However, since the tubes of the prototype system were constructed of aluminum oxide, the brittle nature of the tubes limited the robustness of the system and even limited the length of tubes that could be used.

In order to improve the robustness of the membrane tubes and make the system more suitable for industrial applications, this project was initiated with the objective of developing a system with materials that would permit the system to function successfully on a larger scale and in contaminated and potentially corrosive industrial environments. This required identifying likely industrial environments and the hazards associated with those environments. Based on the hazardous components in these environments, candidate metallic materials were identified that are expected to have sufficient strength, thermal conductivity and corrosion resistance to permit production of longer tubes that could function in the industrial environments identified. Tests were conducted to determine the corrosion resistance of these candidate alloys, and the feasibility of forming these materials into porous substrates was assessed. Once the most promising metallic materials were identified, the ability to form an alumina membrane layer on the surface of the metallic tubes was evaluated.

Evaluation of this new style of membrane tube involved exposure to $\mathrm{SO}_{2}$ containing gases as well as to materials with a potential for fouling. Once the choice of substrate and membrane materials and design were confirmed, about 150 tubes were fabricated and assembled into three modules. These modules were mounted on an industrial size boiler and their performance carefully monitored during a limited testing period. The positive results of this performance test confirm the feasibility of utilizing such a system for recovery of heat and water from industrial waste streams.

The improved module design along with use of long metallic substrate tubes with a ceramic membrane on the outer surface resulted in the successful, limited scale demonstration of the Transport Membrane Condenser (TMC) technology in the GTI test facility. This test showed this technology can successfully recover a significant amount of heat and water from gaseous waste streams. However, before industry will make the investment to install a full scale TMC, a full scale system will need to be constructed, installed and successfully operated at a few industrial sites. Companies were identified that had an interest in serving as a host site for a demonstration system. 



\section{INTRODUCTION AND BACKGROUND}

A large portion of energy consumed today comes from hydrocarbon fuel combustion, and one of the major products of this combustion is water vapor [1]. In natural gas fired industrial process units such as boilers, kilns, ovens, and furnaces, water vapor exits with the flue gases at a volume percentage up to $18 \%$. Other industrial processes such as drying, wet scrubbers, dry scrubbers, dewatering, and water chilling, produce flue gases with $20-90 \%$ moisture content. Typically the water vapor along with its substantial latent heat is exhausted into the atmosphere [2] limiting thermal efficiency of these processes since no conventional heat recovery technique can effectively recover this low grade waste heat and water vapor. Exhaust gas temperature can certainly be reduced to its condensation temperature (dew point), but large heat transfer surfaces are required which typically are not economically favorable and corrosion due to condensation limits recovery of useful energy. If 40 to $60 \%$ of this water vapor and its latent heat could be recovered, thermal efficiency would increase by approximately $10 \%$ for most of these processes.

Gas separation membranes generally can be categorized as porous and non-porous. The separation of a mixture by non-porous membranes results from differences in the solubility and diffusivity of the various components in the membrane material [3]. Non-porous membranes usually display high separation ratios however their transport fluxes are relatively low $[4,5]$. Porous membranes typically depend on some combination of molecular sieving, diffusivity, and surface effects to manage the segregation of gaseous species [6]. Porous membranes, depending on pore size can achieve higher transport fluxes than nonporous membranes but the separation ratio is usually much lower $[4,7,8]$.

However, the vapor separation characteristics of porous membranes can be greatly improved under a condition wherein the vapor condenses within the membrane pore structure to such an extent that it completely blocks the pores and prevents the transport of the non-condensable gas components. Under such a condition, which is designated as the membrane capillary condensation mode, one observes dramatic increases in the membrane separation factor towards the condensable component (e.g., water vapor) $[9,10]$. The condensed vapor transport through the membrane is thought to be governed by a pseudo-liquid phase transport; hence flux is much higher than expected from gas phase transport [11]. By working in this membrane capillary transport mode, porous membranes can achieve both high transport flux and high separation ratio.

Separating water vapor from a gas stream is a typical example of membrane separation involving a condensable component with phase change heat transfer. Relatively little investigation has been done for porous membranes working in the capillary condensation mode in the past. This is due to both the complicated nature of the capillary transport mode and historic perceptions that recovered water vapors are not commercially valuable. Only when increases in energy and water costs occurred did the importance of recovering water vapor and its latent heat from various industrial exhausts make economic sense and the exploration of new techniques began to receive further attention. In addition, fresh water has become more valuable over the past decade and therefore recovered high quality water adds value for the technology development. Water recovery from high moisture, elevated temperature waste streams is quite energy efficient since the water is already in a high energy state (vapor phase) and this energy can be eventually recovered along with the liquid water thereby increasing the overall system efficiency. It is the potential economic value of recovering such waste energy and water which justified investment in separating water vapor by membrane techniques.

The Gas Technology Institute (GTI)'s research found that a nanoporous ceramic membrane with a six 
nanometer mean pore size, when working in the Knudsen diffusion transport mode has low water vapor transport flux and poor separation characteristics, as expected. But when the gas stream is adequately cooled by heat transfer from the permeate side and the relative humidity of the flue gas increases, the capillary transport mode is produced in the porous membrane. Water vapor transport flux then increases by a factor of more than 5 from the value measured in the Knudsen diffusion mode and the separation ratio is greatly improved by a factor of more than 100. Consequently, the onset of the membrane capillary condensation is a critical point for porous membrane vapor separation switching from a low performance mode to a high performance mode.

Figure 1 depicts the Transport Membrane Condenser (TMC) concept for boiler applications with exhaust gas flowing on one side of a nanoporous ceramic membrane tube and cold boiler feed water flowing counter-current on the opposing side. Water vapor from the flue gas is transported through the membrane structure by first condensing inside the inner separation membrane layer $(60 \AA$ to $80 \AA$ pore size), then moving through the intermediate layer ( $500 \AA$ pore size) and finally through the substrate $(0.4 \mu \mathrm{m}$ pore size). Other gas components in the flue gas are blocked from passing through the membrane by the condensed liquid. Condensed water along with its latent heat combines with the cold boiler feed water, helping to raise its temperature prior to entering the boiler feed water tank or deaerator. A small vacuum is maintained on the water side of the device to prevent backflow of water due to liquid pressure head and also to provide additional driving force for water to pass through the membrane.

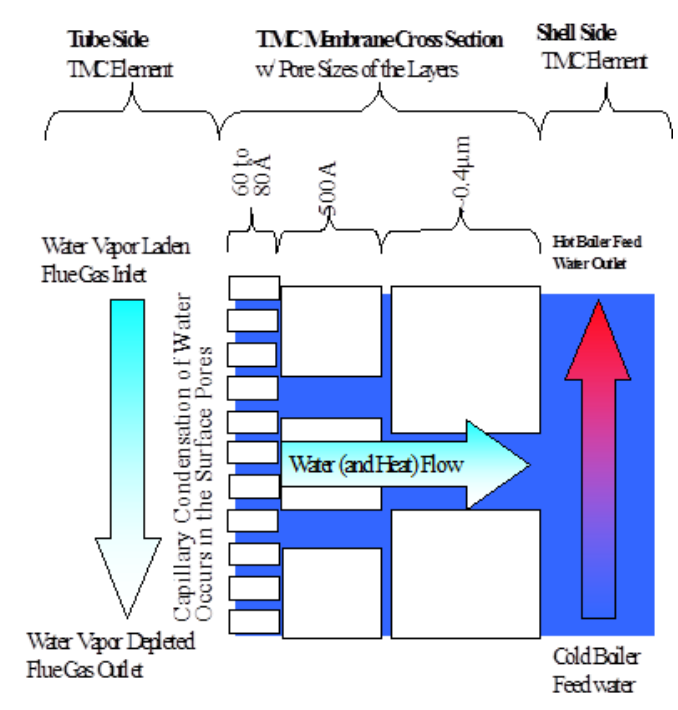

Figure 1. Depiction of the original GTI transport membrane condenser technology with water flow on the shell side and water laden exhaust gas on the tube inner diameter.

Recovery of energy from relatively low-temperature waste streams is a goal that has not been achieved on any large scale. Heat exchangers do not operate efficiently with low-temperature streams and thus require such large heat exchanger surface areas that they are not really practical. Condensing economizers offer one option for heat recovery from such streams, but they have not been widely implemented by industry. A prototype ceramic membrane system using transport membrane technology for separation of water vapor and recovery of heat was successfully tested by GTI on a natural gas fired boiler where the flue gas is relatively clean and free of contaminants. In order to improve the robustness and performance, the entire transport membrane condenser system was redesigned and alternate materials identified that are less fragile and have better thermal conductivity. Industrial waste gas emissions are produced in most industrial processes, but these gas streams will 
contain contaminants that will foul and/or react with the surface of the membranes. Consequently, improved materials are needed that will make the membranes stronger/tougher, that will be better thermal conductors to promote water condensation, and that are sufficiently corrosion resistant to minimize degradation in the hostile industrial environments. 


\section{RESULTS AND DISCUSSION}

The activities on this project were divided into ten tasks, and the work on each task was carried out by a combination of the project participants. The research conducted for each task can be described in the following manner.

\subsection{TASK 1 - IDENTIFY TARGET ENVIRONMENTS AND DESIRED REMOVAL EFFICIENCIES}

Through input from industrial representatives in this project, four major categories of waste gas streams/environments with high water contents have been identified (see Table 1). They are: Super Boilers which primarily burn natural gas but have fuel oil as an alternate fuel; Calciners with natural gas and fuel oil as possible fuels; Lime Kilns which also use natural gas and fuel oil as the fuel; and Other Boilers, primarily recovery boilers, but also biomass and power boilers. These possibilities cover a significant number of industrial waste streams with high moisture content that have potential value for using TMCs to recover moisture and the latent heat. The moisture content of these streams ranges from about 10 to about $60 \mathrm{vol} \%$. For application of TMCs, a moisture content higher than $15 \%$ is preferred, but some of the low moisture content environments produced by burning fuel oil were considered it frequently serves as an alternate fuel for natural gas and other fuels.

A water content higher than $15 \%$ in the exhaust streams would allow the TMCs to work more efficiently in recovering the water vapor and its latent heat, and most of the above applications being considered have much higher moisture content. Possible corrosive components in these streams include $\mathrm{SO}_{2}$ and $\mathrm{CO}_{2}$, and possible fouling components are various particulates, which include soot produced from local, rich combustion, and various salts and other inorganic material carried along in the exhaust gases.

Recovery of water vapor and its associated latent heat from an industrial exhaust stream depends on many other factors besides the membrane characteristics itself. This includes such things as the initial water vapor content in the waste stream, the stream temperature, the available cooling water flow rate and the temperature of the cooling water. As a first estimate, the goal for the new membrane to be developed in this project was an increase in the water transport flux by $50 \%$. In order to provide a better basis for selection of the goal for improvement in water recovery, a study was initiated of the possible process configurations based on the TMC concept in conjunction with conventional heat exchanger. The goal was to establish the overall process economics (capital cost, operating costs, energy savings) as a function of heat/water recovery.

For laboratory and bench-scale testing it is important to identify suitable environments for the testing. In many aspects, the combustion products listed in Table 1 are quite similar but with some variation in the percentage on each component, so a natural gas fired burner should provide a suitable baseline waste stream. By adding selected components, such as $\mathrm{SO}_{2}$, to this gas stream, it should be possible to provide a laboratory simulation of the gas stream produced by combustion of other fuels. This would be used for the laboratory testing. For prototype testing, a natural gas fired waste stream should be the target with fuel oil as the backup fuel. 
Table 1. Industrial environments with high moisture content as proposed by project participants

\begin{tabular}{|c|c|c|c|c|c|c|c|c|c|c|}
\hline Environment & $\begin{array}{c}\text { Temp } \\
\left({ }^{\circ} \mathbf{C}\right)\end{array}$ & $\begin{array}{l}\mathrm{H}_{2} \mathrm{O} \\
(\% *)\end{array}$ & $\begin{array}{l}\mathrm{N}_{2} \\
(\%)\end{array}$ & $\begin{array}{l}\mathrm{O}_{2} \\
(\%)\end{array}$ & $\begin{array}{l}\mathrm{CO}_{2} \\
(\%)\end{array}$ & $\begin{array}{c}\mathrm{CO} \\
(\mathrm{ppm})\end{array}$ & $\begin{array}{c}\mathbf{N O}_{\mathbf{x}} \\
(\mathbf{p p m})\end{array}$ & $\begin{array}{c}\mathbf{S O}_{\mathbf{x}} \\
(\mathbf{p p m})\end{array}$ & $\begin{array}{c}\text { HC/VOC } \\
\text { (ppm) }\end{array}$ & Other \\
\hline \multicolumn{11}{|l|}{ Super Boiler } \\
\hline $\begin{array}{l}\text { Natural gas ( } 3 \% \\
\text { dry } \mathrm{O}_{2} \text { at stack) }\end{array}$ & 210 & 18 & 71.5 & 2.5 & 8 & 0 & 7 & 0 & 0 & $\begin{array}{l}\mathrm{PM}-0.01 \\
\mathrm{Lb} / \mathrm{MMBtu}\end{array}$ \\
\hline $\begin{array}{l}\text { Fuel oil \#2 }(3 \% \\
\text { dry } \mathrm{O}_{2} \text { at stack) }\end{array}$ & 221 & 10.7 & 74.9 & 2.6 & 11.9 & 49 & 70 & 278 & 4 & $\begin{array}{l}\mathrm{PM}-0.025 \\
\mathrm{Lb} / \mathrm{MMBtu}\end{array}$ \\
\hline $\begin{array}{l}\text { Fuel oil \#6 (3\% } \\
\text { dry } \mathrm{O}_{2} \text { at stack) }\end{array}$ & 221 & 9.3 & 75.4 & 2.6 & 12.6 & 95 & 502 & 278 & 70 & $\begin{array}{l}\mathrm{PM}-0.16 \\
\mathrm{Lb} / \mathrm{MMBtu}\end{array}$ \\
\hline \multicolumn{11}{|l|}{ Calciner } \\
\hline Natural gas & 180 & 52.3 & 40.9 & 2.3 & 4.4 & $\begin{array}{c}0.1 \\
\max \end{array}$ & $<50$ & $3-5$ & & \multirow{2}{*}{$\begin{array}{l}10 \text { to } 50 \\
\mathrm{mg} / \mathrm{Nm}^{3} \text { with } \\
\text { excursions to } \\
350 \text { at start up } \\
\& \text { unplanned } \\
\text { shutdown. }\end{array}$} \\
\hline Fuel oil & 172 & 58.2 & 36.1 & 0.9 & 4.8 & $\begin{array}{c}0.1 \\
\max \end{array}$ & $<50$ & $\begin{array}{c}1100 \\
\text { to } \\
1500\end{array}$ & & \\
\hline \multicolumn{11}{|l|}{ Lime Kilns } \\
\hline $\begin{array}{l}\text { Longview - } \\
\text { natural gas }\end{array}$ & & 35.5 & 46.2 & 0.8 & 17.5 & & & & & $2 \%$ carbonate \\
\hline $\begin{array}{l}\text { Longview - fuel } \\
\text { oil }\end{array}$ & & 32.0 & 46.0 & 0.7 & 21.3 & & & & & $2 \%$ carbonate \\
\hline $\begin{array}{l}\text { Pine Hill - } \\
\text { natural gas }\end{array}$ & & 39.3 & 45.0 & 1.1 & 14.6 & & & & & $2 \%$ carbonate \\
\hline $\begin{array}{l}\text { Pine Hill - fuel } \\
\text { oil }\end{array}$ & & 36.6 & 44.4 & 1.1 & 18.0 & & & & & $2 \%$ carbonate \\
\hline $\begin{array}{l}\text { Espanola - \#1 } \\
\text { kiln }\end{array}$ & 70 & 32.5 & & & 14.2 & & & 311 & & \\
\hline $\begin{array}{l}\text { Espanola - \#2 } \\
\text { kiln }\end{array}$ & 67 & 29.3 & & & 16.7 & & & 8 & & \\
\hline Windsor - & 67 & 27.5 & & & 16.6 & & & 19 & & $\begin{array}{l}0.9 \mathrm{~kg} / \mathrm{h} \\
\text { particulates }\end{array}$ \\
\hline Ashdown - \#3 & 179 & 30.1 & & 4.7 & 21.1 & & & & & $\begin{array}{l}\mathrm{PM}-0.137 \\
\mathrm{lb} / \mathrm{hr}\end{array}$ \\
\hline \multicolumn{11}{|l|}{ Other Boilers } \\
\hline $\begin{array}{l}\text { New Bern - } \\
\text { recovery boiler }\end{array}$ & $\begin{array}{l}190- \\
195\end{array}$ & 12.6 & 62.1 & 2.2 & 23.1 & & & & & \\
\hline $\begin{array}{l}\text { Espanola - } \\
\text { recovery boiler }\end{array}$ & 221 & 25.0 & & & 16.0 & & & 0.2 & & \\
\hline $\begin{array}{l}\text { Espanola - \#9 } \\
\text { boiler }\end{array}$ & 96 & 13.4 & & & 8.7 & & & 0.24 & & \\
\hline $\begin{array}{l}\text { Windsor - } \\
\text { recovery boiler }\end{array}$ & 182 & 24.1 & & 5.5 & 13.5 & & & 0.94 & & $\begin{array}{l}29 \mathrm{~kg} / \mathrm{h} \\
\text { particulates }\end{array}$ \\
\hline $\begin{array}{l}\text { Windsor - } \\
\text { biomass boiler }\end{array}$ & 177 & 17.0 & & 8.9 & 11.5 & & & 0.56 & & $\begin{array}{l}2.3 \mathrm{~kg} / \mathrm{h} \\
\text { particulates }\end{array}$ \\
\hline $\begin{array}{l}\text { Ashdown - \#2 } \\
\text { recovery boiler }\end{array}$ & 200 & 27.0 & & 3.0 & 15.6 & & & & & $\begin{array}{l}\mathrm{PM}-3.87 \\
\mathrm{lb} / \mathrm{hr}\end{array}$ \\
\hline $\begin{array}{l}\text { Ashdown - } \\
\text { power boiler }\end{array}$ & 163 & 13.8 & & 9.1 & 9.4 & & & & & $\begin{array}{l}\mathrm{PM}-7.16 \\
\mathrm{lb} / \mathrm{hr}\end{array}$ \\
\hline
\end{tabular}

$*$ All \% are in volume 


\subsection{TASK 2 - DEFINE MATERIAL AND MEMBRANE MODULE DEVELOPMENT REQUIREMENTS AND DEVELOP THE DESIGN}

For efficient recovery of water and the latent heat, it is important that the individual membranes and the membrane bundle be designed to be as efficient as possible in the transfer of heat to the cooling water. Modeling that is described in Task 8 has provided some guidance on the design studies. Use of metal tubes that have sufficient corrosion resistance, high thermal conductivity and higher mechanical strength than the ceramic tubes is one step toward improving the module design.

Since the membrane substrate accounts for more than $90 \%$ of the tube wall thickness, at least with the ceramic substrates, higher thermal conductivity and a thinner wall are preferred. It is also critical that the membrane substrate have adequate porosity, pore sizes and pore structures to allow high heat transfer rate while maintaining mechanical strength.

The overall strength of the membrane module is a critical issue that is strongly influenced by the membrane tube strength and the connections to the supporting structure of the module. With the switch to a metal substrate for the membrane tube, the membrane module can be constructed with metallic components which could be welded or brazed together, thus providing a structure that should meet the requirement of the industrial environments. The previous TMC design used relatively short ceramic tubes with a ceramic membrane layer, and these were attached to the header in the modules using epoxy. Using the metallic substrate permits use of longer tubes which are more robust and fracture resistant than the ceramic tubes.

One critical consideration in membrane design is preventing fouling of the membrane layer. Media and Process Technology Inc. (M\&PT) took the lead on addressing the fouling issue, and the following summary was the result of the study.

One of the major steps that occur in the TMC operation is the in-situ removal of condensed water through a semi-permeable membrane. Presently, commercial ceramic membranes with the pore size ranging from 4 to $>10 \mathrm{~nm}$ are employed for this purpose. Since (i) the permeation of water condensate from the feed side of the membrane to the permeate side is essentially no different from standard water filtration through membrane, and (ii) fouling in liquid filtration is considered as a fact of life and unavoidable, it is important to identify fouling potential during the TMC service and to develop a strategy to control fouling. Contaminants possibly present in condensate relevant to fouling potential include:

- Particulate matter (PM): soot, ash, and other particulate could be present in the flue, which can deposit on the surface of the membrane along with the condensate.

- Dissolved Organic Matter (DOM): Incomplete combustion products present as gaseous/vapor molecules in the flue could be water soluble. These molecules can deposit on and/or within the porous membrane.

- Oily emulsion: unburned oil, large molecular weight hydrocarbons (e.g., tar) or incomplete combustion products are likely present in the flue. Although they are likely insoluble in water, they could be present in the form similar to suspended solid, and possibly form steady emulsion in water. Thus, the emulsion could be retained on the membrane surface through permeation.

To address the fouling issue, each of the above generic contaminants will be addressed with regard to their fouling potential based upon knowledge developed in the literature and incorporating proprietary M\&PT 
information. The primary objective of this study is to develop a simple, compact, no-chemical-usage fouling control process for the TMC operation. In addition, experimental or pilot study required to develop and verify the strategy developed from this study is included as part of this report.

\subsubsection{Morphological Description of Fouling Constituents}

An extensive knowledge base has been developed on membrane fouling mechanisms and methods to control it and/or clean it, and the application know-how developed for ultrafiltration (UF) and microfiltration (MF) of surface water is particularly applicable here. As Figure 2 shows, fouling on the $\mathrm{MF} / \mathrm{UF}$ membrane can be described in terms of (i) pore penetration and plugging via dissolved organic matter, (ii) stagnant cake layer formation (promoted by surface adsorption of foulants) on membrane surface, and (iii) concentration polarization leading to gel layer formation. In the next section, the fouling mechanism for each category will be discussed along with ideas on how to minimize/control it.

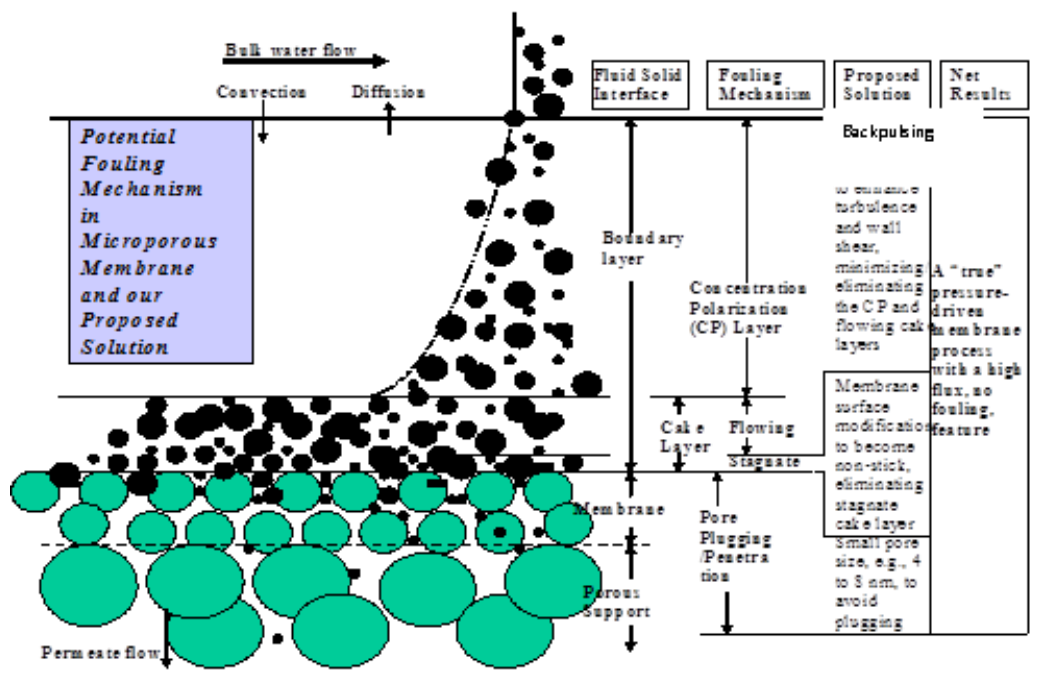

Figure 2. Potential membrane fouling mechanism

\subsubsection{Fouling Mechanism in Filtration via MF/UF}

It is expected that the application know-how developed for UF/MF of surface water is particularly applicable here. Based upon a literature review [12,13] and in-house experience [14], it can be concluded that there are three fundamental fouling problems (see Fig. 2) involved in the fouling of MF/UF-based membranes, specifically,

- contaminant (e.g.: Natural Organic Matter, NOM) pore penetration leading to pore plugging, $\circ$ adsorption of NOM on the membrane surface to form a stagnant and potentially growing layer, and

- irreversible collapse of the concentration polarization (CP) layer into a gel layer, possibly intermingled with the deposition of the suspended particulates.

The water condensed from the TMC likely contains the contaminants of the above three category although depending upon the source of flue gas, the types of contaminants and their concentration could be different. The dissolved organic matter (DOM) could behave similar to the NOM found in surface water, while the PM and the oil emulsion would behave similarly to the suspended solid found in surface water. A mechanistic point-of-view was developed that describes in detail the fouling phenomenon and then leads 
to the technical strategy to mitigate fouling.

\subsubsection{Fouling That Results from Pore Penetration and Clogging/Plugging by Dissolved Organic Matters}

Although a wide spectrum of organic matters could be soluble in water, only those with larger molecular weight could be potential candidates for pore plugging. For water and surface water treatment, natural organic matter, such as humic and fulvic substances, is known to be a major foulant in MF/UF. Although it is not anticipated that NOM will be present in the condensate, NOM is an ideal model for explaining fouling through this mechanism. Literature studies [12, 13] have shown that the permeate flux was much lower than the corresponding clean water flux for membranes with pore sizes from $15 \mathrm{kD}(\sim 6 \mathrm{~nm})$ to $0.2 \mu \mathrm{m}$ even at a low transmembrane pressure (TMP), such as 20 to $100 \mathrm{kPa}$. However, at a smaller pore size, such as $\sim 4 \mathrm{~nm}(\sim 1$ to $10 \mathrm{kD})$, the permeance is similar to its clean water value. In-house studies using Allegheny River water show that only a minor permeance reduction was observed after introduction of the river water for the 4 and $10 \mathrm{~nm} \mathrm{Al}_{2} \mathrm{O}_{3}$ membranes as shown in Fig. 3 and the expanded view in Fig. 4. Significant, but gradual flux reduction was observed for the $50 \mathrm{~nm}$ membrane, which is attributed primarily to pore penetration/plugging as discussed in more detail below.

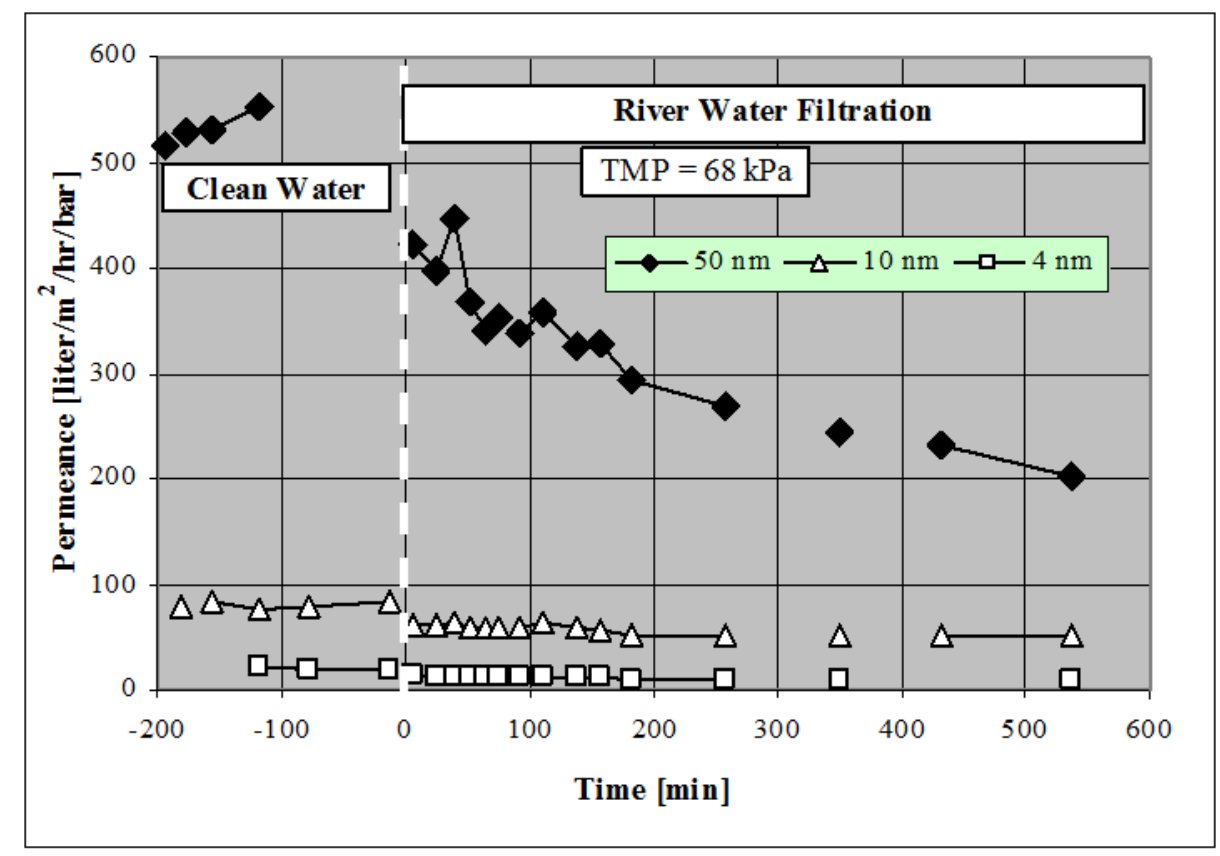

Figure 3. Effect of pore size on membrane permeance decay during filtration of Allegheny River water at a very low TMP. Significant flux loss from pore plugging/penetration was observed for the 50 $\mathrm{nm}$ but not for 10 and $4 \mathrm{~nm}$ (see expanded view in Figure 4) pore size membranes.

For the $50 \mathrm{~nm}$ membrane, non-chemical but purely hydrodynamic "cleaning" (e.g., backpulsing and membrane flushing/scrubbing via increased crossflow velocity at 0 feed pressure) was unsuccessful in restoring the permeance, as shown in Fig. 5 (this is a continuation of the $50 \mathrm{~nm}$ membrane data in Fig. 3 ). The slow permeance decay in the $50 \mathrm{~nm}$ membrane permeance results from pore plugging and/or penetration. This is clear, since (i) the concentration polarization layer is established quickly after startup and (ii) the smaller pore size membranes do not similarly show a continuous steady decay in permeance. In fact, the permeance decay profiles of the $50 \mathrm{~nm}$ membrane in the first and second river 
water filtration cycles (interrupted by a non-chemical based hydrodynamic cleaning cycle) are very similar, indicating that the $\mathrm{CP}$ layer is established rather quickly in the both cycles. Further, pore plugging and/or penetration continues from the previous cycle because the "hydrodynamic" cleaning does not adequately remove these components (i.e., they are irreversible from a hydrodynamic sense).



Figure 4. Expanded view of Fig. 3 showing the effect of pore size (4 and $10 \mathrm{~nm}$ ) on membrane permeance decay during filtration of Allegheny River water. Unlike the $50 \mathrm{~nm}$ pore size membrane, the permeance shows a rapid drop (due to rapid CP layer formation and surface interaction) followed by a steady state permeance, indicative of little or no irreversible pore plugging/penetration.

In short, one can conclude from the in-house results and the literature studies that membrane flushing and backpulsing ("hydrodynamic cleaning") with pure water can restore only a fraction of the original permeance. Further, these non-chemical cleanings become less effective as the filtration experiment continues as Fig. 5 shows. Eventually a nearly total flux loss is expected. On the other hand only chemical treatment, such as pre-ozonation of the feed water suggested in the literature, was demonstrated to be effective [4]. Figure 5 shows that the permeances of the $4 \mathrm{~nm}$ and $10 \mathrm{~nm}$ pore size membranes are to some extent relatively constant throughout the entire run. Hence, a leading source of membrane fouling is penetration of DOM into the porous structure. Suspended solid (SS) is not considered the source of the irreversible fouling although it could participate in the irreversible fouling establishment in the presence of NOM, or the pore size is too big.

This above experience with surface water is consistent with several field tests [15-17] on seawater pretreatment with MF/UF. Hydrophilic hollow fiber membranes at pore sizes ranging from $50 \mathrm{kDa}$ $(>10 \mathrm{~nm})$ to $0.1 \mu \mathrm{m}$ were used in these field tests. Due to these greater than desirable pore sizes, frequent intermittent backpulsing with clean water (or a low ppm chlorine, $\sim 10 \mathrm{ppm}$ ) and chemical cleaning once an hour to once a day were required in order to maintain long-term flux stability. Pore plugging/penetration, however, can be minimized/prevented if the pore size is small enough as shown in Fig. 4. In summary, fouling using existing MF or UF for seawater and surface water is at least partially irreversible (from the hydrodynamic standpoint), most likely due to pore penetration/plugging by NOM. However, for pore sizes in the range of $4-10 \mathrm{~nm}$, little or no membrane fouling under low 
TMP operation is observed and is attributed to the elimination of pore penetration/plugging.

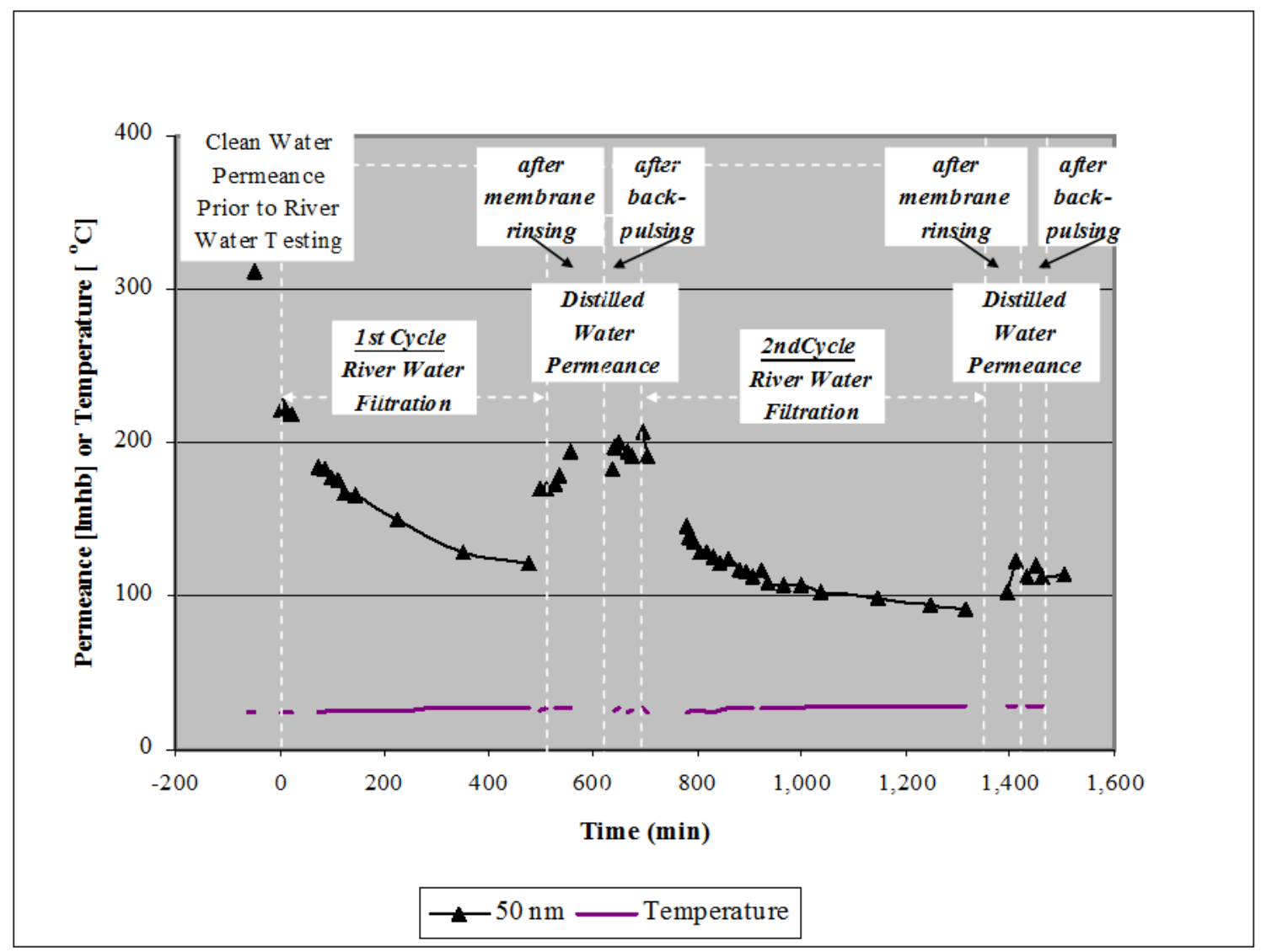

Figure 5. Effect of membrane rinsing and backpulsing on flux permeance recovery for a $50 \mathrm{~nm}$ M\&PT ceramic membrane treating Allegheny River water. TMP is $68 \mathrm{kPa}$. Rinsing and backpulsing was effective, but not completely restoring the original clean water flux. Rinsing and backpulsing effectiveness declined significantly in the following cycling. The permeance flux declined continuously throughout the 1st and 2 nd cycles due to the pore plugging/penetration of the membrane with a large pore size $(50 \mathrm{~nm}$.

\subsubsection{Fouling Due to Surface Interaction with DOM and Formation of Stagnant Cake Layer}

In this section it is shown that foulant interaction with the membrane surface can be a major source of irreversible flux loss. Further, it is shown how this problem can potentially be overcome with surface modification. In addition to pore plugging/penetration, significant membrane flux loss is attributed to fouling above the membrane layer [10], i.e., in the stagnant cake layer, due to interaction of DOM with the membrane surface and/or the CP layer (see Fig. 2).

As shown in Fig. 5, about $75 \mathrm{lmhb}$ was recovered via surface flushing of the $50 \mathrm{~nm}$ membrane following about 500 minutes of river water filtration. This recoverable permeance could be attributed to the removal of (i) the CP layer and/or (ii) the surface NOM foulants.

Figure 6 also shows the difference in recovery between this standard alumina membrane $(50 \mathrm{~nm})$ and its sulfonic acid modified membrane. Interestingly, for the modified membrane, the clean water permeance is lower than the unmodified membrane, yet the permeance decay for the modified membrane is much less significant over the entire filtration run. Since both membranes are the same 
pore size and exposed to the same hydrodynamic conditions during filtration, $\mathrm{CP}$ layer formation and pore plugging effects are expected to be similar. Hence, the immediate and continued lower permeance of the unmodified membrane throughout the filtration run must be due to a difference in DOM interaction with the membrane surface.

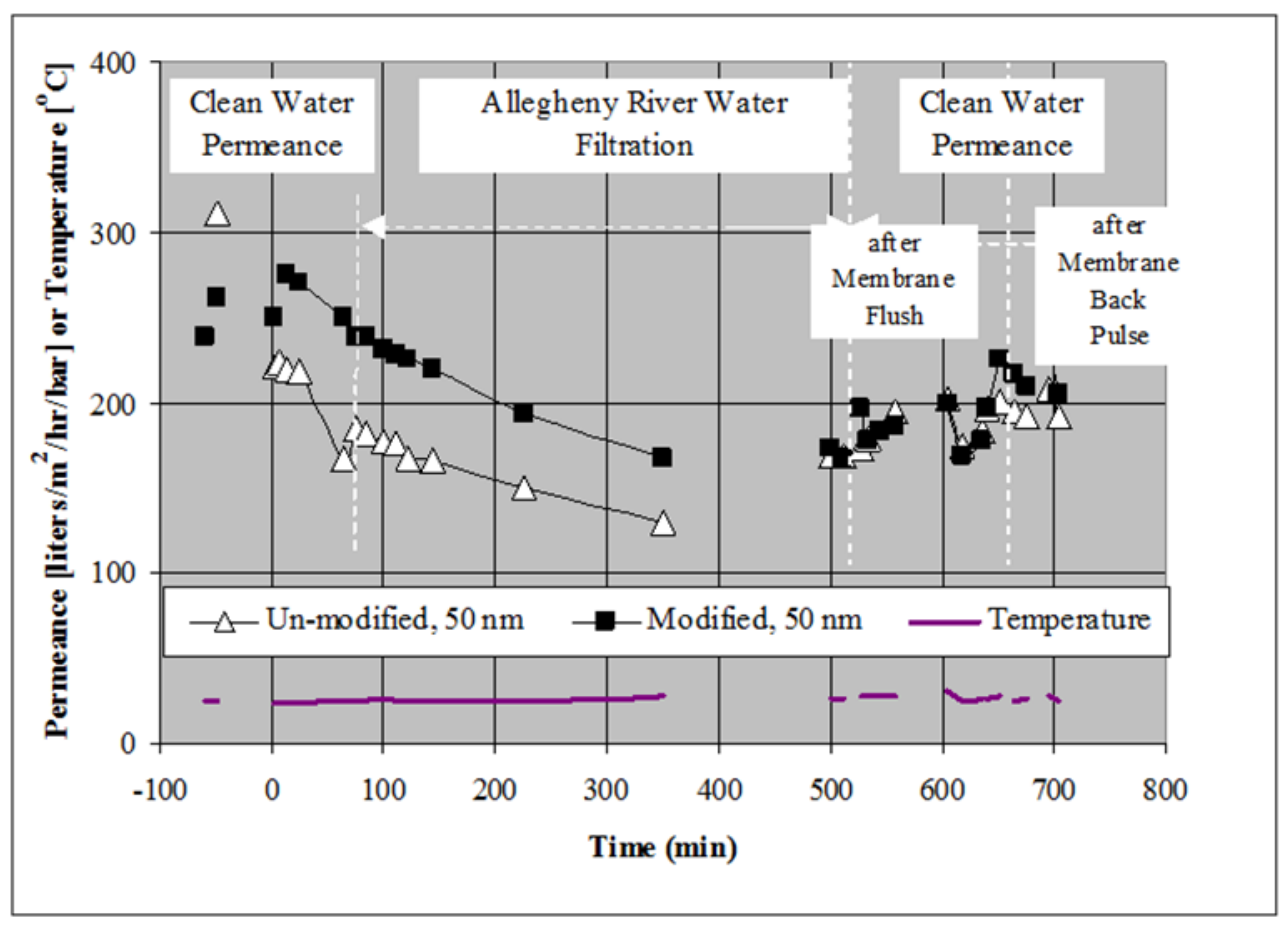

Figure 6. Effectiveness of membrane rinsing and backpulsing for a modified (sulfonic acid) and unmodified M\&PT alumina $(50 \mathrm{~nm})$ membrane at $\mathrm{TMP}=68 \mathrm{kPa}$. Significant permeance flux recovery is noted after rinsing for the alumina membrane. The modified membrane regains little or no permeance via membrane rinsing, although its permeance is higher than the unmodified membrane. This indicates that the fouling in the unmodified membrane partially results from interaction with the membrane surface.

This is also borne out in the membrane flushing (via high cross flow at 0 transmembrane pressure) with distilled water. Membrane flushing with clean water is expected to have two potential effects, specifically, (i) to eliminate the CP layer and (ii) to potentially reduce (or perhaps eliminate) DOM foulants that have interacted with the surface. CP layer removal would be the same for both membranes, since by definition CP layer formation is a purely hydrodynamic phenomenon, independent of membrane chemistry. In contrast, DOM interaction will be dependent upon membrane chemistry. Rinsing of the membranes shows a significant improvement in the unmodified membrane performance yet little effect on the modified membrane. Strikingly, however, both membranes recover to the same permeance. This indicates that DOM interaction with the modified membrane is evidently marginal; hence permeance recovery during flushing is very low. In contrast, high shear flushing yields considerable permeance recovery in the unmodified membrane, indicating that surface fouling plays a role in this membrane. Thus, interaction between the membrane surface and foulants is significant as has been suggested in the literature [18]. This interaction could eventually lead to stagnant irreversible gel layer formation. The existence and significance of the surface interaction with DOM has prompted substantial R\&D into modification of the membrane surface to reduce/eliminate interactions that lead to fouling. 


\subsubsection{Flux Loss due to the Concentration Polarization (CP) Layer Formation and the Degradation of the CP Layer}

Concentration polarization is resulted from the back diffusion of the foulants. In the cross flow filtration mode for most MF/UF operation, this CP layer formation reaches a steady state. Most literature studies $[15,19]$, both lab and field tests, employed low TMP $(<<100 \mathrm{kPa})$ operation in order to keep the flux below the "critical flux $[17,20]$ " thereby attempting to prevent fouling due to CP layer collapse. By definition, at or below the critical flux, the membrane would show no irreversible fouling because the CP layer is in a reversible dynamic steady state. Beyond this flux, however, a cake (gel) layer begins to develop at the membrane surface as a result of the increased CP layer concentration. SS certainly participates in the CP layer formation and increases the resistance. Therefore, commercial practice is to operate below the critical flux at low TMP. According to the literature, the CP layer due to the concentration or pressure could eventually degrade to an irreversible fouling layer. Under the TMC operation, the concentration polarization will never reach a steady state; thus, the concentration increase could favor the formation of the irreversible layer; however, the low TMP, most likely is below the critical pressure and will not lead to the irreversible fouling.

In fact, for surface and seawater MF/UF involving a wide range of organic matter, even the critical flux concept is not justified because pore penetration takes place, which leads to irreversible fouling. In-house results in Fig. 3 and Fig. 6 show the continuing decay of the permeance of the $50 \mathrm{~nm}$ membrane even when operated at an extremely low TMP, $68 \mathrm{kPa}$, due to pore plugging. Hence, steady state operation is never achieved in commercial practice, even at low TMP, and the membranes require frequent chemical cleaning via flushing and backpulsing to maintain a "quasi" steady state operation.

To achieve a true "critical flux" (i.e., no irreversible fouling, steady state) operation, it is first necessary to minimize/eliminate pore penetration and plugging by employing pore sizes in the range of 4 to 10 $\mathrm{nm}$ as shown in Fig. 4. For both of the smaller pore sizes, after an initial decay due to CP layer formation and surface interaction, the permeance is stable at $68 \mathrm{kPa}$ for an extended period (e.g., $~ 600$ $\mathrm{min}$ ) with no evidence of pore plugging as apparent in the much larger $50 \mathrm{~nm}$ membrane. However, even at these pore sizes, increasing the TMP from 68 to $195 \mathrm{kPa}$ for the $10 \mathrm{~nm}$ results in step change decreases in the permeance as shown in Figure 7. A similar yet much smaller decline in the initial permeance at the start of each pressure step is also seen with the $4 \mathrm{~nm}$ membrane. Hence, even though pore plugging is not evident in these smaller pore size membranes (unlike the $50 \mathrm{~nm}$ membrane), it is clear that fouling due to $\mathrm{CP}$ layer development occurs with increasing pressure. Hence, if pore plugging effects are minimized/eliminated, then to maximize a pressure-driven membrane-based process, $\mathrm{CP}$ layer accumulation via hydrodynamic cleaning is necessary. Current techniques to improve the hydrodynamics at the membrane surface, such as periodic cleaning, are discussed and evaluated in the next section and an ideal technique compatible to our proposed membrane will be recommended for this proposed study.

In summary, the three sources of fouling, which handicap current MF/UF practice, have been analyzed based upon in-house know-how. Through a comprehensive approach presented in this section, pore plugging/penentration can be avoided with the selection of an appropriate pore size. Then, hydrodynamic cleaning in the presence of a "non-stick" membrane surface can be introduced to enhance the permeate flux without incurring flux loss due to fouling in the $\mathrm{CP}$ layer. 


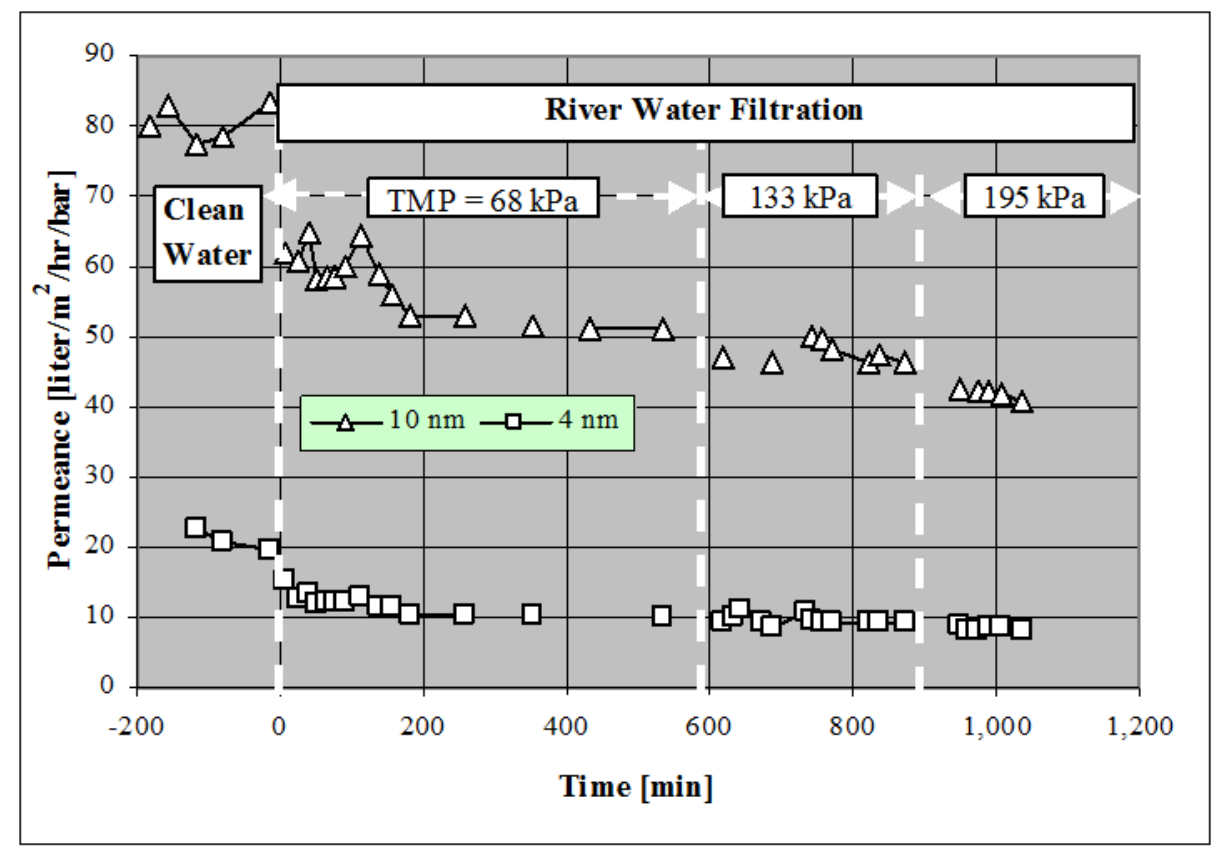

Figure 7. Effects of transmembrane pressure on membrane permeance during filtration of Allegheny River water using the 4 and $10 \mathrm{~nm}$ ceramic membranes.

\subsubsection{Proposed Technical Approach to Overcome Barriers}

Based upon the above discussion, a three-pronged technical approach was proposed (see Fig. 2):

- $\quad$ Use of small pore size membranes $(4-10 \mathrm{~nm})$ to prevent irreversible fouling due to pore penetration/clogging. Pore penetration/plugging is one of the major irreversible fouling contributors as shown in Fig. 5 for membranes with pore sizes of ca. $50 \mathrm{~nm}$. However, membranes with pore sizes of 4 to $10 \mathrm{~nm}$ show insignificant pore plugging. M\&PT proposed the use of the membranes with the pore sizes in this range for the TMC application to avoid pore plugging/penetration. M\&PT manufactures commercial alumina membranes at these pore sizes. Pore size distributions of our commercial membranes are presented in Fig. 8 [16]. It is straightforward for us to prepare membranes at any pore size between 4 and $50 \mathrm{~nm}$ ( 4 to $50 \mathrm{~nm})$.

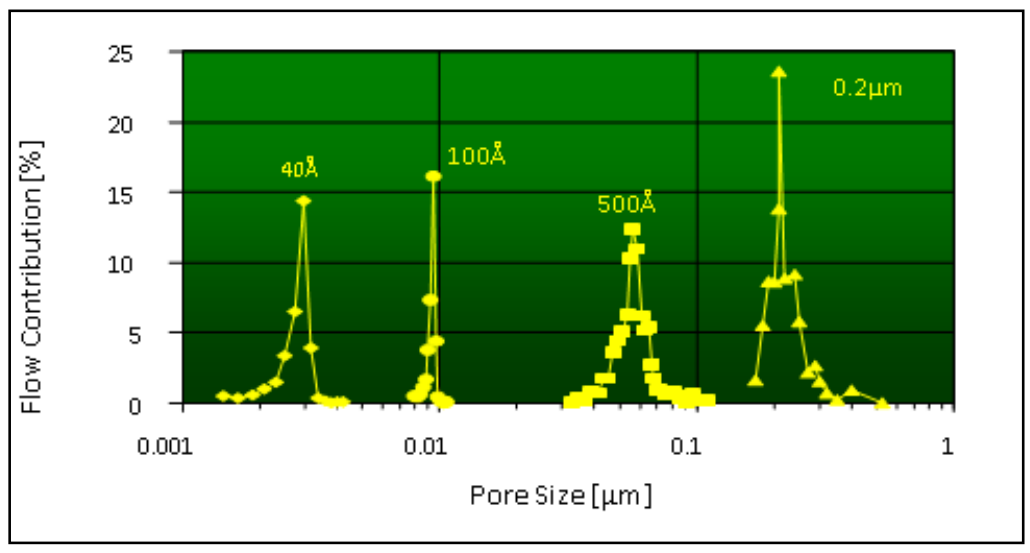

Figure 8. Pore size distribution of M\&PT ceramic membranes.

- Modification of commercial ceramic membranes with a non-stick monolayer surface. 
Formation of the stagnant cake layer as a result of membrane (top) surface interaction with DOM has been identified as the second source of fouling for surface water pretreatment as illustrated in Fig. 2. Further, surface modification of the membrane with anionic/acidic and neutral highly hydrophilic functional groups has been demonstrated to prevent/minimize DOM interaction with the membrane surface [21-24] in several recent literature studies. M\&PT own in-house study has highlighted the difference between the surface interaction of a bare $\mathrm{Al}_{2} \mathrm{O}_{3}$ membrane and surface modified membrane (SMM) $\mathrm{Al}_{2} \mathrm{O}_{3}$ in a side-by-side study shown in Fig. 6. In the TMC operation, M\&PT suggests the preparation of this similar SMM on our membranes with the resultant pore size in the range of 4 up to $10 \mathrm{~nm}$.

- $\quad$ Periodic cleaning with backpulsing to minimize/eliminate the CP layer. Backpulsing has been adopted as a standard practice in many ceramic membrane-based filtrations in order to prevent the accumulation of the CP layer. Although the pay-off through backpulsing for UF is low and is usually not practiced in water filtration with the small pore sizes of the UF membrane, M\&PT believes that it could be a viable strategy for the prevention of CP layer formation for TMC operation. Since the TMC operation is under a very low pressure drop, i.e., several psi, backpulsing of the UF membrane could be achieved effectively and efficiently, which will dislodge the accumulated CP layer. The dirty water thus generated from the feed to the TMC can then be collected and properly treated. The other alternative is the use of two-phase "slug" flow (somewhat similar to air scouring in liquid phase applications), which has been demonstrated to be an energy efficient means to generate turbulence and enhance wall shear, particularly for those systems with low critical flux (ie: the flux at which CP layer collapse to a gel layer occurs). Obviously, this two-phase gas-liquid flow is uniquely suited to the TMC application. Thus, mechanical turbulence devices can be eliminated, yielding a smaller footprint and simpler system. Literature studies have shown a 30\% total energy reduction for simulated drinking water applications with the incorporation of slug flow [25]. Finally, the use of chemicals, such as detergents, is an alternative to the use of the slug flow. Since our strategy is to avoid the chemical interaction of the foulants with the membrane surface as a result of the membrane surface modification, M\&PT does not anticipate the need of the chemical cleaning.

Overall, using the smaller pore size membrane with a modified non-stick surface (in conjunction with two phase "slug" flow), it is likely that high fluxes can be maintained, since fouling can be expected to be significantly reduced at the low transmembrane pressures typical of the TMC operation. More importantly, unlike conventional practice, with this concept the membrane can be operated under a "true" steady state condition without frequent backpulsing, chemical cleaning, nor high crossflow.

\subsection{TASK 3 - SELECT CANDIDATE MATERIALS FOR MEMBRANE AND SUBSTRATE SAMPLES}

The selection of alternate substrate materials was centered on metallic materials that could be obtained in appropriately sized powder. For the membrane layers, availability of powder in a small enough size was one consideration. Because of the extensive experience accumulated with alumina powder in applying a membrane layer on the inner diameter (ID) of alumina tubes, alumina membrane layers on the metallic tubes was considered the most promising option.

The selection of metallic materials to be evaluated had to consider the material cost as well as corrosion resistance, thermal conductivity, and strength. In terms of room temperature strength and thermal conductivity, the ferritic steels had better properties than the austenitic stainless steels (300 series). However, tube fabricators had some experience with both types of materials, so both were considered. Since $\mathrm{SO}_{\mathrm{X}}$ is a reaction product expected to be present when sulfur-containing fuel oil is burned, the requirement of corrosion resistance for the substrate and membrane would include 
compatibility with sulfurous acid. Based on the reported maximum concentration of sulfur in the fuel and the concentration of $\mathrm{SO}_{\mathrm{X}}$ in the exhaust gases, long term exposures of metallic samples were conducted in a fairly dilute aqueous sulfurous acid solution (see Task 5). Based on published data, several alloys could be eliminated due to their poor corrosion resistance in sulfurous acid. Table 2 lists several of the alloys considered along with relevant properties of each.

Table 2. Candidate substrate alloys and relevant properties of each

\begin{tabular}{|c|c|c|c|c|c|}
\hline Material & $\begin{array}{c}\text { Thermal } \\
\text { conductivity } \\
\left(\mathbf{R T}^{\circ} 2^{\circ} 00^{\circ} \mathrm{C}\right) \\
\mathbf{W} /(\mathbf{m} \cdot \mathbf{K})\end{array}$ & $\begin{array}{c}\text { Thermal } \\
\text { expansion } \\
\text { coefficient } \\
\times 10^{-6} \mathrm{~K}^{-1}\end{array}$ & Impact strength & $\begin{array}{l}\text { Corrosion } \\
\text { resistance in } \\
100^{\circ} \mathrm{C} \text { steam }\end{array}$ & $\begin{array}{c}\text { Corrosion } \\
\text { resistance in } \\
\text { sulfurous acid }\end{array}$ \\
\hline Alumina & 27.2 & $7.2-8.6$ & Very low & & \\
\hline Carbon steel & 51.1 & 12.1 & Moderate & $>0.050$ in./year & $>0.050 \mathrm{in} . /$ year \\
\hline $\begin{array}{l}409 \text { stainless } \\
\text { steel }\end{array}$ & 26.4 & 11.0 & Moderate & & \\
\hline $\begin{array}{l}26 \mathrm{Cr}-1 \mathrm{Mo} \\
\text { ferritic steel }\end{array}$ & & 9.9 & Moderate & & $<0.020$ in./year \\
\hline $\begin{array}{l}304 \mathrm{~L} \\
\text { stainless steel }\end{array}$ & 16.2 & 17.3 & High & $<0.020$ in./year & $>0.050$ in./year \\
\hline Copper & 401 & 16.9 & High & $<0.020$ in./year & $>0.050$ in./year \\
\hline
\end{tabular}

\subsection{TASK 4 - FABRICATE MEMBRANES FROM CANDIDATE MATERIALS}

An initial fabrication effort involved forming over 30 support tubes from a small supply of Ametek water atomized $434 \mathrm{~L}$ powder that ORNL had in stock, and these tubes were sintered at $1050^{\circ} \mathrm{C}$. The tubes showed very good uniformity as indicated in Table 3. Subsequently, an additional batch of the same 434L powder was ordered from the same vendor and this new material was characterized once it was received. The particle size distribution was essentially the same as the previous batch. Using this new powder supply, approximately 100 18-inch long tubes were formed, and arrangements were made to sinter these tubes in a commercial continuous furnace. In this furnace, the tubes ride on a continuous belt through the different zones of the furnace. Because every part of the tube travels through the complete furnace, there is much less chance of temperature non-uniformity compared to the environment in the furnaces available at ORNL. Consequently, more consistent sintering occurs. $\mathrm{X} 10^{-6} \mathrm{~K}^{-1}$

Several small samples of metallic support tubes with a coating of the intermediate alumina layer were sintered at ORNL. Samples were sintered at $850^{\circ} \mathrm{C}$ and $1000^{\circ} \mathrm{C}$ under hydrogen. In both sets of samples, the layer appeared continuous with no apparent effects from thermal expansion mismatch. Subsequent processing involved application of the final membrane layer by M\&PT followed by sintering at ORNL.

ORNL has previously employed a process to apply porous membrane layers to the inside of porous support tubes. This method can apply a 3-5 $\mu \mathrm{m}$ thick layer having a pore size of approximately $7 \mathrm{~nm}$ without need for an intermediate layer. A fixture was built for the application of a single layer on the outside surface of a support tube. Although membranes were successfully fabricated for the module tests, an evaluation was conducted of tubes fabricated using this alternate fabrication method. 
Table 3. Properties of Supports Fabricated from 434L Stainless Steel

\begin{tabular}{|c|c|c|c|c|c|c|c|c|}
\hline Sample \# & $\begin{array}{l}\text { Length } \\
\text { (inches) }\end{array}$ & $\begin{array}{l}\text { Temp } \\
\left({ }^{\circ} \mathbf{C}\right)\end{array}$ & $\begin{array}{c}\text { Void } \\
\text { Fraction }\end{array}$ & Mass (g) & $\begin{array}{c}\text { Thickness } \\
\text { (inches) }\end{array}$ & $\begin{array}{c}\begin{array}{c}\text { O. D. } \\
\text { (inches) }\end{array} \\
\text { (in }\end{array}$ & $\begin{array}{c}\text { Air Permeance } \\
\mathrm{cc} / \mathrm{min} / \mathrm{cm}^{2} / \mathrm{cmHg}\end{array}$ & $\begin{array}{l}\text { Pore Dia } \\
\text { (microns) }\end{array}$ \\
\hline $1705-1-1$ & 19.011 & 1050 & 0.4014 & 45.1765 & 0.02283 & 0.4616 & 17.84 & 3.81 . \\
\hline $1705-2-1$ & 19.086 & 1050 & 0.4109 & 44.7584 & 0.02294 & 0.4608 & 17.55 & 3.74 \\
\hline $1705-3-1$ & 18.982 & 1050 & 0.4032 & 44.3432 & 0.02263 & 0.4591 & 17.92 & 3.80 \\
\hline $1705-4-1$ & 18.990 & 1050 & 0.4061 & 44.2838 & 0.02270 & 0.4591 & 17.66 & 3.77 \\
\hline $1705-5-1$ & 18.990 & 1050 & 0.3990 & 46.5091 & 0.02314 & 0.4674 & 17.31 & 3.76 \\
\hline $1705-9-1$ & 19.032 & 1050 & 0.4107 & 45.3261 & 0.02321 & 0.4624 & 17.24 & 3.74 \\
\hline $1705-9-2$ & 19.000 & 1050 & 0.4121 & 45.8780 & 0.02301 & 0.4733 & 14.80 & 3.80 \\
\hline $1705-10-2$ & 18.884 & 1050 & 0.4008 & 44.5198 & 0.02270 & 0.4599 & 16.84 & 3.89 \\
\hline 1705-11-1 & 18.993 & 1050 & 0.4008 & 45.1463 & 0.02276 & 0.4624 & 17.53 & 3.80 \\
\hline $1705-11-2$ & 18.839 & 1050 & 0.3923 & 45.7084 & 0.02294 & 0.4620 & 15.78 & 3.82 \\
\hline 1705-12-1 & 19.022 & 1050 & 0.4084 & 44.0546 & 0.02279 & 0.4562 & 17.90 & 3.81 \\
\hline $1705-12-2$ & 18.928 & 1050 & 0.3973 & 46.7001 & 0.02341 & 0.4645 & 14.73 & 3.90 \\
\hline $1705-13-2$ & 18.898 & 1050 & 0.4027 & 44.4166 & 0.02239 & 0.4658 & 16.46 & 3.87 \\
\hline 1706-1-1 & 19.041 & 1050 & 0.4248 & 43.1177 & 0.02251 & 0.4637 & 17.71 & 3.65 \\
\hline 1706-1-2 & 19.092 & 1050 & 0.4284 & 42.1851 & 0.02224 & 0.4608 & 17.29 & 3.77 \\
\hline $1706-2-1$ & 19.538 & 1050 & 0.4267 & 43.4785 & 0.02231 & 0.4612 & 18.11 & 3.61 \\
\hline $1706-2-2$ & 19.000 & 1050 & 0.4057 & 41.5865 & 0.02159 & 0.4520 & 17.02 & 3.71 \\
\hline 1706-3-1 & 18.134 & 1050 & 0.4205 & 41.8626 & 0.02284 & 0.4628 & 16.96 & 3.70 \\
\hline $1706-3-2$ & 18.309 & 1050 & 0.4058 & 43.8548 & 0.02274 & 0.4699 & 17.11 & 3.79 \\
\hline $1706-4-1$ & 18.219 & 1050 & 0.3980 & 43.1723 & 0.02258 & 0.4624 & 16.68 & 3.72 \\
\hline $1706-4-2$ & 18.814 & 1050 & 0.4098 & 44.4403 & 0.02250 & 0.4712 & 17.42 & 3.73 \\
\hline $1706-5-1$ & 19.048 & 1050 & 0.4059 & 45.6306 & 0.02295 & 0.4662 & 17.28 & 3.66 \\
\hline $1706-5-2$ & 18.963 & 1050 & 0.3802 & 44.7586 & 0.02209 & 0.4570 & 15.54 & 3.82 \\
\hline $1706-6-2$ & 19.074 & 1050 & 0.4111 & 44.2248 & 0.02265 & 0.4612 & 15.51 & 3.77 \\
\hline Average & & & 0.4068 & 44.38053 & 0.02268 & 0.4626 & 16.88 & 3.77 \\
\hline Std Dev & & & 0.0107 & 1.309516 & 0.00038 & 0.0047 & 1.03 & 0.07 \\
\hline $\begin{array}{l}\text { Std Dev } \\
(\%)\end{array}$ & & & $2.63 \%$ & $2.95 \%$ & $1.67 \%$ & $1.01 \%$ & $6.10 \%$ & $1.88 \%$ \\
\hline
\end{tabular}

It is well known that resistance to flow is affected by both the pore size and the thickness of the membrane or membrane layer. While electron micrographs showed a thin (1-2 microns thick) layer of aluminum oxide on the surface of the membranes prepared in a single step by ORNL, it was clear that the effective layer thickness was greater than 1-2 microns when considering the depth of the aluminum oxide that penetrated into the pores of the stainless steel support tube. Based on experimental results and modeling by GTI, it is believed that a high permeance is crucial to the operation of a TMC system. In order to increase the permeance, it was decided to apply an intermediate layer to reduce the penetration of the aluminum oxide powder into the surface pores. This should have minimal impact on the pore size of the membrane layer.

One of the options with the intermediate layer was to use a metallic layer. ORNL conducted an investigation of the efficacy of a thin metal intermediate layer for reducing the effective membrane layer thickness without increasing the pore size or increasing the quantity of leaks using both nickel and stainless steel. Two different fine stainless steel powders and a fine nickel powder were employed for the intermediate layer application. A sintering study revealed that an $800^{\circ} \mathrm{C}$ heat treatment was needed to sinter the stainless steel in place while only $425^{\circ} \mathrm{C}$ was needed for the fine nickel layer. At temperatures lower than $800^{\circ} \mathrm{C}$, the stainless layer was not attached to the stainless steel support tubes very well. The average pore size of the layer made with stainless steel from Ultrafine Technology after 
the $800^{\circ} \mathrm{C}$ heat treatment was $0.94 \pm 0.06$ microns. This compares to $3.48 \pm 0.08$ microns for the stainless steel support tube. The pore size of the layer made with the stainless steel powder from Atmix was $1.05 \pm 0.26$ microns. The pore size of the layer made from the fine nickel powder was 0.35 \pm 0.06 microns. As the penetration depth is directly proportional to the pore size of the layer being coated, the penetration should be reduced by a factor of 3-4 for the two stainless steel intermediate layers and almost a factor of 10 for the nickel intermediate layer.

Aluminum oxide layers were applied to sets of support tubes having both selections of stainless steel powders. Although the nickel layer lowered the average pore size the most, its low sintering temperature would not allow a high enough sintering temperature to sinter the top layer of aluminum oxide. In previous studies with a single layer, temperatures of 850 to $950^{\circ} \mathrm{C}$ were found to result in median sizes of 10-12 $\mathrm{nm}$ for the aluminum oxide separation layer. Sintering the fine nickel layer at temperatures over $600^{\circ} \mathrm{C}$ resulted in extreme over-sintering where the fine particles were no longer discernible in the scanning electron micrographs. It is clear that sintering of the aluminum oxide layer at the required temperatures would result in a very over-sintered intermediate nickel layer. For that reason, the fine nickel is not a viable intermediate layer material.

Characterization was conducted of ORNL prepared outer diameter (OD) coated alumina on modified stainless steel substrates. Tube preparation consisted of preheating the tubes to $300^{\circ} \mathrm{C}$ in air and then to $950^{\circ} \mathrm{C}$ in hydrogen. Preliminary air permeance determined at ORNL was $\sim 25.2 \mathrm{~m} / \mathrm{hr} / \mathrm{m}^{2} /$ bar which is comparable to results obtained with similarly prepared OD coated alumina on M\&PT ceramic substrates (N2 18 to $30 \mathrm{~m}^{3} / \mathrm{hr} / \mathrm{m}^{2} /$ bar). This part was characterized by M\&PT. Clean water permeance at $22^{\circ} \mathrm{C}$ was determined to be ca. $59.8 \mathrm{liters} / \mathrm{m}^{2} / \mathrm{hr} / \mathrm{bar}(\mathrm{lmhb})$ and similar to M\&PT parts fired at this temperature. There is no data available for M\&PT alumina layer modified ORNL stainless steel substrates prepared at this temperature. However, a large number have been fired in $\mathrm{H}_{2}$ at $850^{\circ} \mathrm{C}$ (at ORNL) and typical clean water permeances range from 35 to $50 \mathrm{lmhb}$. Additionally, water bubble testing of the membrane was conducted at pressures up to $15 \mathrm{psig}$, the maximum possible transmembrane pressure in the TMC application, to identify potential leaks. At this pressure, approximately 40 to 50 small pinholes were noted in the membrane. These pinholes were concentrated in the center 10 to 11 " of the 16" part. Further, as has been observed in M\&PT modified ORNL substrates, the bulk of the leaks were concentrated along a line in the part. The number of pinholes decreases as the pressure is reduced, so that below 6 to 8 psig, no leaks are evident in the membrane. This pressure rating is suitable for TMC applications which typically run between 3 and 5 psig. Hence, 5 psig is used as a quality control test for ceramic layer modified ORNL substrates.

In addition to the physical characterization work above, scanning electron microscope (SEM) examination of the ORNL ceramic layer modified stainless substrate was also conducted during this quarter, specifically to identify the source of the pinholes noted in the bubble testing. Figure 9 shows photomicrographs of the ORNL ceramic layer modified stainless substrate at various pinholes identified in the bubble testing. Overall, the layer coating is thin, uniform, and likely embedded in the top few microns of the membrane surface. The pinholes are circled in Fig. 9 and range in size from a few microns up to 20+ microns. They appear to be simply gaps in the coating due to surface roughness as opposed to bubbles or other flaws in the initial deposition layer. A second similar alumina layer may further fill these defects yielding an improved part with substantial reduction in pinholes. The parts in general are high quality displaying only a modest number of flaws given the minimal layer thickness and the substrate roughness. 

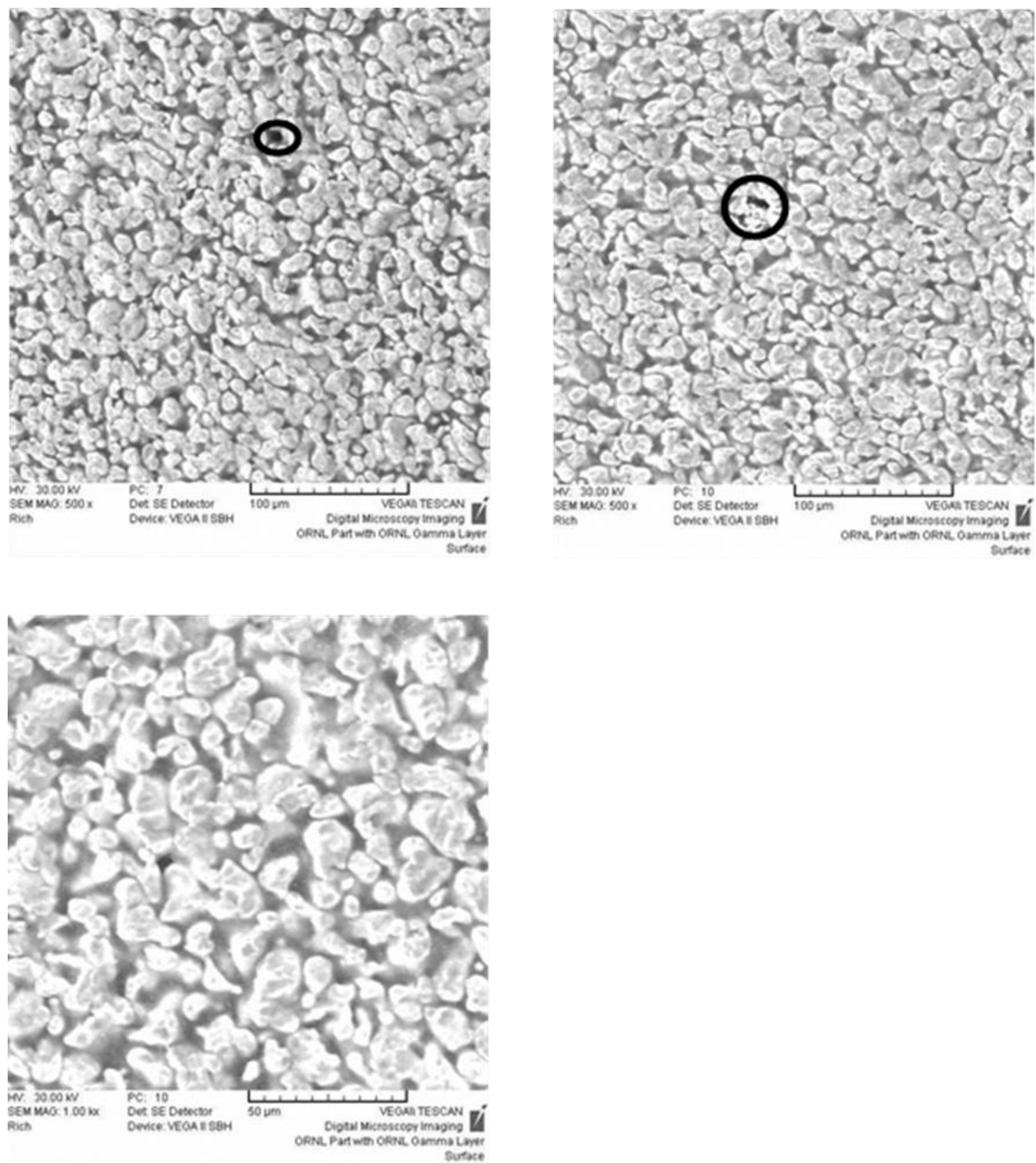

Figure 9. SEM photomicrographs of the TMC membrane elements (ORNL modified ORNL substrate) showing defects that yield bubbles in water bubble testing.

\subsection{TASK 5 - EVALUATE MEMBRANES UNDER LABORATORY CONDITIONS}

The laser flash technique has become a standard testing method for thermal diffusivity measurements of solids. The multiple furnace laser flash thermal diffusivity system available at ORNL was used to determine the thermal conductivity of alumina and ferritic steel substrate materials. The conductivity was measured between room temperature and about $500^{\circ} \mathrm{C}$. For application as substrate material in a $\mathrm{TMC}$, the maximum temperature would be around $100^{\circ} \mathrm{C}$. Results for two alumina substrate samples and three samples of 430L stainless steel substrate material are shown in Table 4. These results show that the metallic material has considerably higher thermal conductivity at the higher measurement 
temperatures. However, in the temperature range of interest, there is very little difference in the conductivities of the two materials.

Table 4. Thermal conductivity of potential membrane components

\begin{tabular}{|l|c|c|c|c|c|c|c|}
\hline \multicolumn{1}{|c|}{ Material } & \multicolumn{7}{|c|}{ Thermal Conductivity (W/mK) } \\
\hline & $\mathbf{2 5}^{\circ} \mathbf{C}$ & $\mathbf{1 1 0}^{\circ} \mathbf{C}$ & $\mathbf{1 5 3}^{\circ} \mathbf{C}$ & $\mathbf{2 0 5}^{\circ} \mathbf{C}$ & $\mathbf{3 0 2}^{\circ} \mathbf{C}$ & $\mathbf{4 0 0}^{\circ} \mathbf{C}$ & $\mathbf{4 9 7}^{\circ} \mathbf{C}$ \\
\hline Alumina 1 & 0.13 & 0.10 & 0.09 & 0.09 & 0.07 & 0.06 & 0.06 \\
\hline Alumina 2 & 0.13 & 0.10 & 0.09 & 0.08 & 0.07 & 0.06 & 0.06 \\
\hline 430L SS 1 & & 0.11 & 0.10 & 0.11 & 0.10 & 0.11 & 0.10 \\
\hline 430L SS 2 & & 0.10 & 0.10 & 0.10 & 0.10 & 0.10 & 0.09 \\
\hline 430L SS oxidized & 0.08 & 0.08 & 0.08 & 0.08 & 0.08 & 0.08 & 0.07 \\
\hline
\end{tabular}

Target industrial waste streams were previously identified, and the possible corrosive components for essentially all the streams included sulfur dioxide. In order to determine which of the alloys being considered had adequate corrosion resistance in sulfur dioxide contaminated water, corrosion tests were conducted. The tests consisted of immersing samples of candidate alloys in a $90^{\circ} \mathrm{C}$ aqueous solution containing sulfur dioxide. The sulfur dioxide concentrations reported for the targeted industrial waste streams ranged from a few ppm to about $300 \mathrm{ppm}$. In order to provide a more severe test of the candidate alloys, corrosion tests were conducted in a more concentrated solution, $600 \mathrm{ppm}$ sulfur dioxide. As a reference, samples were also exposed in distilled water.

Samples were exposed in the $600 \mathrm{ppm}$ solution and in distilled water to get some confirmation of the ability of all the alloys to avoid corrosion in the two environments to which the substrate could be exposed. Results after 12,000 hours of exposure in the $600 \mathrm{ppm}$ solution are shown in Fig. 10 where the weight change is plotted versus the chromium concentration of the alloys. Type 434 stainless steel, which is currently being used for the metallic substrate fabrication, contains a nominal $16.5 \%$ chromium. From this figure it can be seen that, even for the $600 \mathrm{ppm}$ concentration which is significantly higher than expected in the exhaust gases, the type 434 stainless steel has sufficient corrosion resistance, although an increased rate of weight loss has been seen in the last 3,000 hours. Weight change in distilled water was negligible on this scale. Since the amount of sulfur dioxide that is likely to dissolve in the condenser water is much less than $300 \mathrm{ppm}$, this test suggests type 434 stainless steel is suitable for this application.

Additional tests were conducted at M\&PT to more thoroughly evaluate the effect of the environment on the membrane permeance as a result of permeance increases that were noted as a result of membrane exposure to acid gas in a combustion flue gas generated from natural gas spiked with $\mathrm{SO}_{2}$. Initial tests of membrane acid stability was conducted over a $\mathrm{pH}$ range of 2 to 4 in sulfuric acid to examine the impact of $\mathrm{pH}$ on membrane performance and performance stability. It was found that at low pH's, membrane clean water fluxes would increase by about $25 \%$ after about 120 hours of exposure but would then stabilize. However, there was some question as to the impact of other acids on membrane performance (nitric and sulfurous acids) and if there were differences in the membrane durability on ceramic versus stainless steel substrate. 


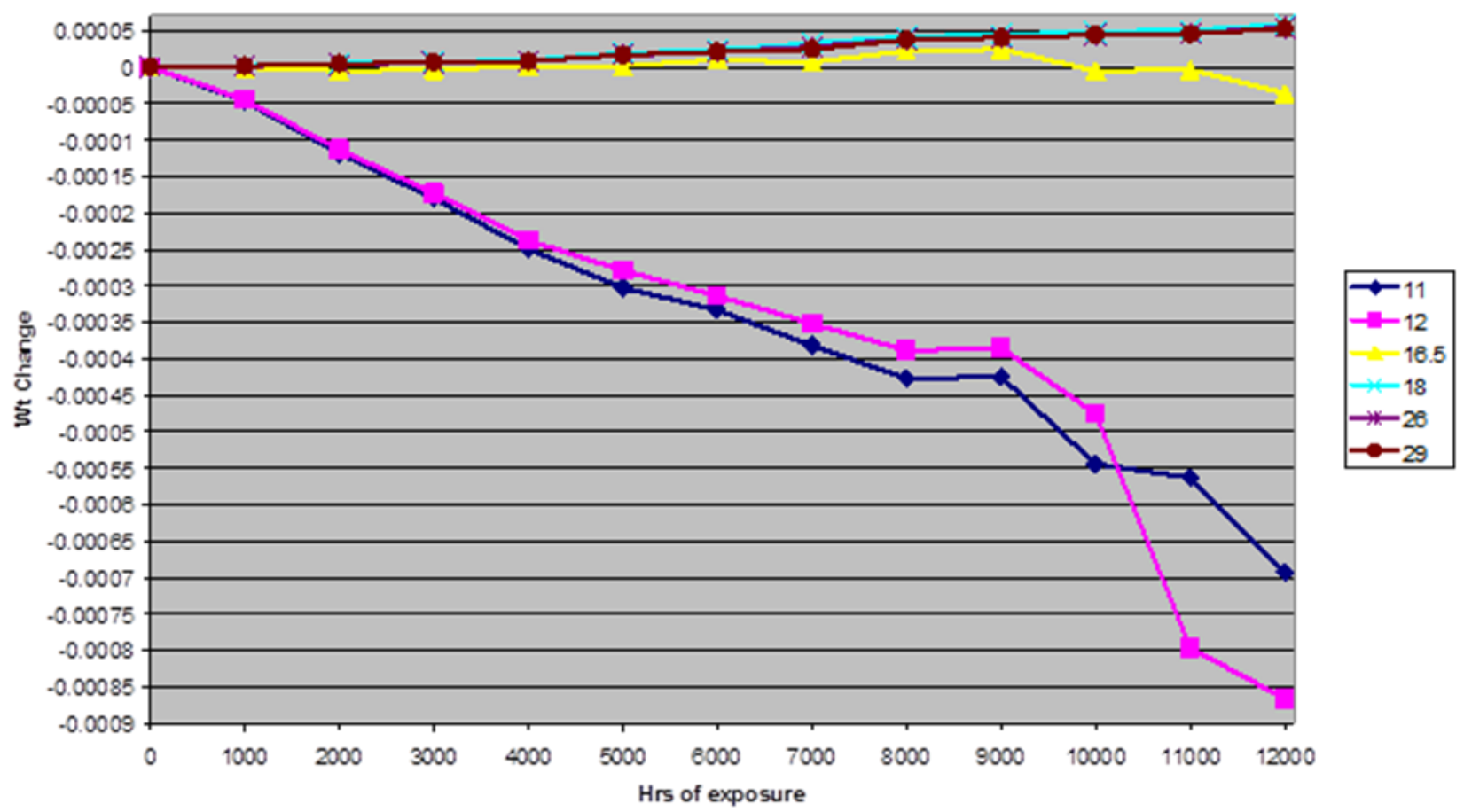

Figure 10. Weight change versus exposure time for ferritic alloys with different chromium content (wt\%) exposed to aqueous solution containing $600 \mathrm{ppm}$ sulfur dioxide at $90^{\circ} \mathrm{C}$.

Sulfuric, sulfurous, and nitric acid exposure testing of M\&PT ceramic layer modified ORNL substrates was conducted at pH's of 2, 3 and 4 to bracket the possible range of flue gas condensate at the membrane surface. In general, the membrane performance, in terms of clean water flux, was found to be independent of acid source. Further, clean water flux was generally stable at $\mathrm{pH} 3$ and 4 but was observed to increase rapidly at $\mathrm{pH} 2$ and saturate near the permeance of the substrate. SEM photomicrographs confirmed damage to the top active layer. Similarly, work was also conducted with an ORNL ceramic layer modified stainless steel, although due to the limited number of pieces available, work was initially conducted at $\mathrm{pH} 3$ and 4 (as well as a control test conducted in distilled water). Because the testing at a $\mathrm{pH}$ of 4 showed essentially no detrimental effect, this sample was used for additional testing conducted at a $\mathrm{pH}$ of 2 .

Figure 11 shows the effect of nitric acid exposure at various $\mathrm{pH}$ 's on the performance stability of ORNL ceramic layer modified ORNL stainless steel substrate. As can be seen, at $\mathrm{pH} 2$ the clean water permeance increases dramatically but is relatively stable at $\mathrm{pH} \sim 3$ and 4 . This trend is consistent with the results obtained with the various acid stability testing conducted on the M\&PT ceramic layer modified substrates as shown in Fig. 12. However, it is interesting that the increase in water permeance of the ORNL modified membrane at $\mathrm{pH} 2$ lags that obtained with the M\&PT modified substrates. Specifically, within 5 days of exposure the M\&PT modified parts show very high water permeances of $>170$ liters $/ \mathrm{m}^{2} / \mathrm{hr} / \mathrm{bar}$ [lmhb], which is consistent with the substrate permeance of ca. $220 \mathrm{lmhb}$ and suggests almost complete failure of the alumina top layer. By contrast, the ORNL modified part shows very little permeance change during the first ten days of exposure before a clean water permeance increase is observed. 


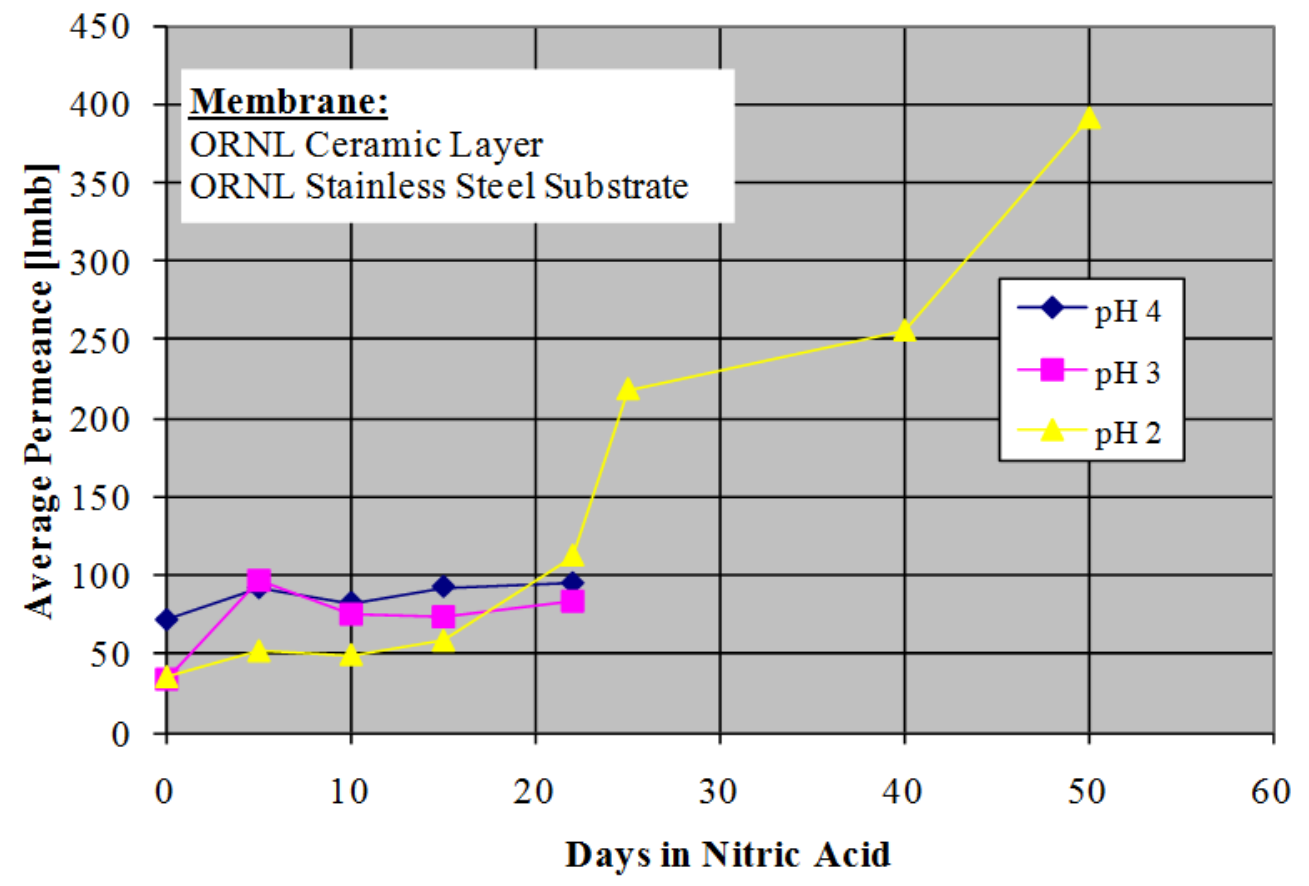

Figure 11. TMC membrane element (ORNL ceramic layer on ORNL stainless substrate) clean water permeance following exposure to nitric acid at $\mathrm{pH} 2,3$, and 4.

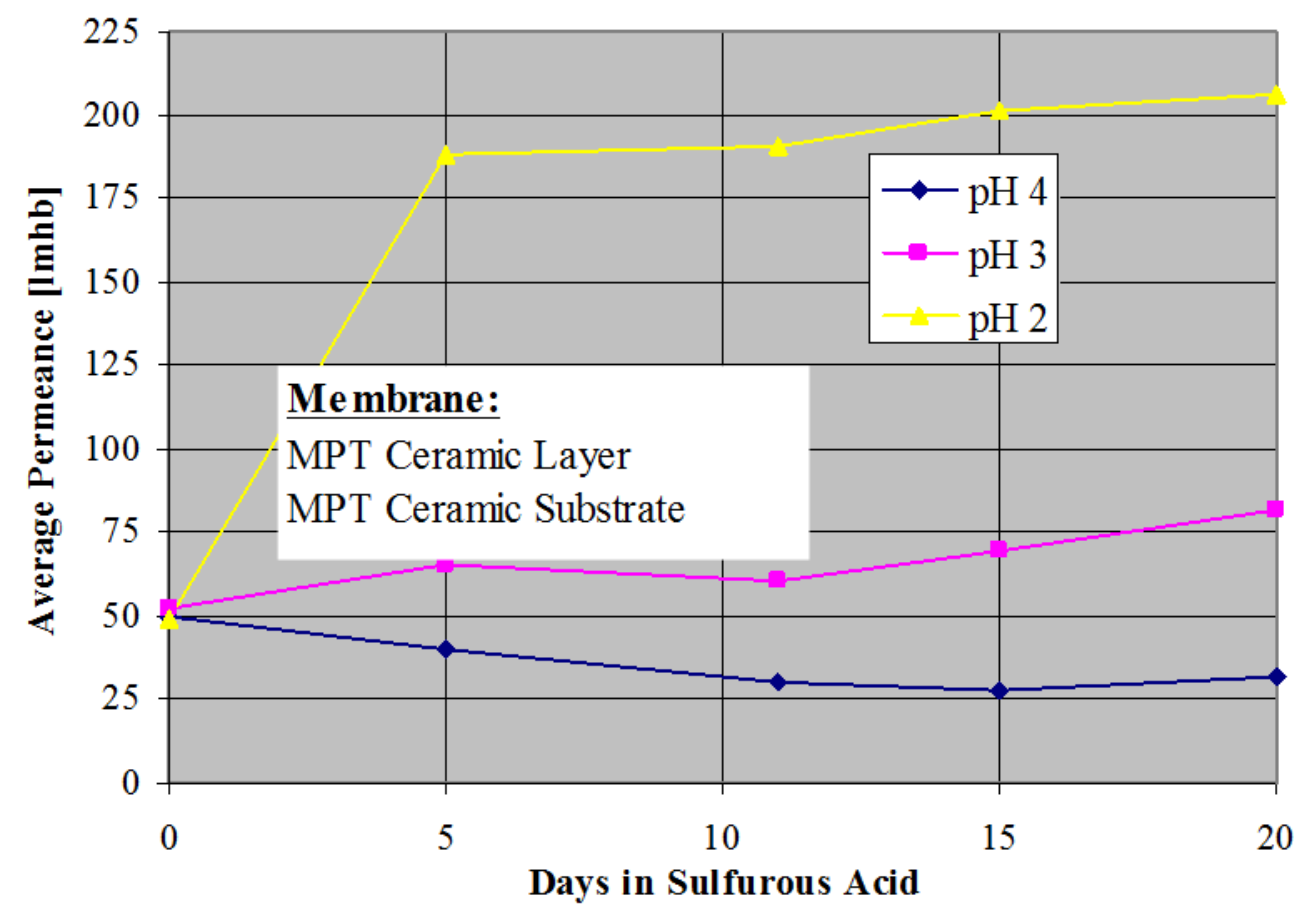

Figure 12. TMC membrane element (MPT ceramic layer on M\&PT ceramic substrate) clean water permeance following exposure to sulfurous acid at $\mathrm{pH} 2,3$, and 4 for up to 20 days.

Several explanations for the slightly different behavior of the ORNL ceramic coating are considered. For instance, it is possible that the presence of the more stable $\alpha$-alumina phase in the $\gamma$-alumina layer brought in by the ORNL boehmite used in the layer preparation could offer some added layer stability. 
It is known that $\alpha$-alumina is inert under these conditions and hence may act as suitable anchors for the $\gamma$-alumina phase. Alternatively, the fact that the alumina layer is embedded in the substrate may make it more resistant to damage, particularly with regard to delamination of sections of the membrane observed in the M\&PT ceramic layer modified parts.

Figure 13 shows SEM photomicrographs of the ORNL ceramic layer coated part before and after exposure to nitric acid at $\mathrm{pH} 3$ for 55 days. It appears that "roughening" of the surface is occurring, including not only the embedded alumina layer but also perhaps the particles of the substrate. Still, it appears that considerable portions of the layer remain embedded in the substrate, which would be consistent with the higher resistance to acid exposure. By contrast, Fig. 14 shows the effect of acid exposure on the M\&PT surface coated layer. In this case, the active layer is supported on and not embedded in the substrate, and hence considerable delamination is possible and observed.
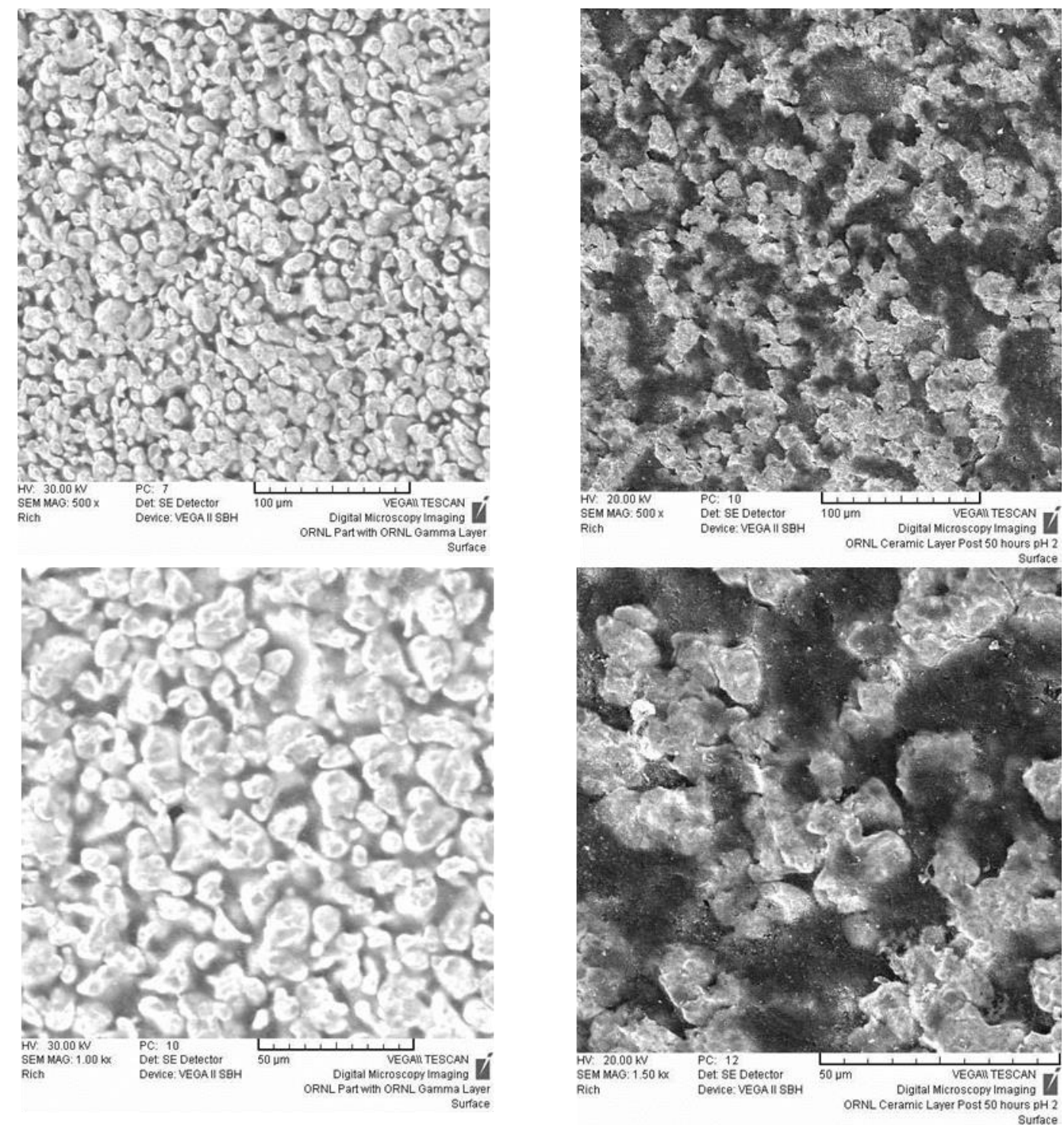

Figure 13. SEM photomicrographs of the TMC membrane elements (ORNL modified ORNL substrate) showing original membrane (left) and membrane after 55 days in nitric acid at $\mathrm{pH} 2$ and $85^{\circ} \mathrm{C}$ (right). 

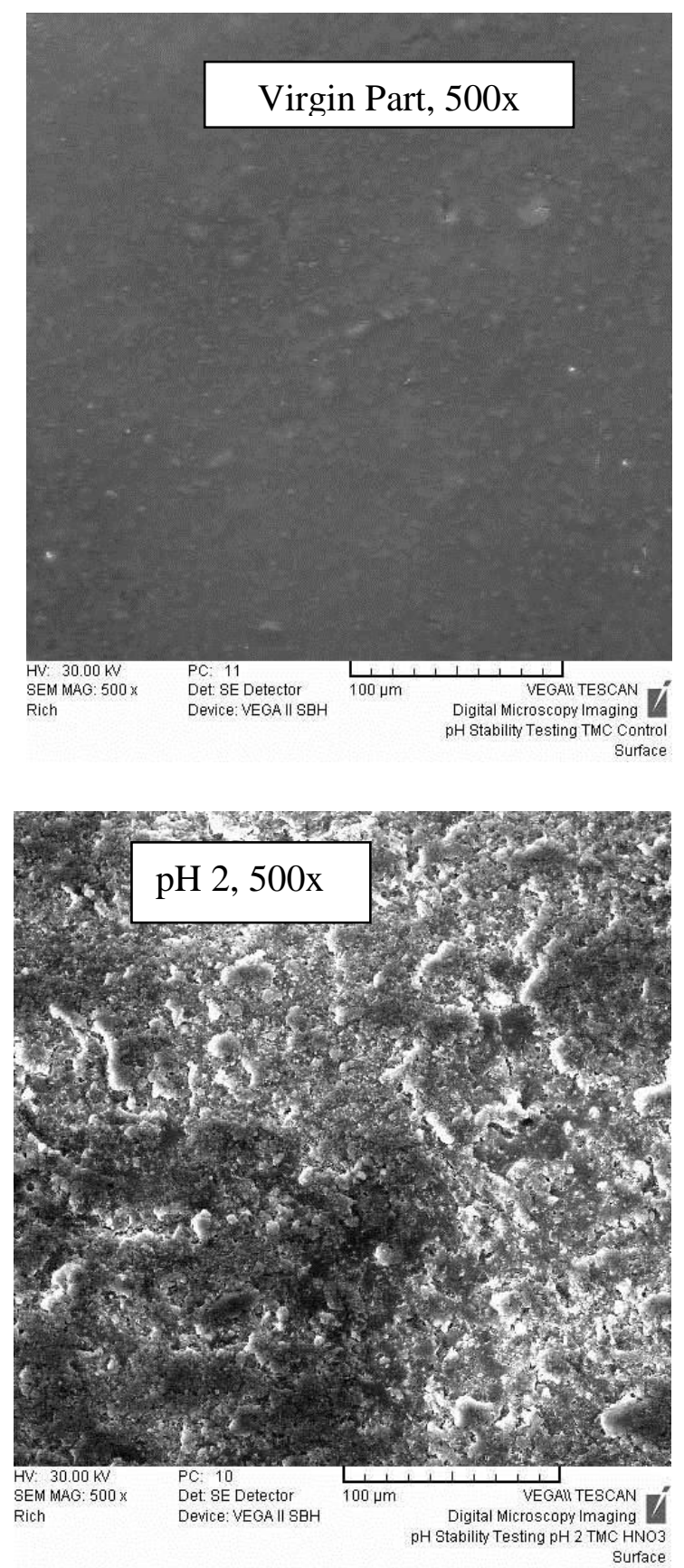
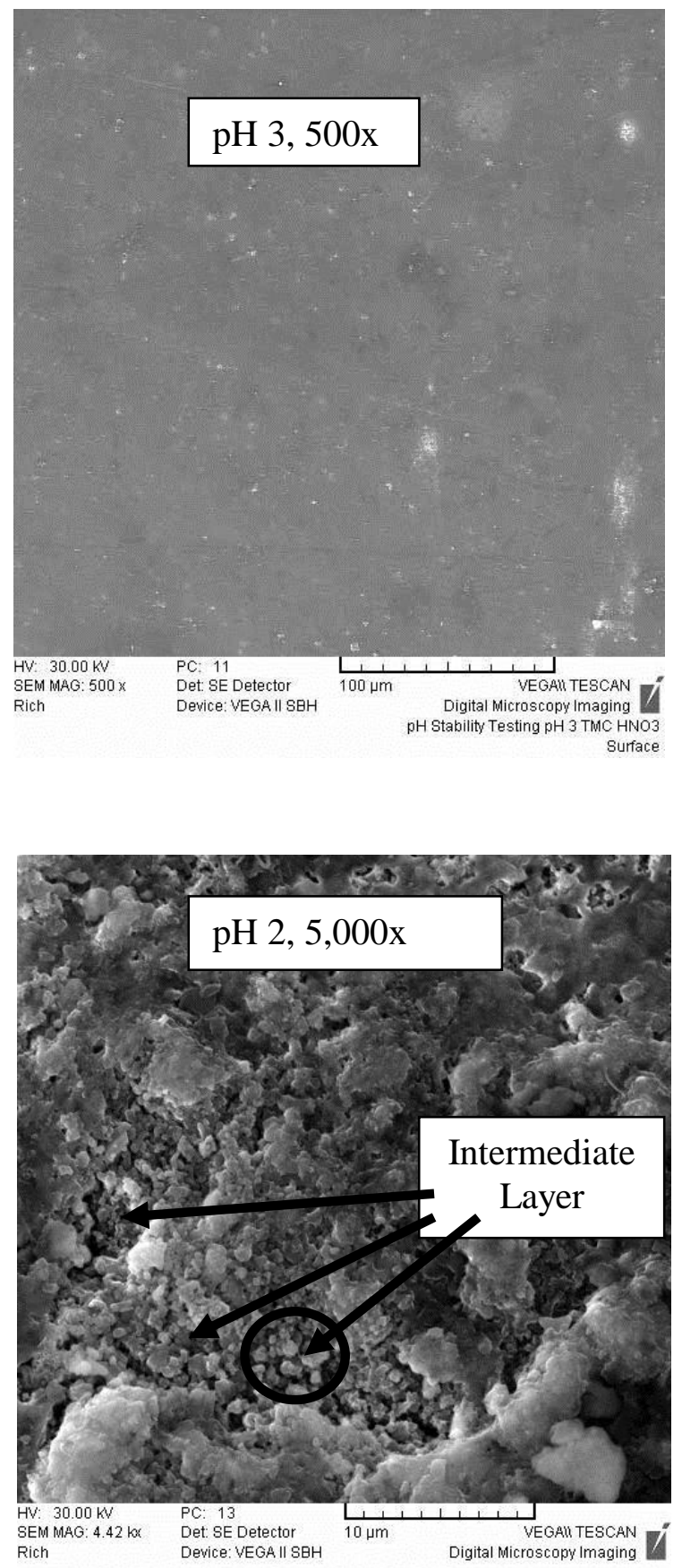

Figure 14. SEM photomicrographs of the TMC membrane elements (M\&PT modified M\&PT substrate) following exposure to $\mathrm{pH} 2$ and 3 and compared with the virgin (control) membrane. Intermediate substrate is clearly visible through the heavily damaged $\mathrm{pH} \sim 2$ exposed part in the 4,420X micrograph.

\subsection{TASK 6 - FABRICATE PROTOTYPE TMCS FROM THE MOST PROMISING CANDIDATES}

ORNL conducted initial application trials by applying a thin aluminum oxide separation layer on the outside of tubular stainless steel supports and two were first treated at $300^{\circ} \mathrm{C}$ and then at $950^{\circ} \mathrm{C}$ in 
hydrogen. The membranes were characterized for air permeation under a range of conditions, for leaks using alcohol bubble testing, by scanning electron microscopy and for pore-size using a flow-weighted pore-size distribution test system. The results were compared with results obtained on metal supported membranes coated by M\&PT and sintered at $\mathrm{ORNL}$; one at $850^{\circ} \mathrm{C}$ and one at $950^{\circ} \mathrm{C}$ in hydrogen. For the membranes prepared by M\&PT, the air permeances at STP were determined to be 2.49

$\mathrm{cm}^{3} / \mathrm{min} / \mathrm{cm}^{2} / \mathrm{cm} \mathrm{Hg}$ or $112 \mathrm{~m}^{3} / \mathrm{hr} / \mathrm{m}^{2} / \mathrm{bar}$ for a membrane treated at $850^{\circ} \mathrm{C}$ and $3.41 \mathrm{~cm}^{3} / \mathrm{min} / \mathrm{cm}^{2} / \mathrm{cm}$ $\mathrm{Hg}$ or $153 \mathrm{~m}^{3} / \mathrm{hr} / \mathrm{m}^{2} / \mathrm{bar}$ for a membrane treated at $950^{\circ} \mathrm{C}$. The flow-weighted pore size distributions are shown in Fig. 15 and the cumulative flow as a function of pore-size is shown in Fig. 16.

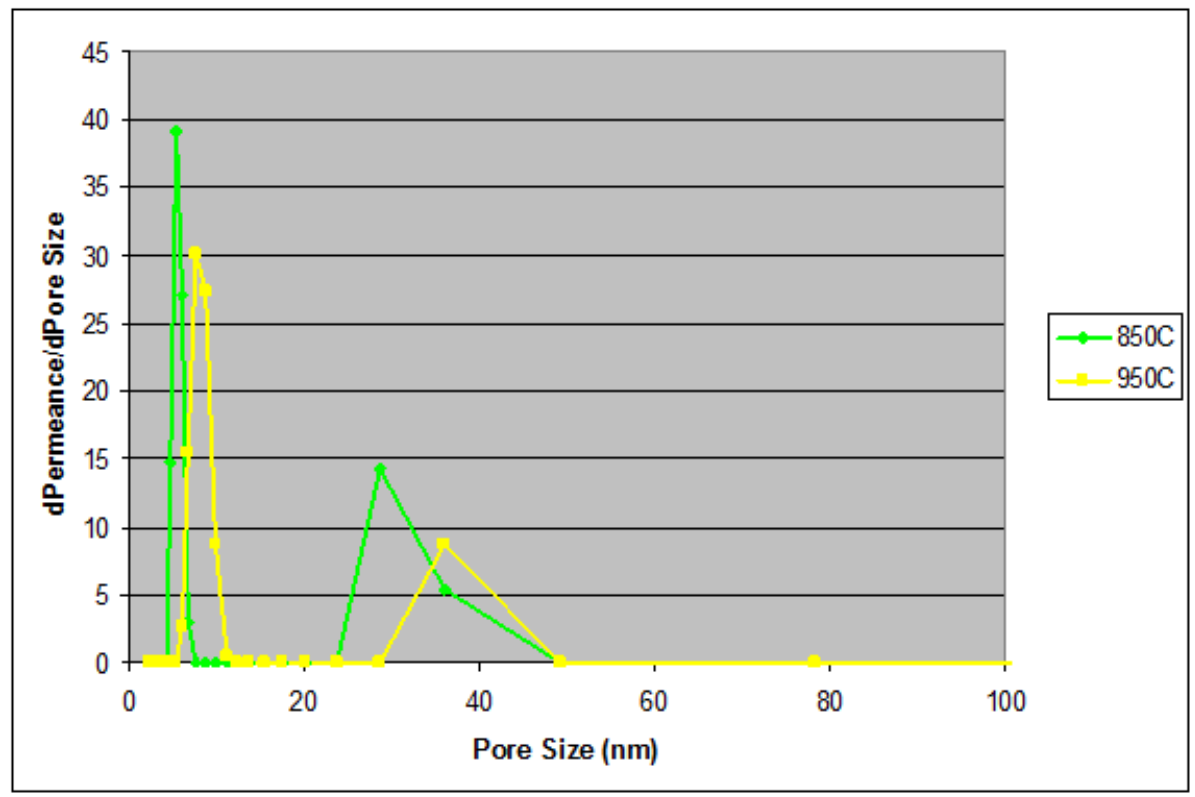

Figure 15. Flow-weighted pore size distribution of metallic supported membranes coated by M\&PT heated at two temperatures.

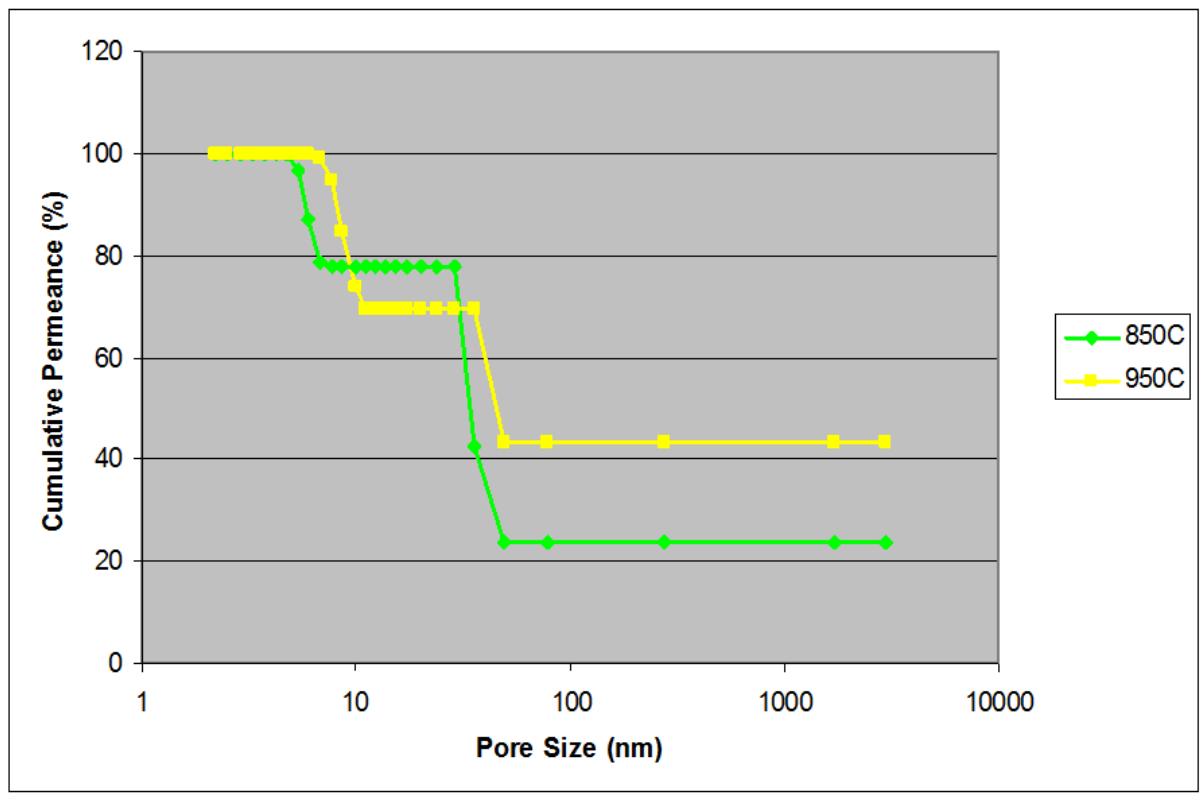

Figure 16. Cumulative flow starting at large pore sizes versus pore size for metal supported membranes coated by M\&PT in two steps. 
For improved resolution at low pore sizes, the distribution in Fig. 15 only shows the pores below 100 $\mathrm{nm}$. There are two distinct regions in each plot. For the $850^{\circ} \mathrm{C}$ membrane, there are peaks at $5.6 \mathrm{~nm}$ and $32 \mathrm{~nm}$. In addition, Fig. 16 shows that there was approximately $23 \%$ of the flow through pores larger than 1 micron. Figure 16 also show that only $23 \%$ of the flow was through pores smaller than approximately $7 \mathrm{~nm}$ while $54 \%$ of the flow was through pores ranging from 23 to $49 \mathrm{~nm}$. The membrane heated to $950^{\circ} \mathrm{C}$ shows a small shift to slightly larger pore-sizes. As the membrane is heated, the particles of aluminum oxide particles comprising the membrane grow and create slightly larger pores (or spaces between the particles) which have less resistance to gas flow resulting in the approximately $36 \%$ higher measured permeance. For the membrane treated at $950^{\circ} \mathrm{C}$, approximately $43 \%$ of the flow was through pores larger than 1 micron, $26 \%$ was through pores ranging from 28 to $49 \mathrm{~nm}$ and $31 \%$ was through pores smaller than approximately $12 \mathrm{~nm}$. The peak at approximately $30-$ $50 \mathrm{~nm}$ is consistent with the pore-size of the intermediate layer and indicates an area where the top layer has insufficient coverage and the intermediate shows through.

For the tubular membranes coated by ORNL (170-86 and 1710-87) in a single step, the air permeances for the membranes when heated to $300^{\circ} \mathrm{C}$ were determined to be 0.51 and $0.57 \mathrm{~cm}^{3} / \mathrm{min} / \mathrm{cm}^{2} / \mathrm{cm} \mathrm{Hg}$ or 22.9 and $25.7 \mathrm{~m}^{3} / \mathrm{hr} / \mathrm{m}^{2} / \mathrm{bar}$ showing good reproducibility for the two membranes. When heated to $950^{\circ} \mathrm{C}$, the permeances increased to 0.51 and $0.56 \mathrm{~cm}^{3} / \mathrm{min} / \mathrm{cm}^{2} / \mathrm{cm} \mathrm{Hg}$ or 22.9 and $25.2 \mathrm{~m} / \mathrm{hr} / \mathrm{m}^{2} / \mathrm{bar}$. A flow-weighted pore size distribution was completed for the two samples treated at $300^{\circ} \mathrm{C}$ and is shown in Fig. 17. The cumulative flow curve, starting at large pore sizes, as a function of pore size is shown in Fig. 18. It shows that for one of the two membranes there is much less than $10 \%$ of the flow through pores larger than $600 \mathrm{~nm}$ and that approximately $90 \%$ of the flow is through pores ranging from $5 \mathrm{~nm}$ to $40 \mathrm{~nm}$. For the second sample approximately $25 \%$ of the flow is through pores larger than $600 \mathrm{~nm}$.

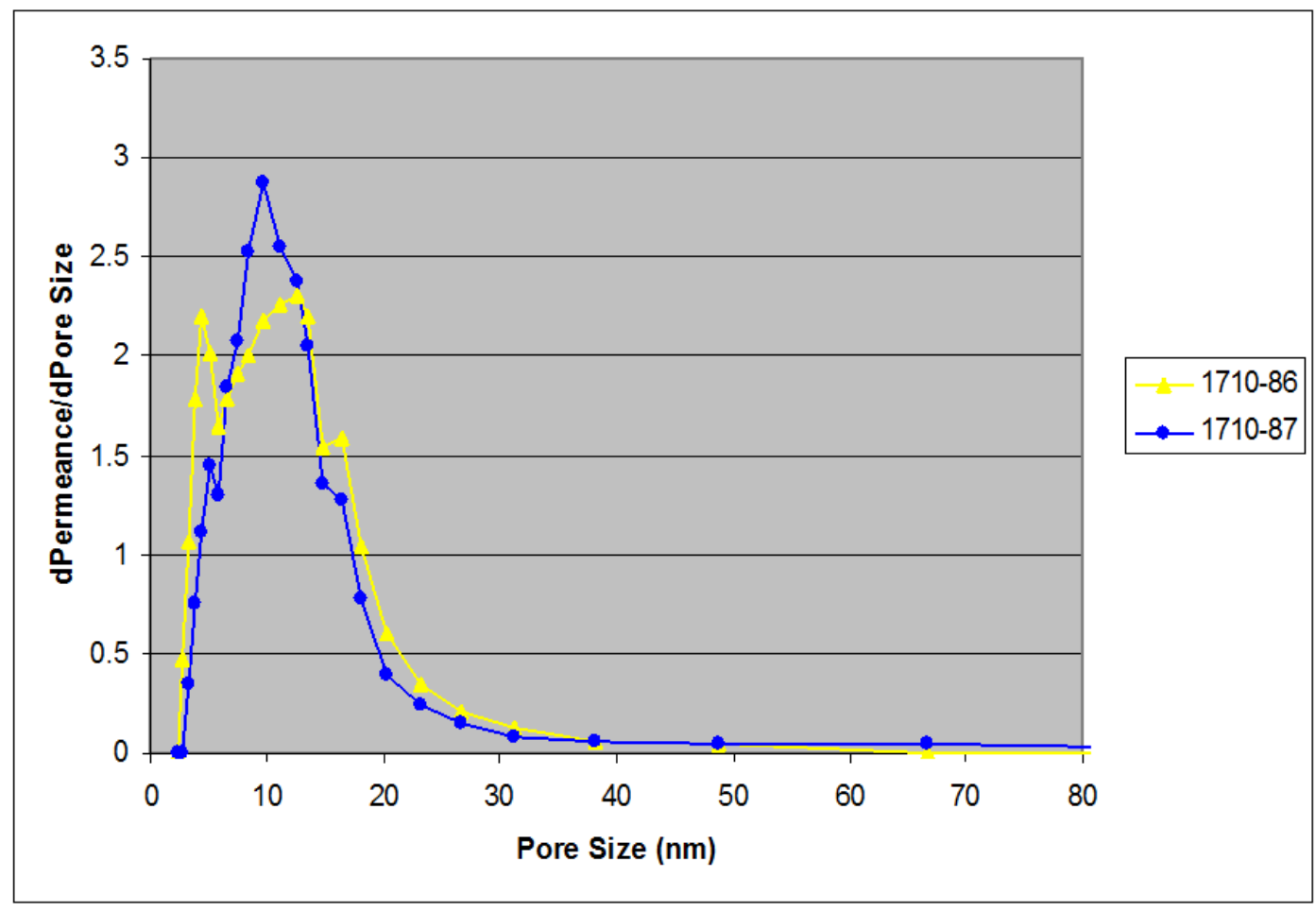

Figure 17. Flow weighted pore size distribution of membranes coated by ORNL in a single step and treated at $300^{\circ} \mathrm{C}$ 


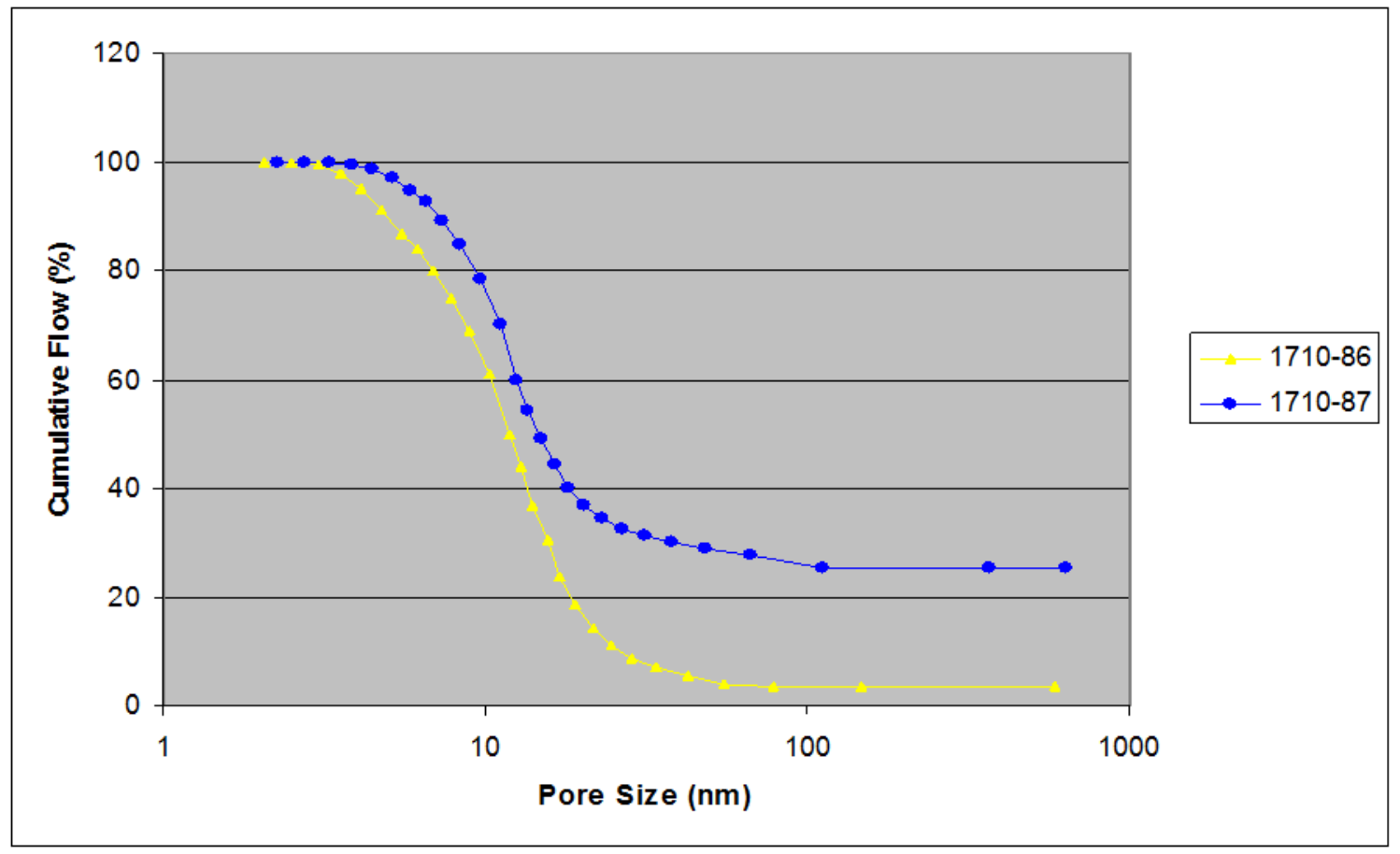

Figure 18. Cumulative flow versus pore size for membranes coated by $\mathrm{ORNL}$ in a single step at $300^{\circ} \mathrm{C}$

When these membranes were treated at $950^{\circ} \mathrm{C}$, their air permeances increased approximately $20 \%$ to 0.62 and $0.73 \mathrm{~cm}^{3} / \mathrm{min} / \mathrm{cm}^{2} / \mathrm{cm} \mathrm{Hg}$ or 27.8 and $33.0 \mathrm{~m}^{3} / \mathrm{hr} / \mathrm{m}^{2} / \mathrm{bar}$. The flow-weighted pore size distribution and cumulative flow curves are shown in Figs. 19 and 20. Figure 19 shows the emergence of pores in the range of 35 to $50 \mathrm{~nm}$ for both membranes. Figure 20 shows that the pores larger than 3 microns account for approximately $10 \%$ of the flow in $1710-86$ and $20 \%$ of the flow in the $1710-87$. The pores ranging from $35-50 \mathrm{~nm}$ account for $10 \%$ of the flow in $1710-86$ and $20 \%$ of the flow in the 1710-87. At first glance, the permeances for these membranes appear to be much lower than for the membranes coated by M\&PT in two steps. However, if you only compare the amount of flow in pores less than $20 \mathrm{~nm}$, the membranes coated by M\&PT had air permeances of approximately 1.06 $\mathrm{cm}^{3} / \mathrm{min} / \mathrm{cm}^{2} / \mathrm{cm} \mathrm{Hg}$ or $47.4 \mathrm{~m}^{3} / \mathrm{hr} / \mathrm{m}^{2} /$ bar for a membrane treated at $950^{\circ} \mathrm{C}$ while the membranes coated by ORNL averaged $0.43 \mathrm{~cm}^{3} / \mathrm{min} / \mathrm{cm}^{2} / \mathrm{cm} \mathrm{Hg}$ or $19.4 \mathrm{~m}^{3} / \mathrm{hr} / \mathrm{m}^{2} /$ bar or slightly less than $50 \%$ of the flow of the M\&PT coated membranes. 


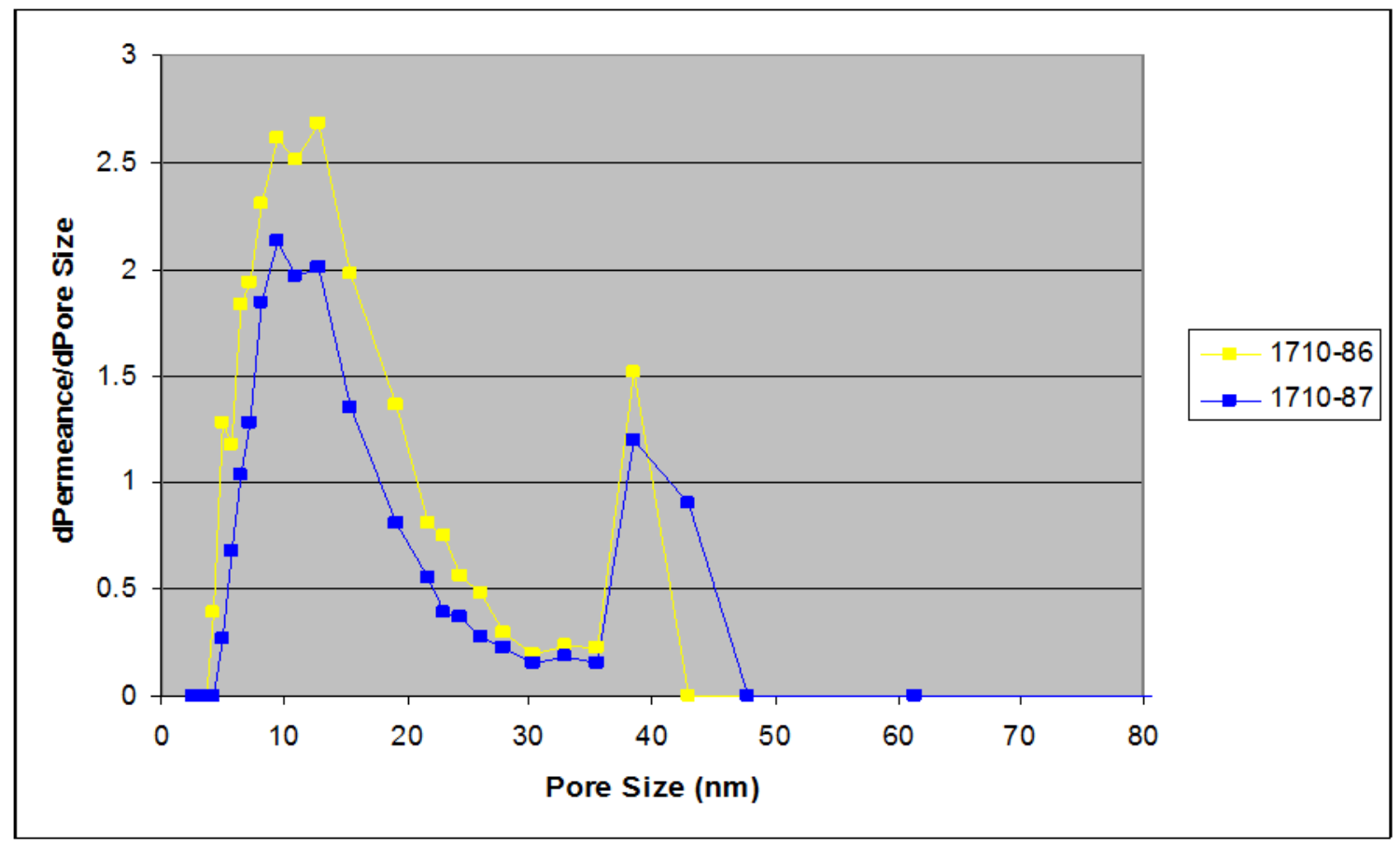

Figure 19. Flow weighted pore-size distribution of ORNL prepared membranes treated at $950^{\circ} \mathrm{C}$.

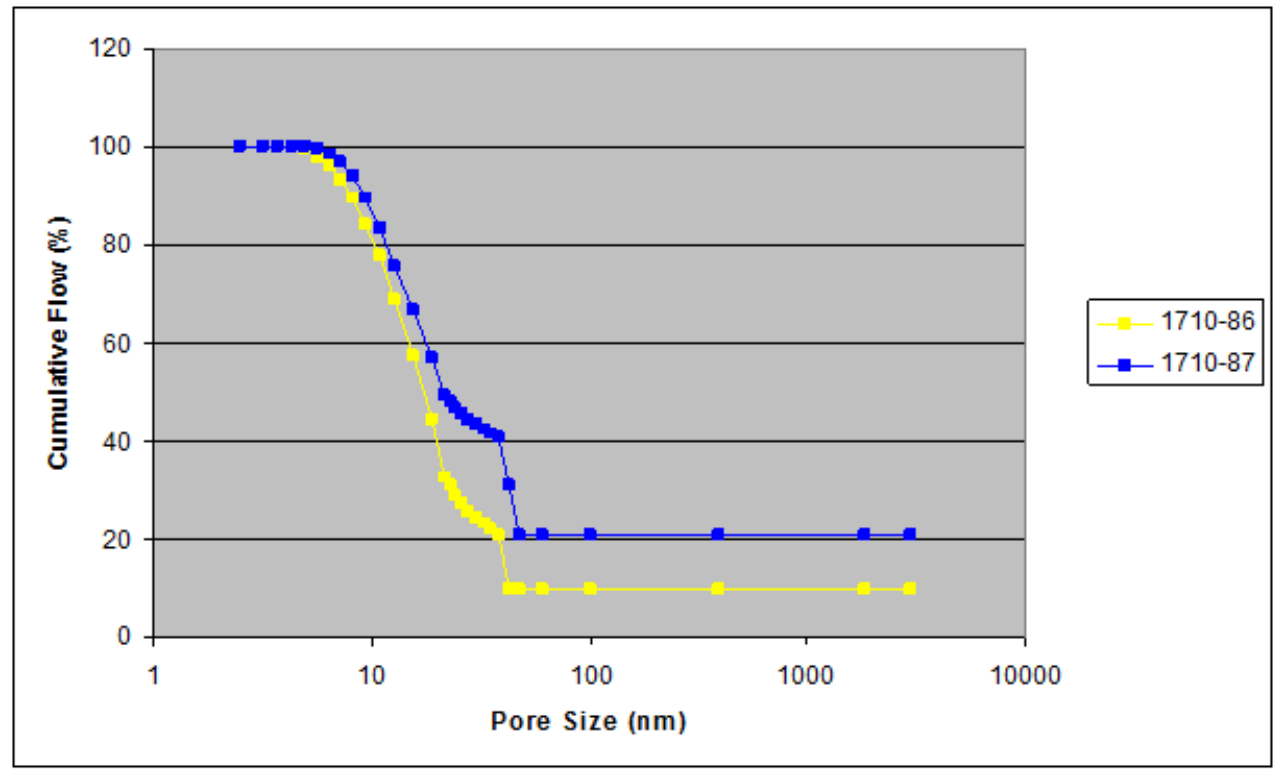

Figure 20. Cumulative flow versus pore size for membranes coated by ORNL in a single step treated at $950^{\circ} \mathrm{C}$.

Resistance of flow is affected by both the pore size and the thickness of the membrane or membrane layer. While the electron micrographs show a thin (1-2 microns thick) layer of aluminum oxide on the surface of the membranes prepared in a single step by ORNL (Fig. 21 and 22), it is clear that the effective layer thickness is greater than 1-2 microns when considering the depth of the aluminum oxide that penetrates into the pores of the stainless steel support tube as shown in the blow-up in Fig.22. Figure 22 shows an enlarged view of a surface pore filled with the aluminum oxide where the depth of 
the aluminum oxide is approximately 7 microns. Based on experimental results and modeling by GTI, it is believed that a high permeance is crucial to the operation of a TMC system. If the permeance is not high enough, water can condense on the surface of the membrane and not only in the pores via capillary condensation. This condensed water will be in contact with the exhaust gases increasing the potential for dissolution of potential acid gases such as $\mathrm{SO}_{2}$ into the water which would lower the $\mathrm{pH}$ and require additional cleanup of the condensed water. Because it is not possible to reduce the thickness of the membrane layer without creating some leaks, reducing the penetration of the aluminum oxide powder into the surface pores is the most likely option for increasing membrane permeance without increasing the pore size of the membrane layer.

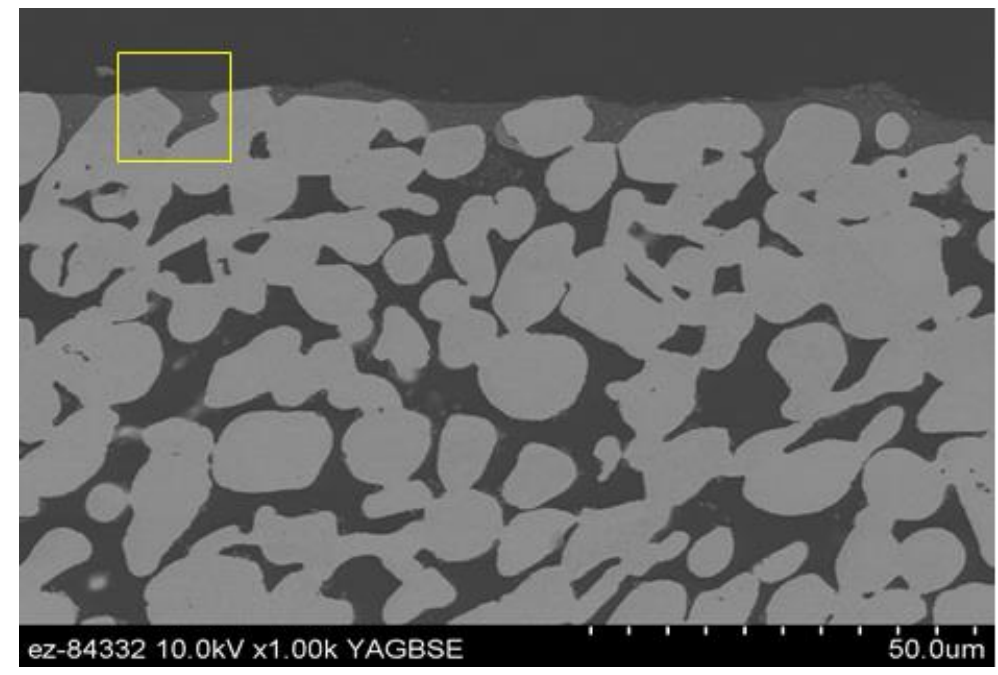

Figure 21. Electron micrograph showing cross section of aluminum oxide ooxide layer on surface of support tube applied in a single step by ORNL.

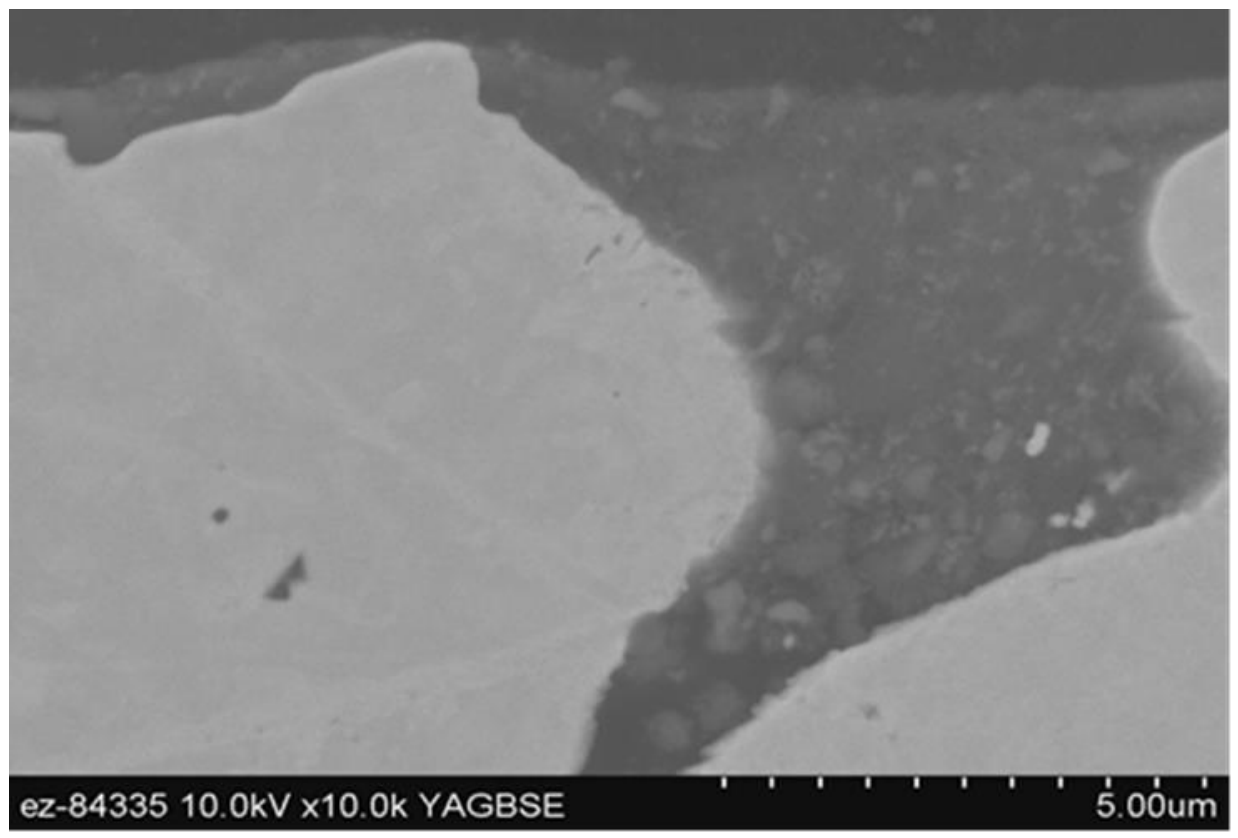

Figure 22. Electron micrograph showing enlarged area where aluminum oxide penetrates into the gap between the support tube particles. 
ORNL investigated the efficacy of a thin metal intermediate layer for reducing the effective membrane layer thickness without increasing the pore size or increasing the quantity of leaks using both nickel and stainless steel. Figures 23 and 24 are electron micrographs at two different magnifications showing the layer made from 4-micron $316 \mathrm{~L}$ stainless steel. It is clear from the micrographs that the layer filled the spaces between the support tube particles without building up a thick layer to increase the resistance to flow through the structure. The layer decreased the pore-size of the support from an average of 3.6 microns without the layer to between 0.7 and 1.2 microns with the intermediate porous metal layer. Because the stainless steel layer is so thin, it had only a minor impact on the permeance of the support. This layer should decrease the depth of penetration of the aluminum oxide layer into the surface pores and increase the overall membrane permeance.

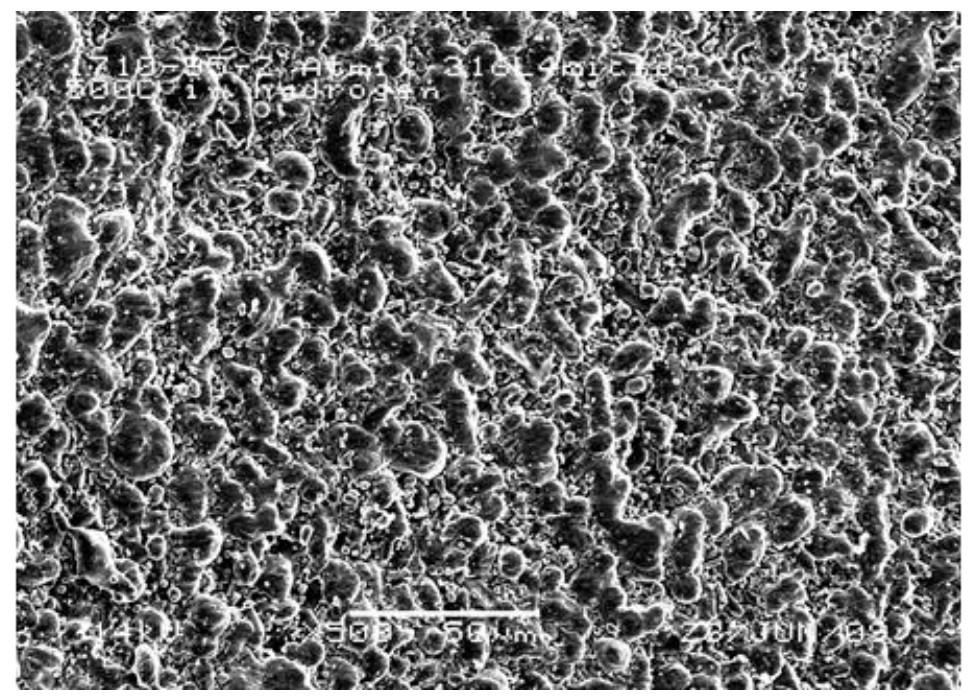

Figure 23. Electron micrograph showing layer of fine stainless steel on surface of support tube taken at 500X.

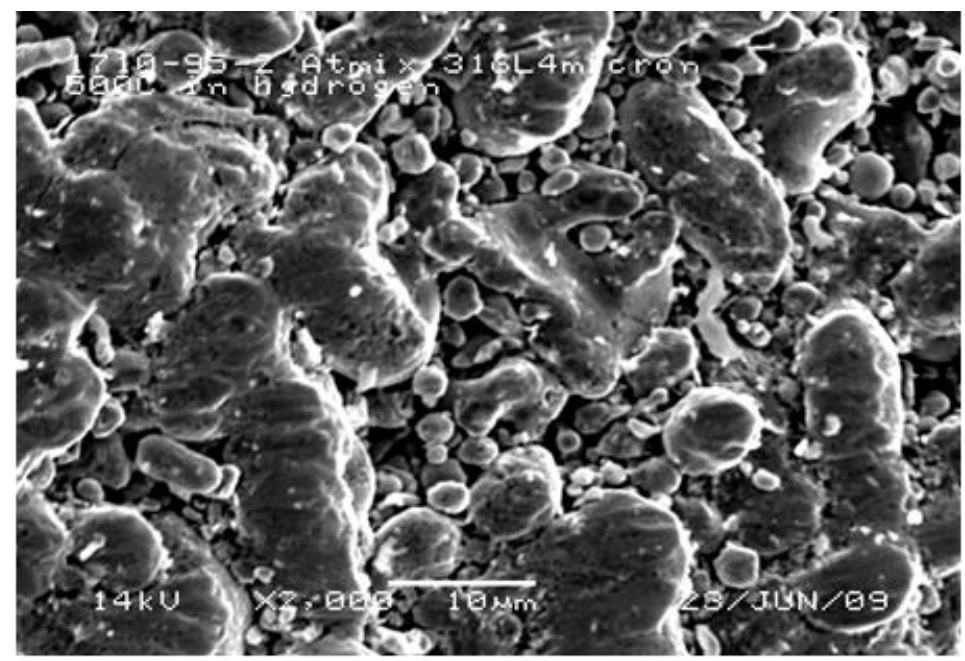

Figure 24 Electron micrograph showing layer of fine stainless steel on surface of support tube taken at 2000X.

Figures 25-27 are electron micrographs showing the layer made of fine nickel on the support surface. Figures 25-26 are perpendicular views at two magnifications to show the uniformity of coverage. Figure 27 is taken at an angle to the surface and it shows that again the nickel only fills the gaps 
between the support tube particles without completely covering the surface. The average pore size of the nickel layer was determined to be between 0.3 and 0.5 microns. Because of the smaller pore-size of this layer compared to the stainless steel layer, this nickel layer resulted in a slightly larger permeance decrease than the stainless steel layer. This finer pore layer may further reduce the penetration of the aluminum oxide layer which has the potential to further increase the membrane permeance.

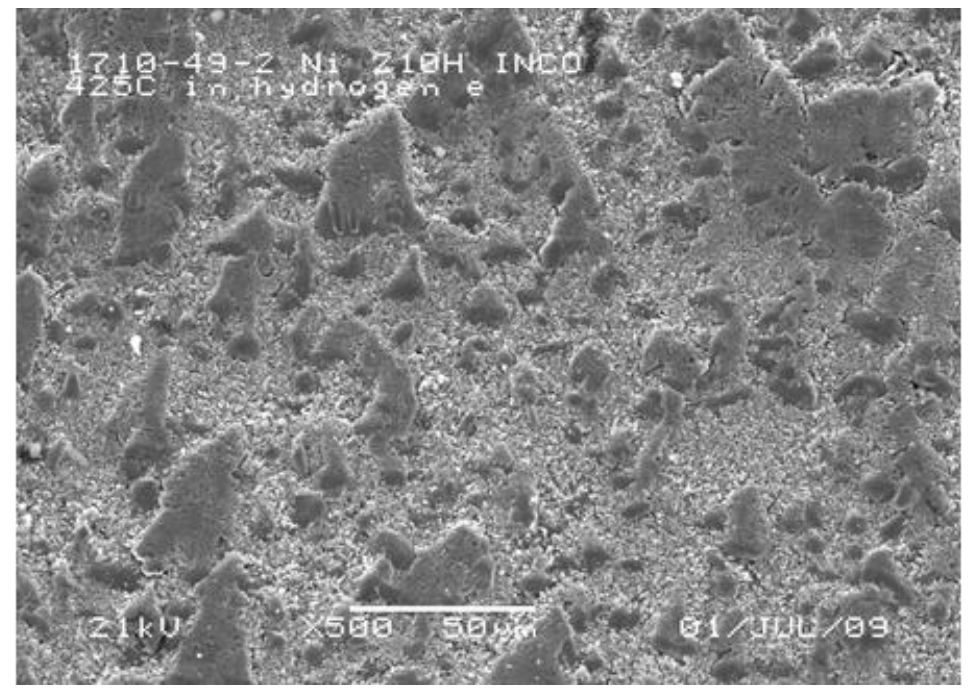

Figure 25. Electron micrograph showing layer of fine nickel on surface of support tube taken at 500X.

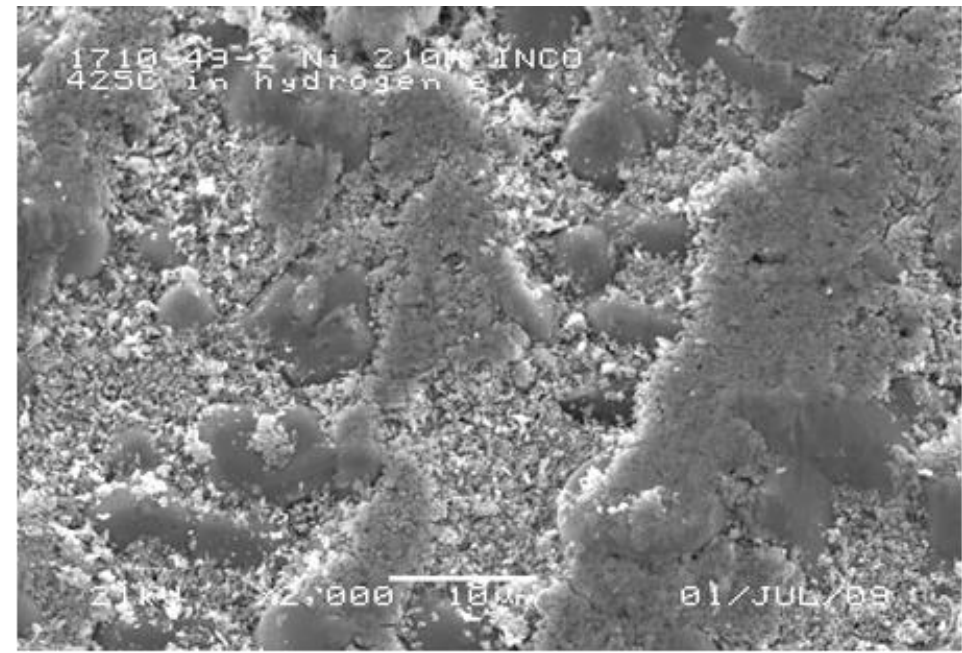

Figure 26. Electron micrograph showing layer of fine nickel on surface of support tube taken at $2000 \mathrm{X}$. 


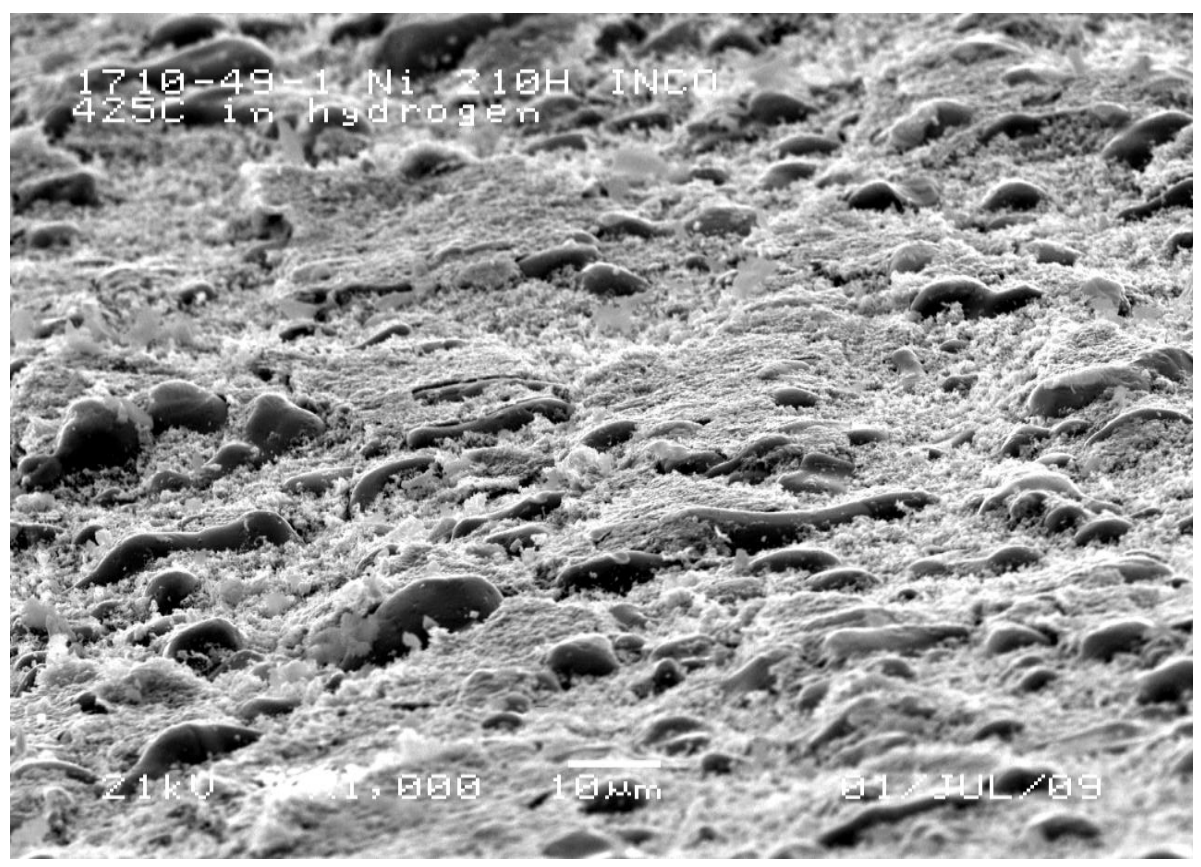

Figure 27. Electron micrograph taken at an angle showing how layer of fine nickel improves smoothness of surface. Large particles from support can be seen sticking through nickel layer.

The initial attempts to use the ORNL-developed process to apply an outside coat to the metallic supports produced tubes with a few small leaks and slightly lower air permeance through the smallest pores than the M\&PT coated membranes. However, the M\&PT coated membranes showed higher leak rates which accounts for the part of the higher air permeances. The pore-size distribution is tighter for the small pores on the M\&PT membrane but it appears that there is significant flow through pores of the size of the intermediate layer and support tube indicating possible leaks. Also, preliminary results of metal intermediate layers looked very promising, as will be described, issues arose because the sintering temperature of the final membrane layer were high enough that the metallic intermediate layer was detrimentally affected. The layers are very uniform without impacting the permeance of the support greatly.

In order to evaluate the strength and functionality of tubes fabricated with the conventional ceramic membrane layers, a total of 459 full length (34") tubes with stainless steel substrates and ceramic separation layers were characterized. Figure 28 shows SEM surface and cross sections of a standard finished membrane. The cross section shows a $500 \AA$ pore size ceramic intermediate layer with a thickness of 15 to $20 \mu \mathrm{m}$ and an $80 \AA$ pore size surface layer of 2 to $3 \mu \mathrm{m}$ thickness. These results are consistent with previous data obtained during the early development and scale up of the ceramic layer modified stainless steel substrate. High magnification imaging of the surface shows no evidence of surface layer cracking or pinholing and this is consistent with the bubble testing results that will be described. In addition to SEM examination, the membranes were characterized for dimensional consistency, bubble point, and water permeance as part of the QA/QC effort. 

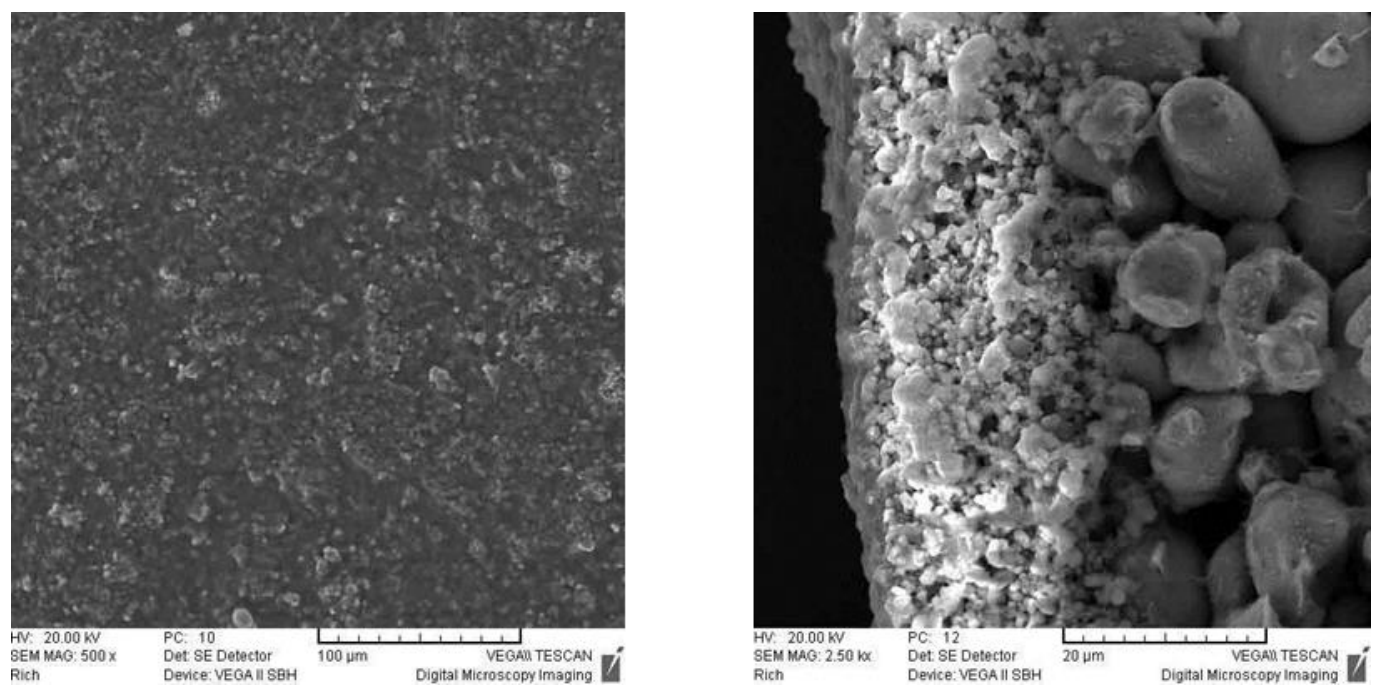

Figure 28. SEM micrographs of the surface and cross section of the typical finished full length tube with a stainless steel substrate and ceramic intermediate and outer layers.

In this task, 192 of the total of 459 of the full length ORNL stainless steel substrates were characterized for dimensional consistency as part of the scale up to the 34 " membrane and QA/QC database development. Figure 29 shows a plot of the OD maximum and OD maximum - OD minimum, for each of the tubes tested. The OD consistency for a single tube (both maximum and "out of roundness") as well as from tube to tube in a batch and between batches is an important QC parameter, since it dictates ease of module preparation in terms of insertion of the tubes into the tube sheet and loss of epoxy in the gap between the tube and tube sheet. Further, inconsistencies in tube dimensions from batch to batch may point to potential problems in the powder precursor or tube preparation (extrusion, firing conditions, etc.) that can be quickly determined and fixed.



Figure 29. Dimensional consistency of the stainless steel substrates; Maximum OD and Maximum OD-Minimum OD for 192 tubes are characterized. 
The maximum OD measurement and standard deviation of the tubes is the same at each end of the part at 0.472 " and 0.008 ", respectively. This is clearly the result of the post production swaging of the membranes that is performed and demonstrates that high precision can be maintained in the OD consistency at the end of the parts. The maximum OD and at the center of the parts is generally smaller than the ends and reflects the enlargement of the ends due to the swaging operation. Similarly the OD variability is about 3-fold higher in the center, again reflecting the end smoothing that occurs during swaging. The maximum deviation permitted based upon previously developed specifications for ceramic substrate tubes is $4 \%$. At the average maximum OD of $0.472 \%$, an on-spec tube would fall in the range of 0.45 " to 0.491 " ( \pm 0.019 " on the maximum OD). Given this spec, it is clear that the vast majority of the parts QC' $d$ here would pass. However, based upon an inspection of the maximum OD measurements in Fig. 29, it is clear that 6 or 7 tubes would fall outside of this spec and may not be suitable in the future for a commercial installation.

The maximum OD measurement will dictate the minimum hole diameter for the tmc membranes in the module tube sheet. To keep the module fabrication cost low, it is critical to maintain good consistency of the tube OD to prevent excessive gapping between the tubes and tube sheet. Of equal importance is the minimum od at each end. It is a measurement of the degree to which the part is "out of round" and further dictates the maximum gap size between the tube sheet and tube. Hence, it is a critical measurement that predicts the potential for the epoxy to leak past the tube sheet during potting and hence the ease of bundle production. Figure 29 shows a plot of the "out of roundness" of the parts as reflected by the difference between the maximum and minimum od at one end of the part. Further, without actual testing of the potting methodology with these tubes, it is difficult to establish an appropriate "out of roundness" spec.

Overall, it appears that the variation in the OD based upon measurement of the maximum diameter will satisfy the $\pm 4 \%$ spec. Although 6 or 7 tubes of the 192 tested fell slightly outside this spec, this should be expected for a first pass through production run using laboratory and/or pilot scale production equipment. Further, improvements in the tube end swaging equipment likely guarantee production of on-spec parts with very high consistency and reproducibility.

All of the full scale TMC membrane elements prepared as part of the 400+ tube production run for the GTI pilot test were characterized via bubble point, water permeance and/or visual inspection. Bubble point testing was conducted with air at 5,8 and 10 psig in water with the finished membranes to assess the quality of the ceramic layer coatings. The number of pinholes in the membrane was recorded at each pressure. In addition, any layer cracks or delaminations were also noted. Of the 459 tubes bubble tested, 13 did not pass the bubble point test at 5 psig, although the number of pinholes at this pressure was very modest and below three in all cases. All of the parts that did not pass at 5 psig were patched with epoxy. Following patching, all of these parts passed the bubble test at 8 psig with no leaks. In addition to the tubes that showed minor pinholes during bubble testing, there was an additional subset of 25 tubes that were not suitable for use in a module because of such issues as cracking/splitting at the end of the tube, breakage during handing or insufficient length.

In addition to bubble testing, water permeance testing was conducted with the finished TMC membranes using distilled water filtered with a 100å pore size membrane. Testing was conducted at room temperature at an operating pressure of $10 \mathrm{psig}$. The average permeance of the membranes is 64.0 liters $/ \mathrm{m}^{2} / \mathrm{hr} / \mathrm{bar}$, consistent with the typical range of 40 to $80 \mathrm{lmhb}$ for the ceramic based TMC membrane elements prepared under similar conditions. Interestingly, the water permeance for the roughly 160 membranes tested ranges from as low as 18 to $135 \mathrm{lmhb}$ which is quite a bit broader than typically observed with the standard ceramic support based TMC elements. However, the quality of 
the membranes appears to be quite good, based upon bubble testing and visual inspection. Hence, the broader permeance distribution may be due to differences in firing conditions and atmosphere control during firing, layer thickness distribution differences along the length of the part, or likely a host of other factors. It is expected that as additional scale-up and production experience is gained, much tighter control in the membrane permeance will be achieved.

Overall, the results for the 459 finished ceramic layer modified stainless steel substrates suggest that reasonably on-spec tmc membrane elements based upon the metallic substrates can consistently be prepared. SEM analysis shows no obvious defects in the membrane surface, consistent with the bubble test results. Further, the thickness of the two ceramic layers is consistent with previous results and the in-house data for ceramic substrate based TMC membrane elements. Based upon the QC testing, about 46 of the 459 tubes appear to have failed due to an inordinate amount of pinhole or delamination defects resulting from a flaw in the membrane coating layers. However, these parts were repaired and made available for pilot testing. An additional 25 tubes were found to be either too short or had split ends and could not be used as part of the GTI pilot test.

At the conclusion of the QC inspections, it was accepted that the average water permeance of the full scale membrane elements was $64 \mathrm{lmhb}$ which was consistent with typical values obtained in previous work under this project as well as with data for similar coatings on ceramic tubular substrates. The broader permeance distribution, ranging from 18 to $135 \mathrm{lmhb}$, likely reflects a number of factors including firing condition control, substrate consistency, layer thickness control, and others. This would also be consistent with the delamination difficulties observed in several of the membrane elements.

At the conclusion of this task, of the 459 ceramic layer modified stainless steel TMC membrane elements prepared by ORNL and MP\&T and characterized by M\&PT, 424 were found to be on-spec and made available for further testing by GTI.

\subsection{TASK 7 - CONDUCT BENCH-SCALE TESTING OF PROTOTYPE TMC MODULES}

In order to conduct bench-scale testing it was necessary to identify the industrial environments to which modules would be exposed. One concern is the anticipated effect of dissolved gases on the acidity of the water. The $\mathrm{pH}$ of the condensed water can be influenced by the presence of gases in the flue gas. Carbon dioxide, nitrogen oxides, and sulfur oxides all form acids when dissolved in water. The equilibrium amount of gas dissolved into the water depends on the gas composition and the temperature of the water. The amount of gas that dissolves in the water can also be influenced by the $\mathrm{pH}$ of the water. In other words, the presence of another stronger acid can influence the amount of a second gas that can dissolve in the water. With the proper mathematical relationships, the equilibrium concentration of the gases in water can be determined. However, it is expected that the continuous capillary condensation and transport of the water through the membrane pores could limit the contact of the acid forming gases with the condensed water thereby resulting in much less dissolution of the gas than would be present at equilibrium.

Henry's Law states that the solubility of a gas in a liquid at a particular temperature is proportional to the pressure of that gas above the liquid. Henry's Law can be written as:

$$
C=k_{H}^{*} p
$$

where $\mathrm{C}$ is the concentration of gas dissolved in the fluid, $k_{H}$ is the Henry's Law constant and $p$ is the partial pressure of the gas. Henry's Law constants for carbon dioxide, nitrogen dioxide, and sulfur 
dioxide in water are all found in standard chemistry reference books and on sites such as Wikipedia.org. Additionally, the dissolution of the acid formed from the dissolution of the gas influences the $\mathrm{pH}$ of the water and the amount of total gas dissolved in the water. For example, when carbon dioxide dissolves in water it forms $\mathrm{H}_{2} \mathrm{CO}_{3} . \mathrm{H}_{2} \mathrm{CO}_{3}$ dissociates to form the ions $\mathrm{H}^{+}$and $\mathrm{HCO}_{3}{ }^{-}$. $\mathrm{HCO}_{3}^{-}$- can dissociate again to form $\mathrm{H}^{+}$and $\mathrm{CO}_{3}^{-2}$. Equilibrium calculations were made for a total pressure of 1 atmosphere and a carbon dioxide concentration of $8 \%$. The calculated equilibrium $\mathrm{pH}$ measurements would be 4.46 at $25^{\circ} \mathrm{C}, 4.52$ at $40^{\circ} \mathrm{C}$ and 4.55 at $50^{\circ} \mathrm{C}$. For $\mathrm{SO}_{2}$ at $316 \mathrm{ppm}$ in equilibrium with water, the calculated $\mathrm{pH}$ of the water would be 2.66 at $25^{\circ} \mathrm{C}, 2.82$ at $40^{\circ} \mathrm{C}$ and 3.02 at $50^{\circ} \mathrm{C}$. These calculations show that the dissolution of sulfur dioxide is much higher than it is for carbon dioxide and is a stronger acid. The equilibrium of nitrogen dioxide and its dissolution in water is extremely complicated and equilibrium chemical equations were hard to find. There were many different stoichiometric relationships found in the chemistry handbooks and the literature. However, the one common feature was the conversion of dissolved $\mathrm{NO}_{2}$ to nitric acid, a very strong acid. Therefore, it is believed that the presence of nitrogen oxide and nitrogen dioxide in flue gas could lower the $\mathrm{pH}$ to very acidic level. Since nitrogen oxides form at high temperatures when nitrogen and oxygen are both present, nitrogen oxides are expected to be formed in any fossil fuel combustion process. The presence of sulfur dioxides would only occur when burning a fossil fuel containing sulfur, such as fuel oil or coal.

Calculations also showed that the presence of a strong acid such as nitric acid would have a large influence on the equilibrium $\mathrm{pH}$ of the water and the ultimate $\mathrm{pH}$ could influence the amount of the dissolved species from a weaker acid such as carbon dioxide that would be present in the water. For example, the equilibrium $\mathrm{pH}$ of water in contact with $316 \mathrm{ppm}$ carbon dioxide would be 5.66 at $25^{\circ} \mathrm{C}$ with a total carbon dioxide concentration (sum of $\mathrm{H}_{2} \mathrm{CO}_{3}, \mathrm{HCO}_{3}{ }^{-1}$, and $\mathrm{CO}_{3}{ }^{-2}$ ) of $1.29 \times 10^{-5}$ moles per liter. If the $\mathrm{pH}$ were adjusted to 3.0 with a strong acid, such as nitric acid, the total carbon dioxide would be $1.07 \times 10^{-5}$ moles per liter or a $17 \%$ reduction.

In summary, a comparison of the actual $\mathrm{pH}$ with the $\mathrm{pH}$ expected from the theoretical calculations will determine how close to equilibrium the gas is with the condensed water. If the measured $\mathrm{pH}$ were to be much higher than the theoretical value, the hypothesis that the capillary condensation and immediate transport through the pores minimizes the contact of the condensed water with the acid forming gas would be supported.

In order to evaluate the effect of $\mathrm{SO}_{2}$ in the flue gas on the membrane transport rate, two tests of $100 \mathrm{hr}$ each were conducted at GTI. Baseline testing was done in the flue gas produced by combustion of natural gas. A second test was conducted in flue gas produced the same way but with $\mathrm{SO}_{2}$ added to get a concentration of approximately $200 \mathrm{ppm} \mathrm{SO}_{2}$. The membrane transport rates of tubes exposed to the undoped and the doped flue gases were measured by M\&PT. Results of the gas analyses conducted at GTI are shown in Table 5 and the measured transport rates are shown in Tables 6 and 7. These results show there is a minimal flux loss for the material exposed to the flue gas produced by combustion of natural gas while the tubes exposed to the $\mathrm{SO}_{2}$ doped flue gas showed a permeance increase of up to $50 \%$. This increase has been attributed to the low $\mathrm{pH}$ of the condensed water and hence pore growth in the $\gamma$-alumina surface layer. During this quarter, tests have been conducted to assess the effect of $\mathrm{pH}$ on the permeance of our TMC membrane elements with a pore size on the order of 80 to $100 \AA$. 
Table 5. Results of analysis of flue gas and cooling water

\begin{tabular}{|c|c|c|c|}
\hline & TMC inlet & TMC outlet & Stack condensate \\
\hline Natural gas flue gas & & & \\
\hline $\mathrm{CO}_{2}(\mathrm{ppm})$ & 102 & 107 & $<30$ \\
\hline $\mathrm{pH}$ of cooling water & 7.40 & 7.36 & 3.70 \\
\hline & & & \\
\hline Natural gas flue gas $+\mathrm{SO}_{2}$ & & & 58 \\
\hline $\mathrm{CO}_{2}(\mathrm{ppm})$ & 183 & 360 & 2300 \\
\hline $\mathrm{SO}_{2}(\mathrm{ppm})$ & 25 & 26 & 3.53 \\
\hline & 7.67 & 7.40 & \\
\hline
\end{tabular}

Table 6 . Batch \#1 fouling test results: Permeance of $100 \AA$ pore M\&PT ceramic membranes before and after fouling tests conducted at the GTI test facility following exposure to combustion gas from a natural gas burner for 100 hours. Permeance is in liters $/ \mathrm{m} 2 / \mathrm{hr} / \mathrm{bar}$. Testing was conducted with distilled water prefiltered to $80 \AA$. Water permeance tests were conducted at about $22^{\circ} \mathrm{C}$ and $10 \mathrm{psig}$ transmembrane pressure.

\begin{tabular}{|c|c|c|c|c|}
\hline \multirow{2}{*}{ Membrane ID } & \multicolumn{3}{|c|}{ Membrane permeance } & \multirow{2}{*}{$\begin{array}{c}\text { Batch reference } \\
\text { ID }\end{array}$} \\
\cline { 2 - 4 } & Before [Imhb] & After [lmhb] & Change [lmhb] & Batch \#1 \\
\hline$\# 10$ & 34.3 & 33.2 & -1.1 & Batch \#1 \\
\hline$\# 11$ & 36.2 & 35.6 & -0.6 & Batch \#1 \\
\hline$\# 12$ & 31.9 & 32.9 & 1.0 & Batch \#1 \\
\hline$\# 13$ & 38.3 & 38.1 & -0.2 & Batch \#1 \\
\hline$\# 14$ & 40.4 & 40.1 & -0.3 & Batch \#1 \\
\hline$\# 15$ & 38.3 & 37.1 & -1.2 & Batch \#1 \\
\hline$\# 16$ & 39.1 & 38.9 & -0.2 & Batch \#1 \\
\hline$\# 17$ & 37.5 & 35.3 & -2.2 & \\
\hline Average & 37.0 & 36.4 & -0.6 & \\
\hline
\end{tabular}

Table 7. Batch \#1 fouling test results: Permeance of $100 \AA ̊$ pore M\&PT ceramic membranes before and after fouling tests conducted at the GTI test facility following exposure for 100 hours to combustion gas

from a natural gas burner spiked with $300 \mathrm{ppm} \mathrm{SO2}$. Permeance is in liters $/ \mathrm{m} 2 / \mathrm{hr} / \mathrm{bar}$. Testing was conducted with distilled water prefiltered to $80 \AA$. Water permeance tests were conducted at about $22^{\circ} \mathrm{C}$ and $10 \mathrm{psig}$ transmembrane pressure.

\begin{tabular}{|c|c|c|c|c|}
\hline \multirow{2}{*}{ Membrane ID } & \multicolumn{3}{|c|}{ Membrane permeance } & \multirow{2}{*}{$\begin{array}{c}\text { Batch reference } \\
\text { ID }\end{array}$} \\
\cline { 2 - 4 } & Before [lmhb] & After [lmhb] & Change [lmhb] & Batch \#2 \\
\hline$\# 18$ & 40.7 & 50.1 & 9.4 & Batch \#2 \\
\hline$\# 19$ & 35.4 & 54.3 & 18.9 & Batch \#2 \\
\hline$\# 20$ & 40.2 & 57.6 & 17.4 & Batch \#2 \\
\hline$\# 21$ & 39.6 & 62.6 & 23.0 & Batch \#2 \\
\hline$\# 22$ & 36.4 & 62.8 & 26.4 & Batch 32 \\
\hline$\# 23$ & 35.4 & 51.8 & 16.4 & Batch \#2 \\
\hline$\# 24$ & 40.7 & 57.7 & 17.0 & Batch 32 \\
\hline$\# 25$ & 32.1 & 51.8 & 19.7 & \\
\hline Average & 37.6 & 56.1 & 18.5 & \\
\hline
\end{tabular}

Tests were conducted at pH's of 2,3, and 4 (sulfuric acid) for up to 1,344 hours, initially at room temperature and then at $85^{\circ} \mathrm{C}$. At each $\mathrm{pH}$, three alumina based membranes and one stainless steel based TMC membrane element was used. At various times, one of the alumina membrane elements was removed and the water permeance was tested. Only visual inspection of the metallic substrate was 
conducted. The results of the water testing are shown in Table 8 .

Table 8. Water permeance of ceramic based TMC membrane elements following exposure to sulfuric acid spiked water at $\mathrm{pH}=2,3$, and 4 for the times shown at room temperature and $85^{\circ} \mathrm{C}$. Test solutions were prepared with distilled water. Water permeance testing was conducted with distilled water prefiltered at $80 \AA$. Water permeance tests were conducted at about $22^{\circ} \mathrm{C}$ and 10 psig transmembrane pressure. No permeance testing was conducted with the ceramic layer modified stainless steel substrates.

Sulfuric acid exposure testing. Effect of $\mathrm{pH}$ and temperature on membrane performance.

\begin{tabular}{|l|l|l|l|l|l|l|l|} 
Exposure Temperature $\left[{ }^{\circ} \mathrm{C}\right]$ & RT & RT & & 85 & & 85 & \\
\hline
\end{tabular}

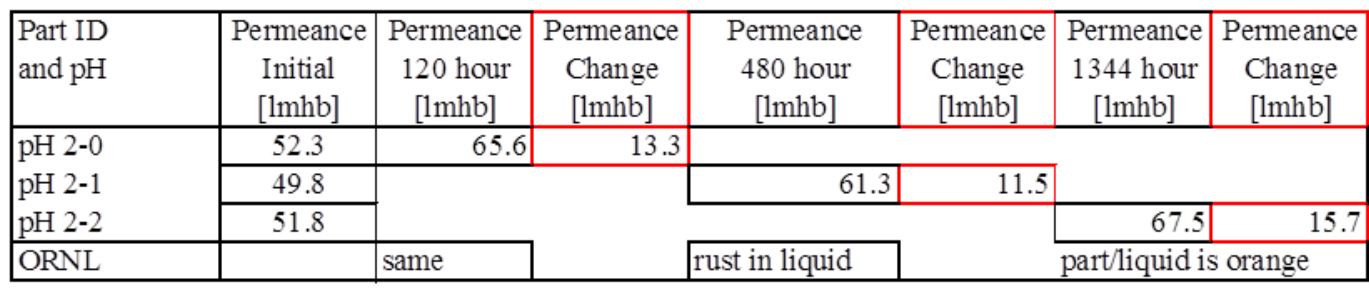

\begin{tabular}{|c|c|c|c|c|c|c|c|}
\hline \multirow{2}{*}{$\begin{array}{l}\text { pH 3-0 } \\
\text { pH 3-1 }\end{array}$} & 54.7 & |51.4 & \multirow[t]{2}{*}{-3.3} & & & \multirow[b]{3}{*}{27.9} & \\
\hline & 44.2 & & & \begin{tabular}{|l|l|}
29.4 \\
\end{tabular} & -14.8 & & \\
\hline $\mathrm{pH} \mathrm{3-2}$ & 54.1 & & & & & & -26.2 \\
\hline ORNL & & same & & most rust in liquic & & same & \\
\hline
\end{tabular}

\begin{tabular}{|c|c|c|c|c|c|c|c|}
\hline \multirow{2}{*}{$\begin{array}{l}\mathrm{pH} 4-0 \\
\mathrm{pH} 4-1\end{array}$} & 49.8 & 50.6 & \multirow[t]{2}{*}{0.8} & & \multirow[b]{2}{*}{-12.8} & & \\
\hline & 48.5 & & & 35.7 & & & \\
\hline $\mathrm{pH} \mathrm{4-2}$ & 46 & & & & & 26 & -20 \\
\hline ORNL & & same & & & & same & \\
\hline
\end{tabular}

As can be seen, at an initial exposure of 120 hours at room temperature, the water permeance increases by about $25 \%$ for the sample stored at a $\mathrm{pH}=2$, but remains essentially unchanged for the samples stored at $\mathrm{pH} 3$ and 4 . Following this testing, the storage temperature was raised to $85^{\circ} \mathrm{C}$ and additional water permeances were obtained at 480 and 1,344 hours. At $\mathrm{pH}=2$, the increase in the clean water permeance was similar to that observed in the initial 120 hours of room temperature exposure. Hence, no additional increase in permeance was observed on further exposure of the membrane to low $\mathrm{pH}$ at $85^{\circ} \mathrm{C}$. Interestingly, the permeance of the sample membranes stored at $\mathrm{pH} 3$ and 4 fell considerably at 480 hours and additionally at 1,344 hours.

The increase in water permeance of the sample stored at $\mathrm{pH}=2$ is likely due to pore growth. This is not an unexpected result given the relatively poor $\mathrm{pH}$ stability of alumina phases other than $\alpha$-alumina (soluble only in concentrated HF). Based upon previous experience, it is known that $\gamma$-alumina, prepared from boehmite fired at ca. $450^{\circ} \mathrm{C}$ (ie: the precursor for the membranes prepared here), displays poor stability outside the $\mathrm{pH}$ range of 4-10. Hence, even though membranes prepared under this project have been fired at $850^{\circ} \mathrm{C}$, yielding primarily the $\delta$-alumina phase and hence improved acid stability over $\gamma$-alumina, at $\mathrm{pH}$ extremes some pore growth was anticipated. Still, the membranes at $\mathrm{pH} \geq 3$ do not show similar pore growth over 1,300 hours of exposure suggesting that the membranes are acid stable in this $\mathrm{pH}$ range $(\geq 3)$.

The decrease in water permeance of the samples stored at the higher pH's ( 3 and 4) is not yet understood. This effect has not been observed in actual TMC testing in the presence of flue gas generated from natural gas combustion as Table 2 demonstrates. Figures 30 and 31 show SEM 
photomicrographs of the Batch \#2 membrane surface following exposure to SO2 laden flue gas and are representative of the typical surface morphology observed under these conditions. (Note that the large flake of material in the upper left photomicrograph in Figure 30 is soot from the combustion flue gas.) Figures 32, 33, and 34 show SEM photomicrographs of the surface of the membranes following the sulfuric acid testing described above and in Table 8 at $\mathrm{pH}$ 's of 2,3, and 4, respectively. In general, there is no evidence of "catastrophic" membrane damage, specifically, cracking, pinholing, delamination, etc., in either the $\mathrm{SO}_{2}$ or sulfuric acid exposed membranes. The stripes, chips, flakes, and other features on the membrane surface visible in these photomicrographs are likely due to scratches and other superficial damage resulting from handling.

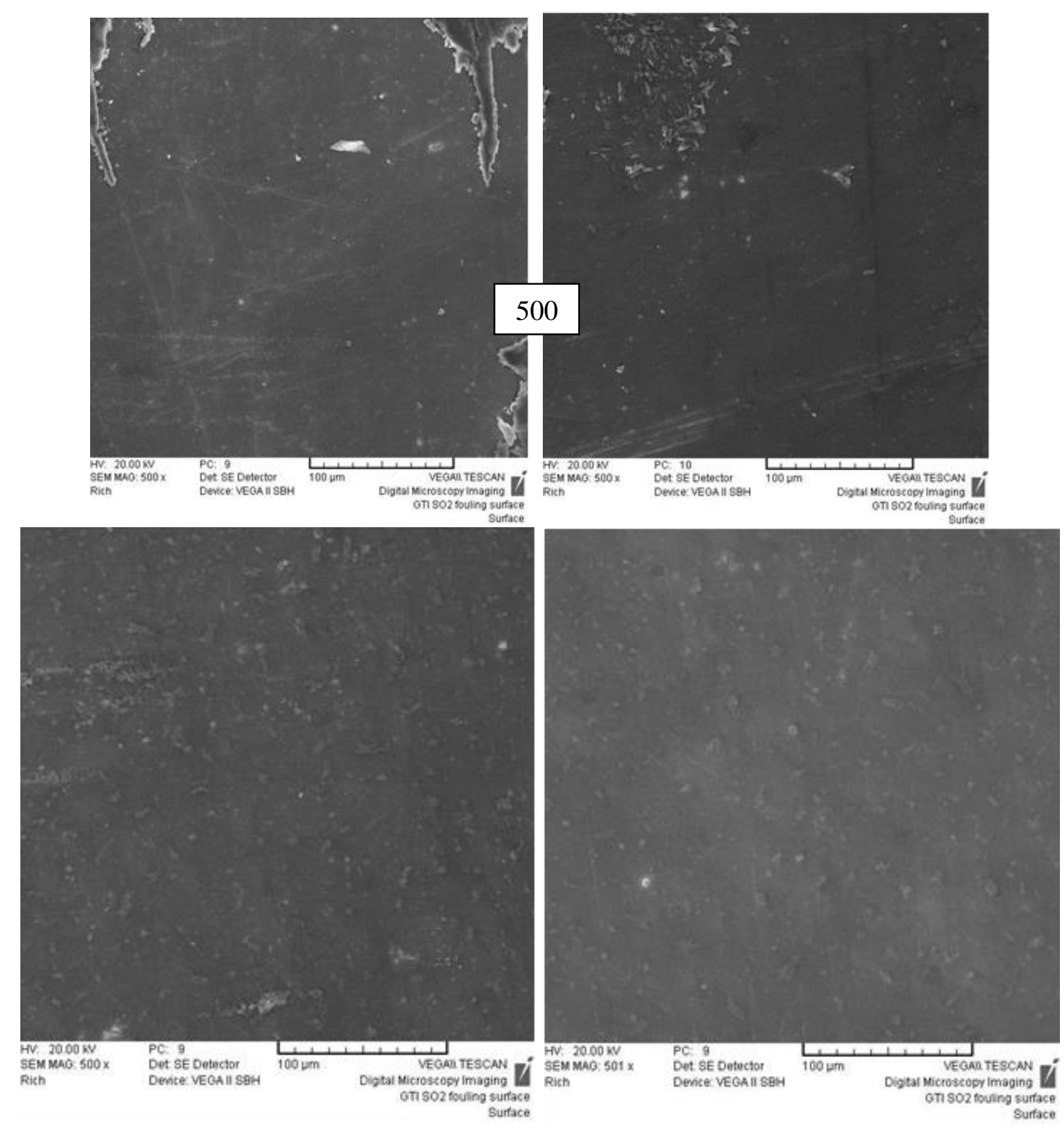

Figure 30. SEM photomicrographs of the surface of the Batch \#2 membranes at 500x following exposure to $\mathrm{SO}_{2}$ laden combustion gas. There is no evidence of membrane cracking or pinholing. The stripes in the part are scratches likely due to handling. 


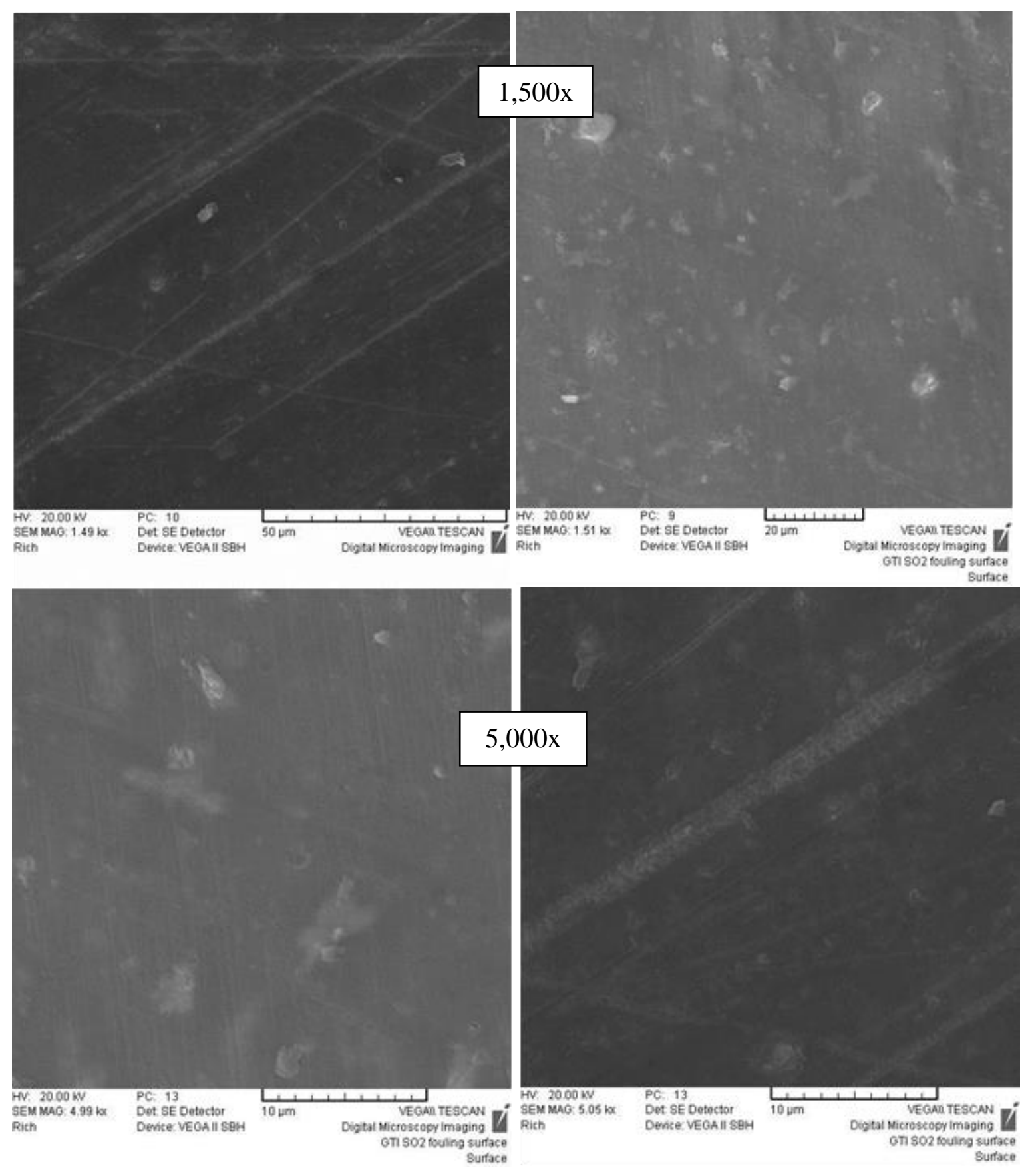

Figure 31. SEM photomicrographs of the surface of the Batch \#2 membranes at 1,500x and $5,000 x$ following exposure to $\mathrm{SO}_{2}$ laden combustion gas. There is no evidence of membrane cracking or pinholing. The stripes in the part are scratches likely due to handling. 

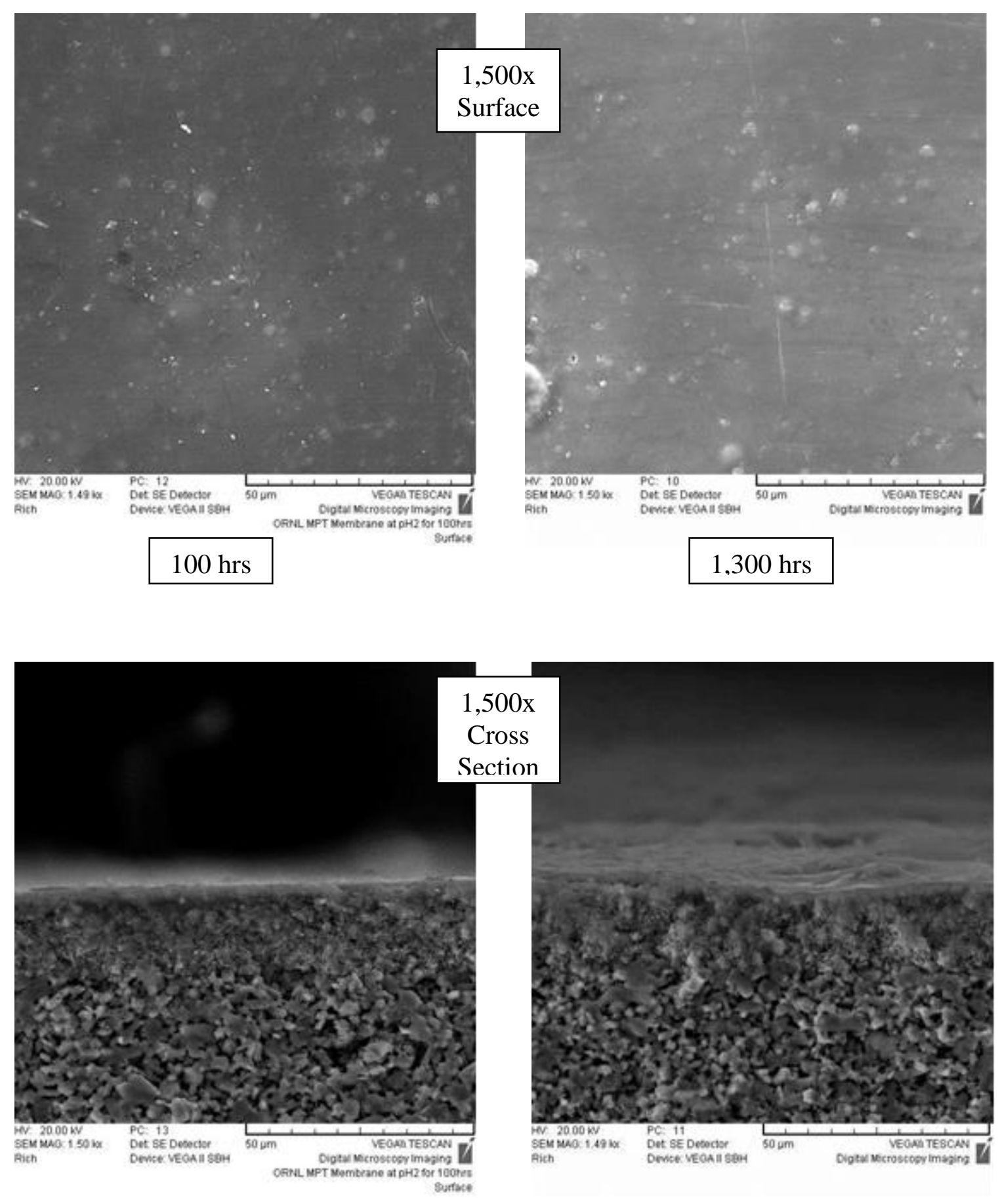

Figure 32. SEM photomicrographs of the surface of the M\&PT TMC membrane elements exposed to $\mathrm{pH} 2$ of sulfuric acid in tests described in Table 8 after 100 and 1,300 hours of exposure at $85^{\circ} \mathrm{C}$. 



Figure 33. SEM photomicrographs of the surface of the M\&PT TMC membrane elements exposed to $\mathrm{pH} \mathrm{3}$ of sulfuric acid in tests described in Table 8 after 100 and 1,300 hours of exposure at $85^{\circ} \mathrm{C}$. 

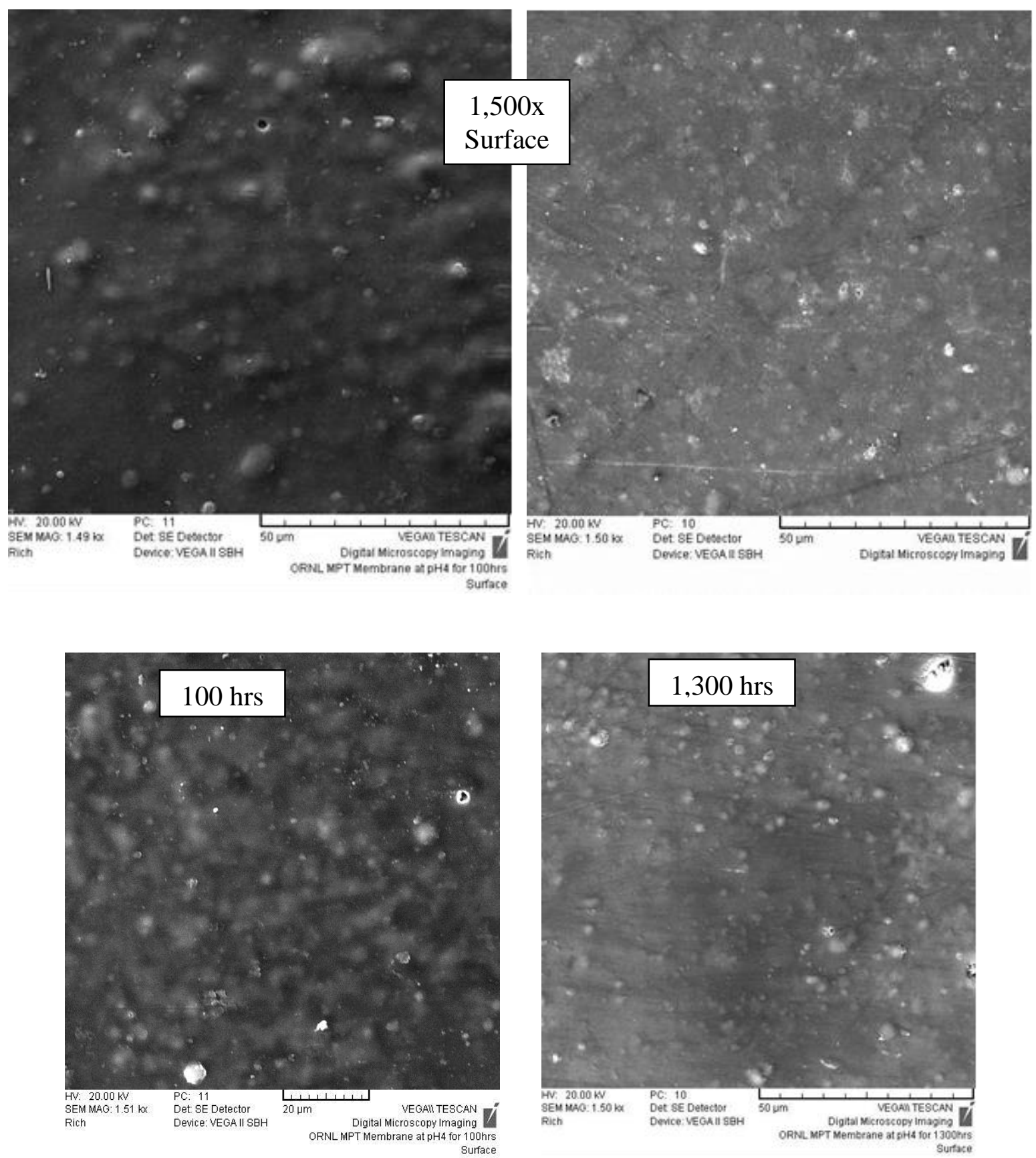

Figure 34. SEM photomicrographs of the surface of the M\&PT TMC membrane elements exposed to $\mathrm{pH} 4$ of sulfuric acid in tests described in Table 8 after 100 and 1,300 hours of exposure at $\mathbf{8 5}^{\circ} \mathrm{C}$.

Figure 35 shows cross sections of the surface of the membranes exposed at $\mathrm{pH} \sim 2$ and $\sim 4$ at 5,000x magnification. Figure 32 shows additional photomicrographs at 1,500x for the $\mathrm{pH} 2$ exposed membrane. It is difficult to judge from the SEM in Figure 35 if there is any difference in morphology of the surface layer. Although the $\mathrm{pH} 2$ SEM appears to display more roughness, this is likely due to contours in the underlying substrate. A lower magnification (1,500x) image of the $\mathrm{pH} 2$ cross section (left hand image in Figure 32) shows much less surface contours (or more planar surface). (Note that the right hand image in this figure is the $1,500 x$ version of the same image in Figure 35). In addition, 
the layer thicknesses appear to be similar and in the range of what are expected for M\&PT standard membranes at ca. 1 to $3 \mu \mathrm{m}$, although the thickness of the $\mathrm{pH} 2$ exposed membranes may be slightly larger. Only a slight expansion of the layer yielding slightly larger pore size and/or porosity would give a large increase in water permeance. Overall, for the sulfuric acid exposed samples, the morphologies displayed in the various cross sections appear to be very similar. Any variations can likely be attributed the underlying support. Further, although not shown in Figures. 30 and 31, cross sections of the $\mathrm{SO}_{2}$ laden flue gas exposed surface layer did not appear to show any irregular features that would suggest membrane damage. In fact, they were generally consistent with the virgin membranes and with the sulfuric acid exposed membranes shown in Figs. 32 and 35. Hence, the increase in permeance of the Batch \#2 ( $\mathrm{SO}_{2}$ exposed membranes) in Table 5 and the sulfuric acid exposed membranes in Table 8 is likely due to pore growth as a result of exposure of the membrane surface to low $\mathrm{pH}(\sim 2)$ at high temperature and not due to dissolution, cracking or other damage to the top membrane layer.

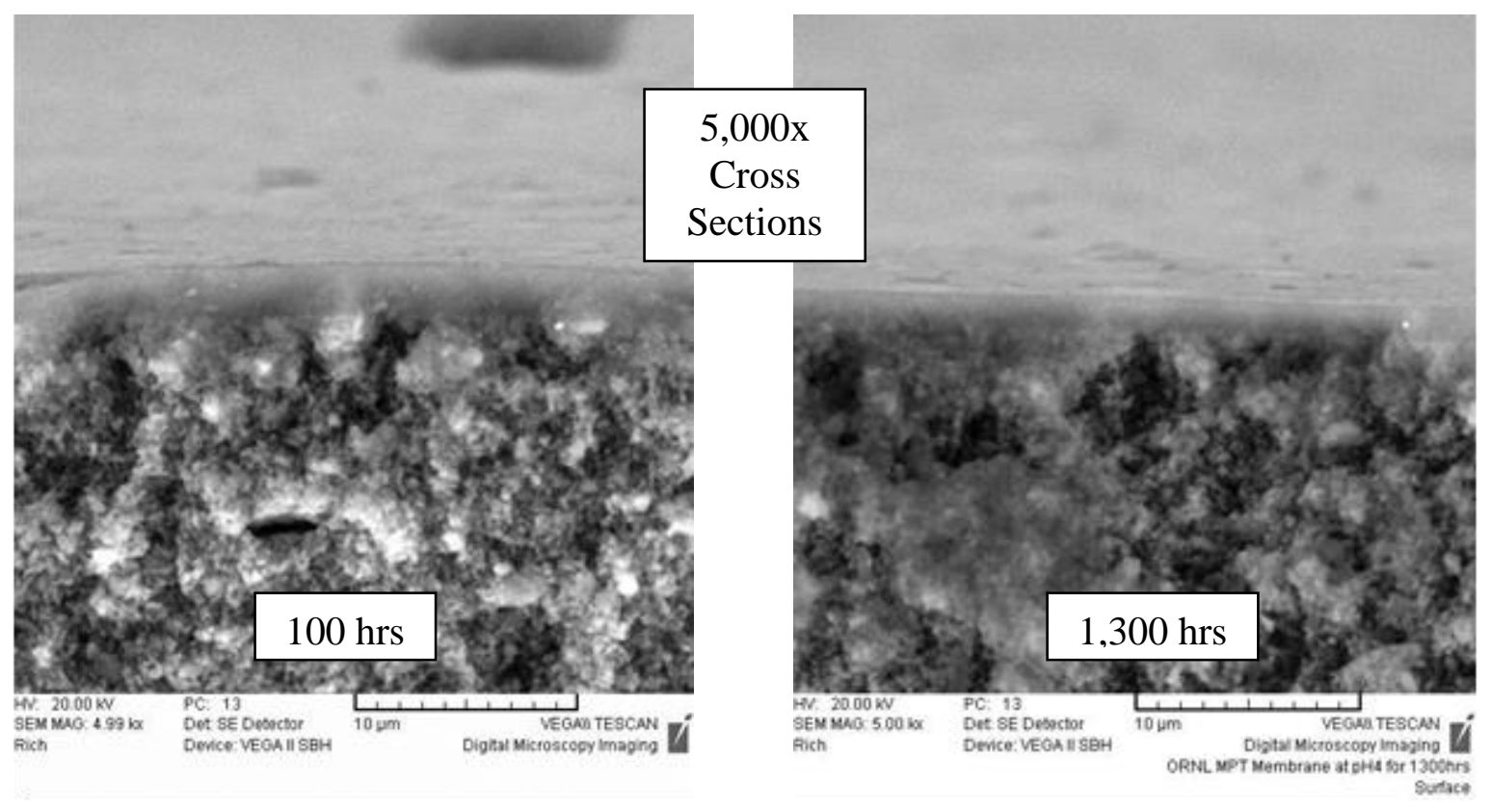

Figure 35. SEM photomicrographs of the cross section of the M\&PT TMC membrane elements exposed to $\mathrm{pH} \sim 2$ and $\sim 4$ of sulfuric acid in tests described in Table 8 after 100 and 1,300 hours of exposure at $85^{\circ} \mathrm{C}$.

It is not clear if the pore growth on exposure to $\mathrm{SO}_{2}$ laden flue gas for about 100 hours represents an end point or if pore size enlargement will continue with additional exposure. However, the initial permeance increase after 100 hours of exposure in the $\mathrm{SO}_{2}$ and sulfuric acid $(\mathrm{pH} 2)$ exposed membranes is very similar. Hence, it is reasonable to expect that no additional pore growth will occur on further $\mathrm{SO}_{2}$ exposure. In general, for the stainless steel based TMC elements, only visual observation of the impact of low $\mathrm{pH}$ on the membranes is available. As can be seen, at $\mathrm{pH}=4$, no apparent change in the water or membrane is observed. However, at the lower $\mathrm{pH}$ 's the water color changes to a slight orange and orange precipitate is noted at the bottom of the storage vials. No attempt was made to test the water permeance of these membranes.

The original single module test rig was modified to enable easier control and testing of different modules. Figure 36 shows the new test rig. The test setup is equipped with temperature, pressure, 
humidity, flow rate measurements and complete gas analysis. Data generated through experiments were collected using a data acquisition system for on-line display and storage. Water quality was sampled for analysis of dissolved components and particulates. The recovered water mass rate was measured from the difference of TMC inlet and outlet water flow rates and/or the flue gas humidity difference. Energy savings were calculated from TMC inlet and outlet water temperature and mass flow rate changes.

The membrane module was installed horizontally with the flue gas going up through the membrane tube banks. By modifying the design so that water flows inside the tubes, it is easier to maintain the water level and to pump out the water. A lab size module with 78 tubes was built (see Fig. 37), and it passed the pressure test, vacuum cycle test and relatively long term hot flue gas real condition tests. Using this equipment, a series of parametric studies was conducted using the individual modules exposed to the flue gas from a 0.25 million Btu/h natural gas combustor.

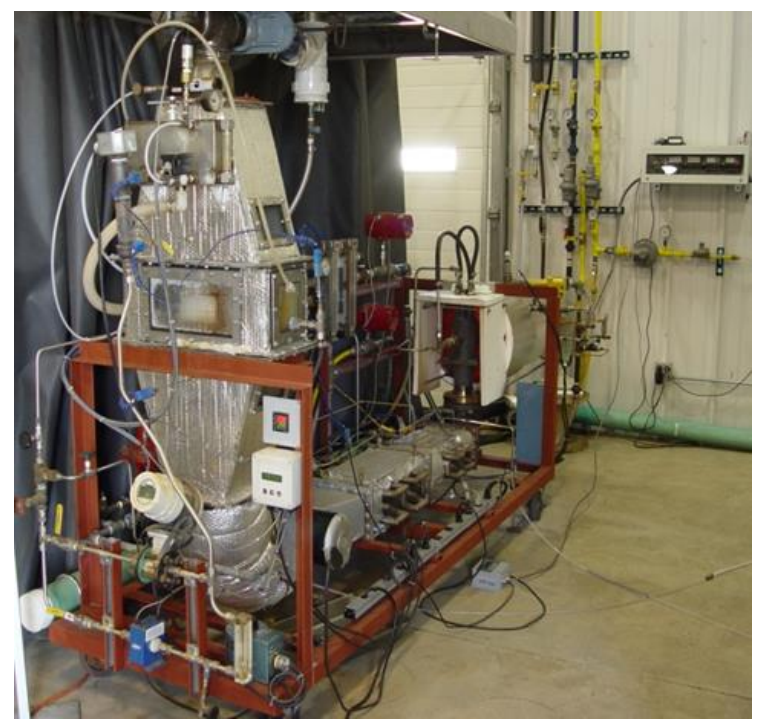

Figure 36. Test rig for testing of single modules



Figure 37. Single membrane module 
1). Flue gas inlet temperature effect

From the data shown in Fig. 38, it was determined that the lower the flue gas inlet temperature, the higher the water vapor transport rate.

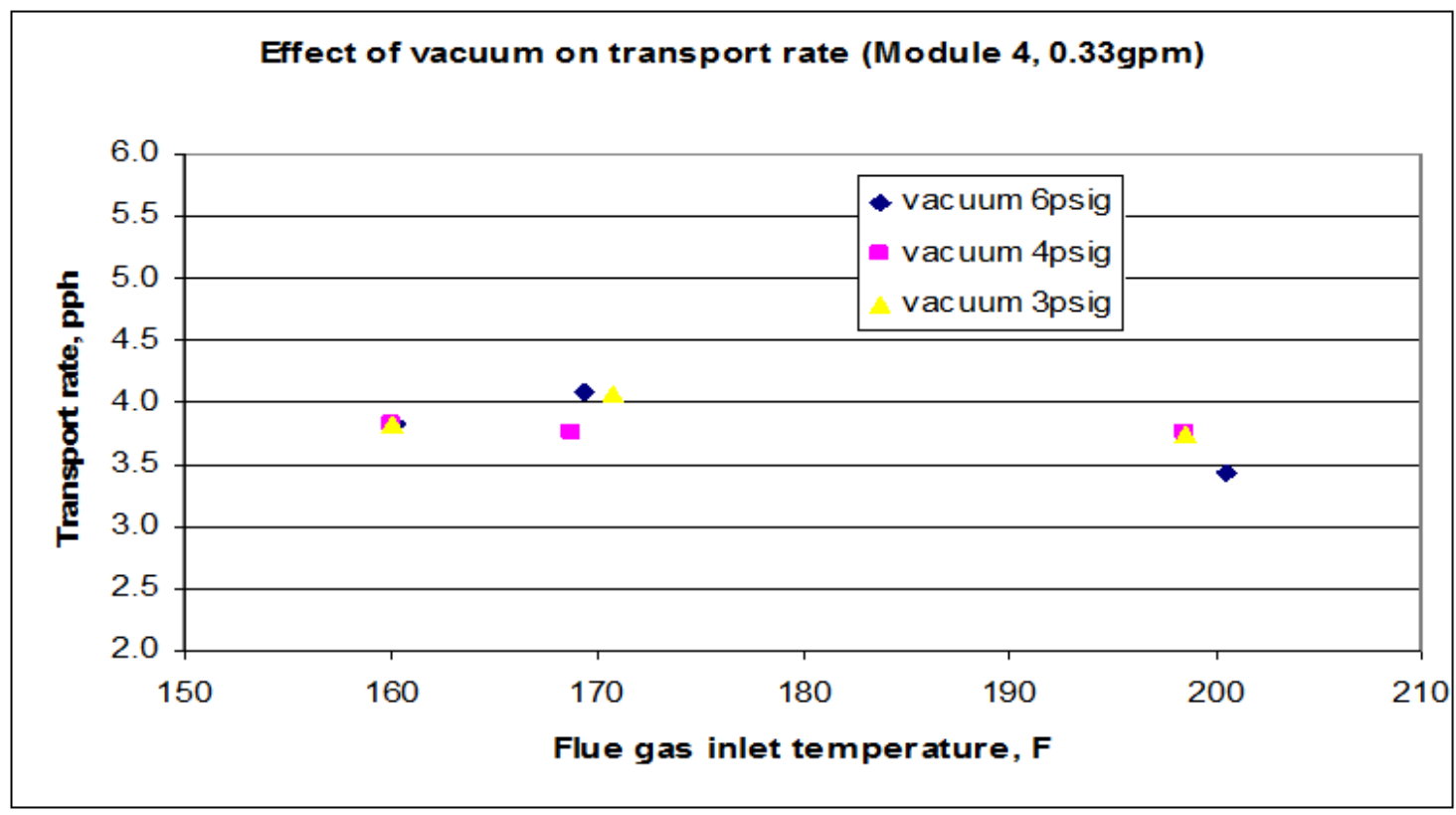

Figure 38. Flue gas inlet temperature effect on TMC water transfer rate.

2). Water inlet temperature effect

Figure 39 shows that the lower the cooling water inlet temperature, the higher the water transport rate.

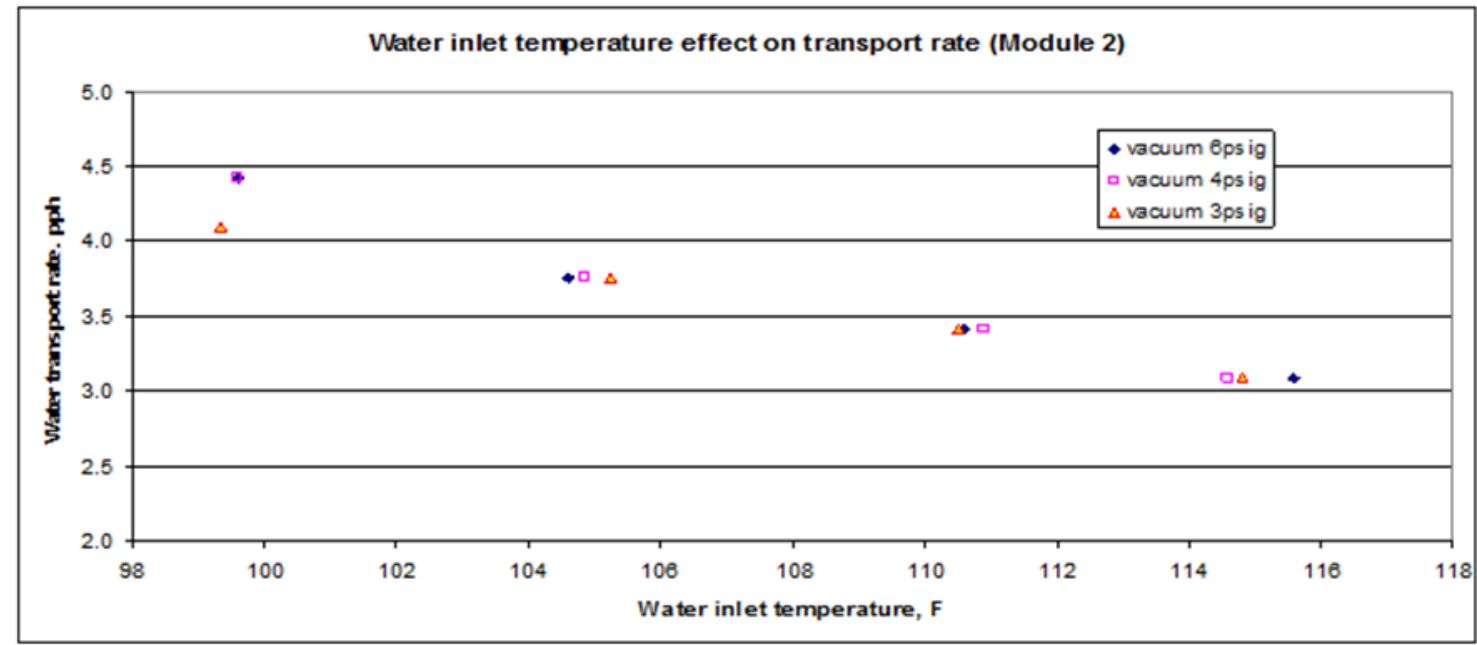

Figure 39. Water inlet temperature effect on TMC water transfer rate

3). Water flow rate effect

The data shown in Fig. 40 indicate that the higher the cooling water flow rate, the higher the water transport rate. 


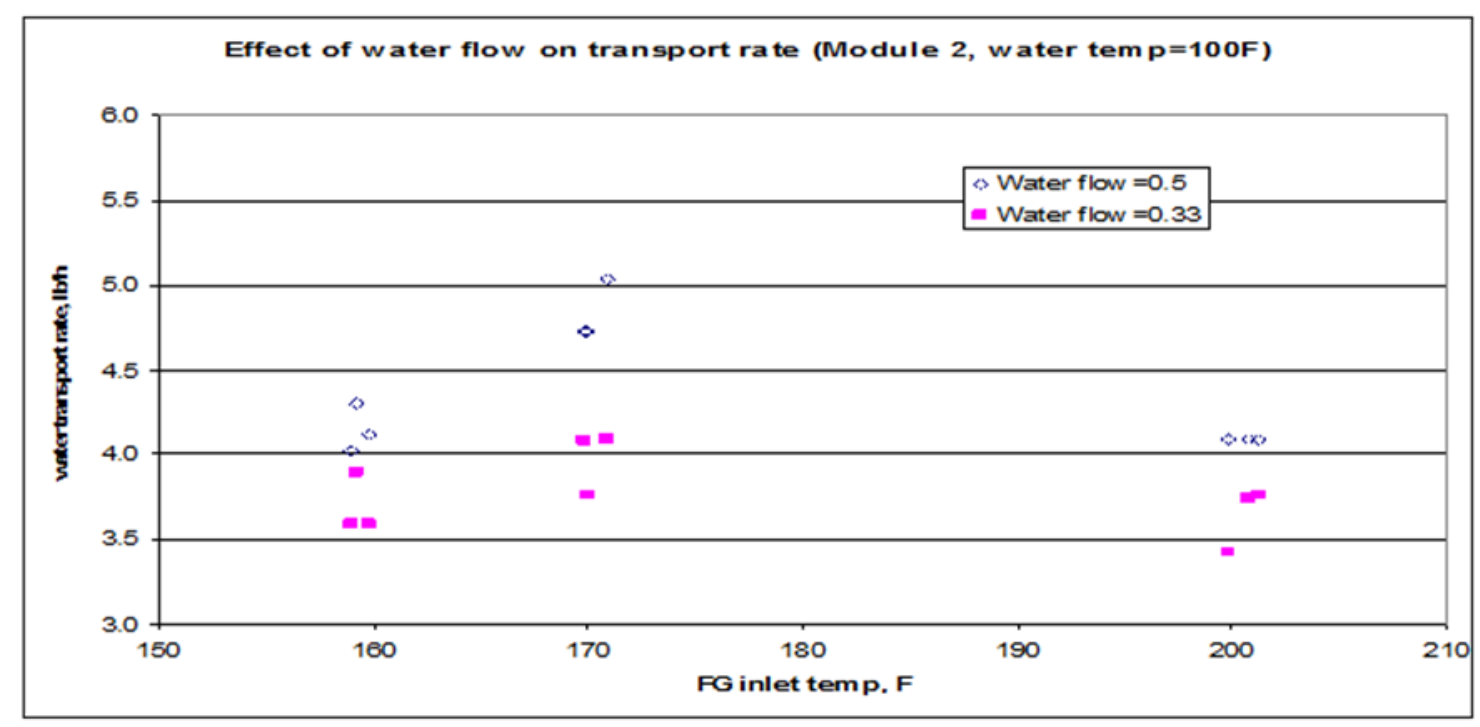

Figure 40. Water inlet flow rate effect on TMC water transfer rate.

4). Vacuum effect

No obvious change for water transport was found for most cases when the vacuum was increased from 3 psi to 6 psi for most (Fig. 41).

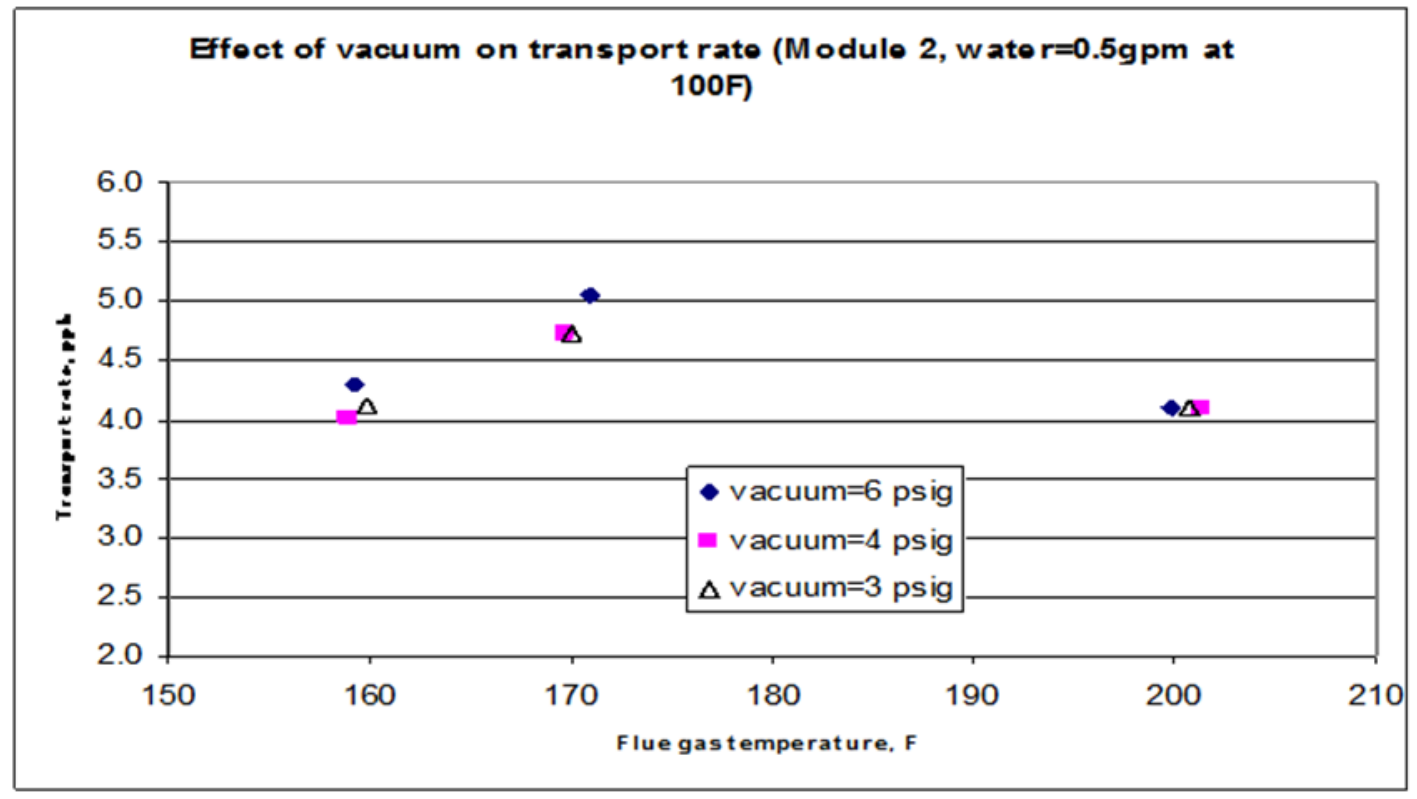

Figure 41. Water vacuum effect on TMC water transfer rate.

5). ID and OD membrane coating effect

As shown in Figure 42, at a high cooling water flow rate $(0.5 \mathrm{gpm})$ and a high flue inlet temperature condition, OD membrane shows advantage over ID membrane on transport rate. 

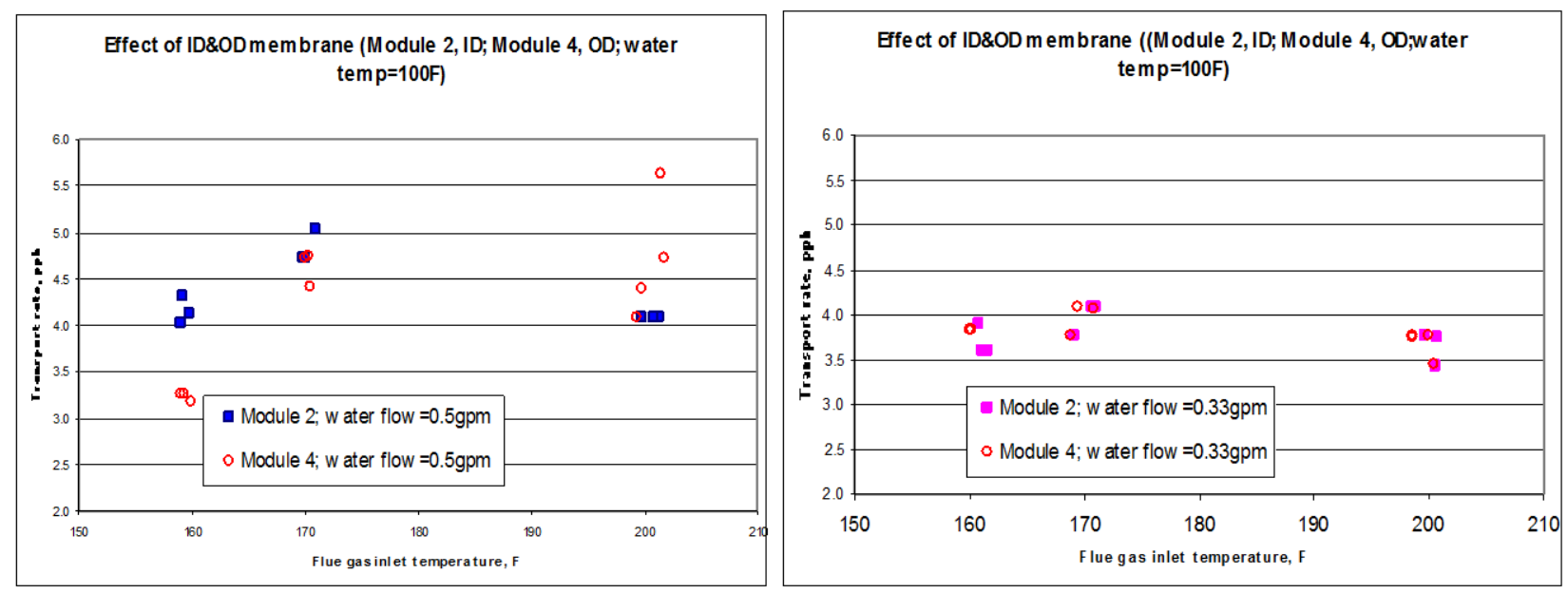

Figure 42. ID and OD membrane coating effect on TMC water transfer rate.

6). Different membrane pore size effect

Three membrane modules with different pore sizes $(8.5 \mathrm{~nm}, 15 \mathrm{~nm}$, and $25 \mathrm{~nm})$ are constructed and tested, and results are shown in Fig. 43. Average cooling water temperature is a good representative for cooling water temperature and flow rate combined effect, so the water vapor transport rate was plotted against it. For the same average cooling water temperature, the water vapor transport rates are the same for different pore size membrane modules. For smaller pore size, when cooling water temperature reaches certain low value, condensed water droplets start to form on the membrane surface and drop back to the flue stream; this point is identified as the limit of this pore size. For the $25 \mathrm{~nm}$ membrane module, the critical limit could not be reached for the limitation of the test setup, so larger pore size membranes can transport much more water than the smaller pore membranes at low water average temperature.



Figure 43. Different membrane pore sizes effect on TMC water transfer rate.

7). Flue gas moisture content effect

Injection of water into the natural gas flue gas stream increased flue gas dew points from $134^{\circ} \mathrm{F}$ to $150^{\circ} \mathrm{F}$, which corresponds to a moisture increase from $16.8 \%$ to $25.3 \%$. Figures 44 and 45 show the 
results and indicate that both the moisture transport rate and heat recovery are more than doubled, which proves the TMC can be more effective when being used for high moisture waste heat exhausts.

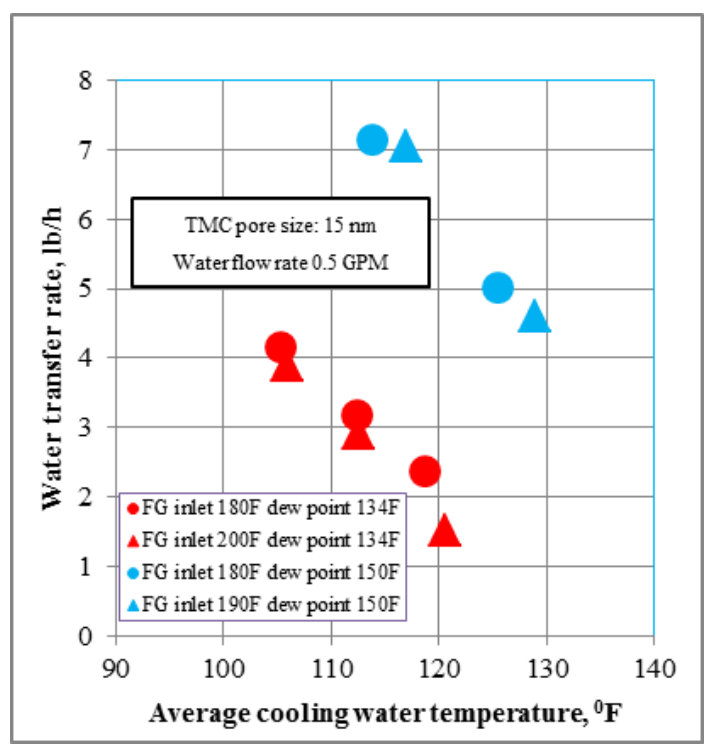

Figure 44. Flue gas high moisture content effect on TMC water transfer rate.

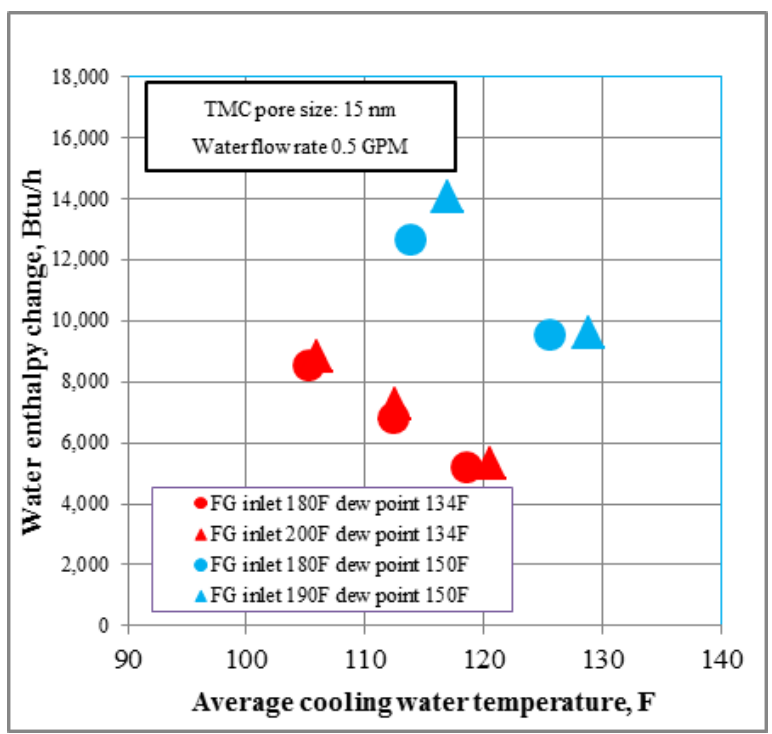

Figure 45. Flue gas high moisture content effect on TMC heat recovery rate.

8). Membrane fouling test

Two tests to assess the potential fouling effects of $\mathrm{SO}_{2}$ were conducted at GTI, each for 100 hours with hot flue gases. One was baseline testing with natural gas flue gas, and one involved adding $\mathrm{SO}_{2}$ into the natural gas flue to get approximately $200 \mathrm{pm} \mathrm{SO}_{2}$ in the flue. Results of these tests, described earlier in this report, are shown in Tables 6 and 7 and indicate the tubes exposed to the $\mathrm{SO}_{2}$ doped gas showed permeance increasing by up to $50 \%$.

9). Metallic membrane module vs. single TMC module

A TMC module for laboratory testing was assembled using 44 metallic substrate membrane tubes, and 
a counterpart module built with ceramic substrate membrane tubes was used for comparison. Both membrane modules water vapor transport and heat transfer performance were compared side by side. Table 9 lists the main parameters of the two modules with GTI's regular small diameter ceramic membrane tube module as reference. The following are some observations and testing results (for details see Fig. 46 and 47).

For a low cooling water flow rate of $0.33 \mathrm{GPM}$, transport rates for both modules are similar; and for high flow rate $1.0 \mathrm{GPM}$, the transport rate of the ceramic-tube module is $20-40 \%$ higher than the metallic tubes. The heat recovery results are similar. For the higher cooling water flow rate conditions, the metallic tubes had a water film on the surface and this was expected to increase the heat transfer resistance, compared with only droplets on the ceramic tubes. This would explain poorer performance of the metallic tubes compared to that of the ceramic tubes at high cooling water condition.

Table 9: Key parameters of the two TMC modules and the small OD module as reference

\begin{tabular}{|l|r|r|r|}
\hline & \multicolumn{1}{|c|}{ Metallic } & \multicolumn{1}{c|}{ Ceramic (large OD) } & \multicolumn{1}{c|}{ Ceramic (small OD) } \\
\hline Tube number & 44 & 44 & 78 \\
\hline ID (inch) & 0.410 & 0.335 & 0.138 \\
\hline OD (inch) & 0.456 & 0.469 & 0.217 \\
\hline Wall thickness (inch) & 0.023 & 0.067 & 0.039 \\
\hline Surface $\left(\right.$ inch $^{2}$ ) & 1071.56 & 1102.11 & 0.53 \\
\hline Surface $\left(\mathrm{m}^{2}\right)$ & 0.69 & 0.71 & 45 to 60 \\
\hline $\begin{array}{l}\text { Water permeate rate } \\
\text { (liter/m2/hr/bar): }\end{array}$ & 30 to 45 & 45 to 60 & 25 to 30 \\
\hline Air permeate rate $\left[\mathrm{m}^{3} / \mathrm{m}^{2} / \mathrm{hr} / \mathrm{bar}\right]:$ & 80 & 25 to 30 & 30 \\
\hline $\begin{array}{l}\text { Solid material thermal conductivity } \\
\text { (W/mK) }\end{array}$ & 26 & 30 & $20 \%$ \\
\hline Porosity & $35 \%$ & $20 \%$ & 24.12 \\
\hline $\begin{array}{l}\text { Effective thermal conductivity } \\
\text { (W/mK) }\end{array}$ & 17.11 & 24.12 & $4.1 \mathrm{e}-5$ \\
\hline Thermal resistance $(\mathrm{K} / \mathrm{W})$ & $3.4 \mathrm{e}-5$ & $7.1 \mathrm{e}-5$ & \\
\hline
\end{tabular}

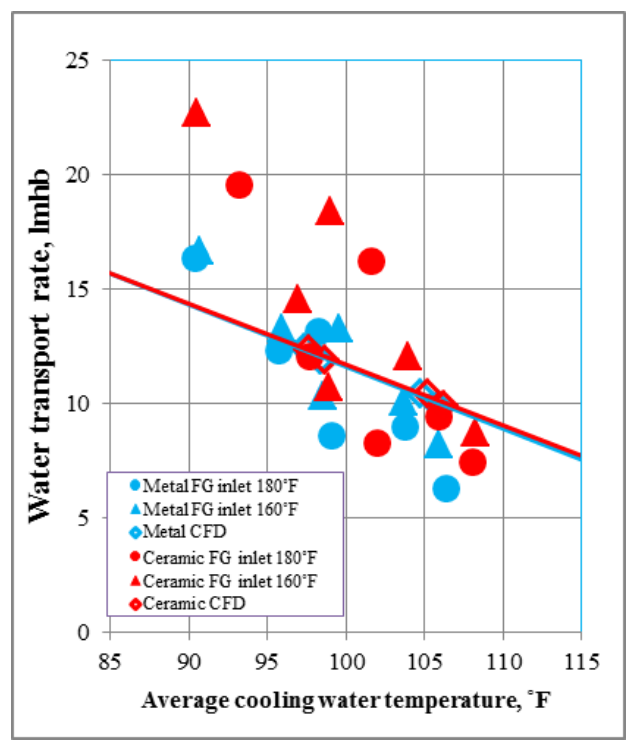

Figure 46. Water transfer rate for metallic and ceramic substrate membrane tubes 


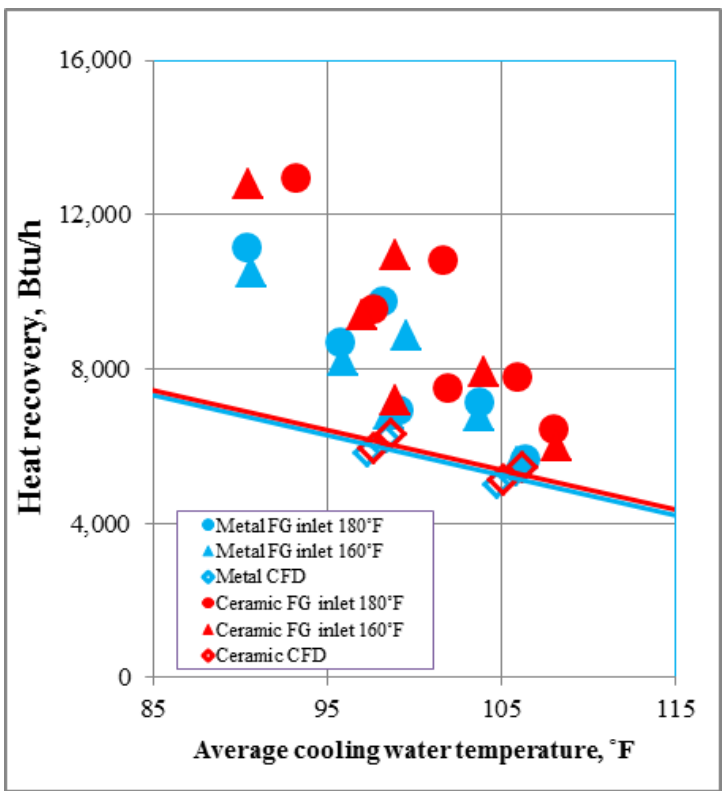

Figure 47. Heat recovery rate for metallic andceramic substrate membrane tubes

Summary of Task 7: The prototype TMC water transport and heat recovery performance at different flue gas parameters (temperature, inlet moisture content concentrations), and different water parameters (temperature, flow rates) was evaluated. The membrane structure effect on TMC performance, such as membrane pore sizes, was also studied. The parametric study based on singlemodule test showed the TMC worked well in a wide parameters range. The results helped to develop and optimize the TMC module design and multi-module arrangement for Task 9.

\subsection{TASK 8 - PERFORM CFD SIMULATION OF TMC FOR WATER VAPOR AND HEAT RECOVERY PROCESS}

The objective of this task was to develop a model to describe the overall performance of the TMC along with models to describe the performance of the membrane, condensation of water in the membrane and heat transfer.

For computational fluid dynamics (CFD) simulation of the overall TMC performance, the commercial program FLUENT was used to simulate the flue gas flow with water vapor condensing and transporting through the membrane tubes, and water flow inside the membrane tubes to receive the heat and water itself. Membrane surface water vapor condensation /evaporation and transportation models have been developed and validated by using lab TMC testing results. Figure 48 shows the schematic of simulation models. The current simulation models divide the simulation domain of the TMC module into four different zones:

1) Flue gas zone

2) Cooling water zone, inside the membrane tubes

3) Porous medium zone of the membrane

4) Thin water film zone, attached to the outer surface of the membrane 


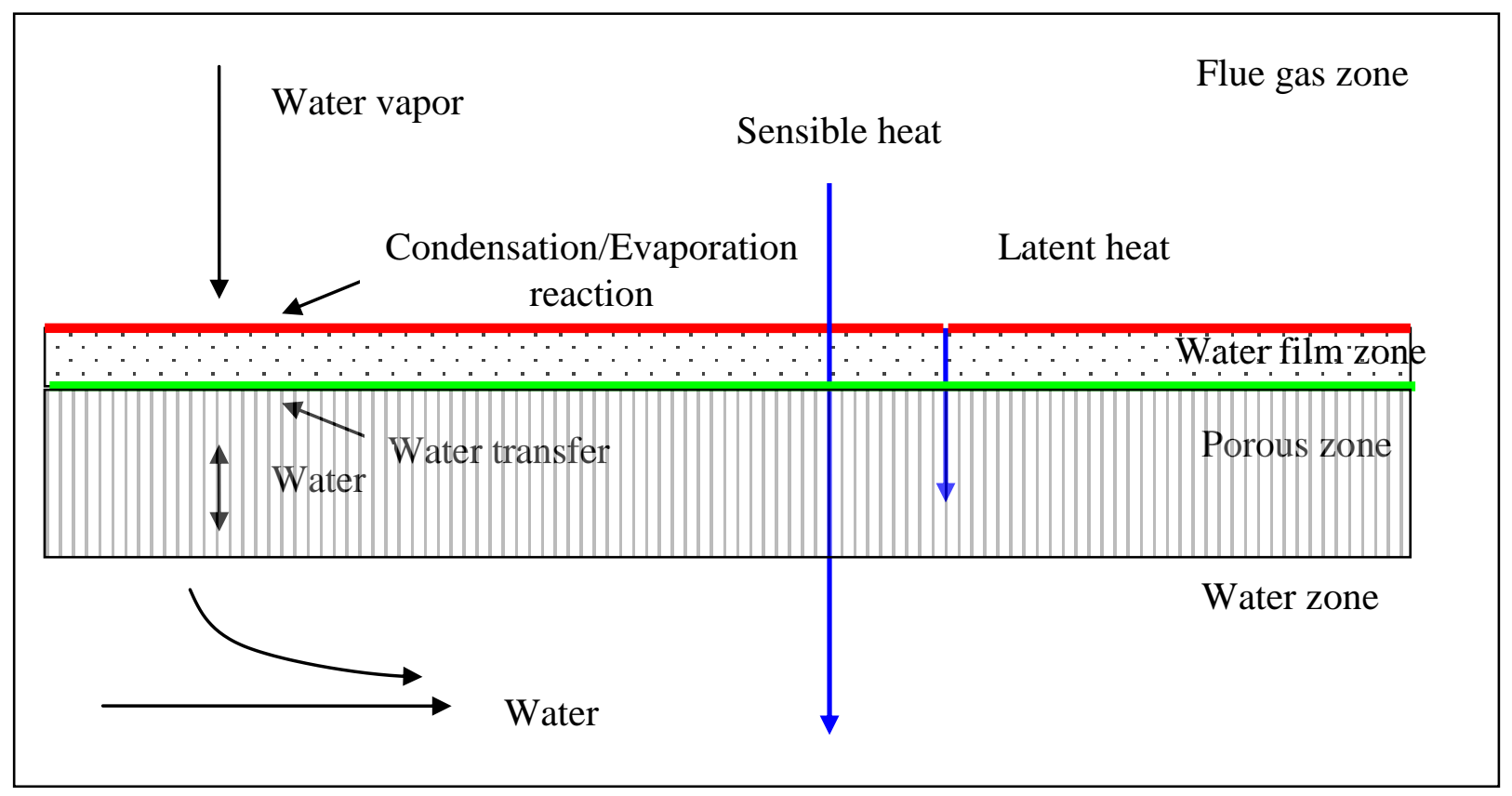

Figure 48. Schematic of the CFD condensation/evaporation and transportation models.

Condensation and evaporation are surface reactions on the outer surface of thin water film, the red line in Fig. 48. To transfer the condensed liquid water into the cooling water steam, another surface reaction, called "transfer reaction", is put on the internal surface of the water film, the green line. The transfer reaction will bring the corresponding amount of liquid water into the porous medium zone, and then cooling water zone. Similarly, the transfer reaction also can bring the required liquid water into the water film, and then the outer surface, to support the evaporation reaction. The detailed reaction mechanisms are:

i) At the outer surface of the water film, (red line on the Fig.48)

$$
\mathrm{H}_{2} \mathrm{O}(\mathrm{gas}) \stackrel{\text { Condensation/Evapration }}{\longleftrightarrow} \mathrm{H}_{2} \mathrm{O}(\text { virtual_solid })+\text { heat } .
$$

The condensation reaction releases heat and evaporation absorbs heat.

ii) At the internal surface of the water film, (green line on the Fig. 48)

$$
\left.\mathrm{H}_{2} \mathrm{O} \text { (virtual_solid }\right) \stackrel{\text { Transfer }}{\longleftrightarrow} \mathrm{H}_{2} \mathrm{O} \text { (liquid) } \text {. }
$$

The condensation rate is based on the empirical formula of the film condensation on cylinders body [26],

$$
\dot{m}^{\prime}=C\left[\frac{R^{3} k_{l}^{3}\left(T_{s a t}-T_{w}\right)^{3}\left(\rho_{l}-\rho_{v}\right) g}{h_{l v}^{3} v_{l}}\right]^{1 / 4},
$$

where, $R$ pipe radius

$k_{l}$ thermal conductivity of liquid

$T_{\text {sat }}$ saturation temperature 
$T_{w}$ wall temperature

$\rho_{l}$ liquid density

$\rho_{v}$ vapor density

$h_{l v}$ latent heat of vaporization per unit mass

$v_{l}$ liquid kinematic viscosity.

Here, $T_{w}$ is outer surface temperature of the water film zone. When the thickness of the water film is small enough, the temperature is uniform through the water film, and wall temperature is equal to the outer surface temperature of the water film.

The evaporation rate is similar with the condensation rate.

$$
\dot{m}^{\prime}=0.2 * C\left[\frac{R^{3} k_{l}^{3}\left(T_{w}-T_{s a t}\right)^{3}\left(\rho_{l}-\rho_{v}\right) g}{h_{l v}^{3} v_{l}}\right]^{1 / 4},
$$

which is $1 / 5$ of the condensation rate for the same $\left|T_{w}-T_{s a t}\right|$

The simulation results for lab TMC module agree with the experimental results well, as listed at Table 10. It shows the CFD tool can predict water vapor condensation on the membrane outer surface and transportation through the membrane tube wall for TMC module. CFD simulation results also provide a viable tool to study the membrane working mechanism and optimize the TMC operating parameters.

Table 10. Comparison of the CFD and the test data

\begin{tabular}{|c|c|c|}
\hline File Name & Test & CFD \\
\hline Gas Flow rate (SCFH) & 201.6 & \\
\hline $\mathrm{O}_{2}$ at stack $(\%)$ & 3.84 & 2551 \\
\hline Flue gas flow rate(SCFH) & 2551 & 2.052 \\
\hline Flue gas inlet velocity (ft/sec) & & 0.34 \\
\hline Water flow rate $(\mathrm{gpm})$ & 0.34 & 0.247 \\
\hline Water inlet velocity $(\mathrm{ft} / \mathrm{sec})$ & & 200 \\
\hline Flue Inlet Temp $\left({ }^{\circ} \mathrm{F}\right)$ & 200 & 139.8 \\
\hline Flue Outlet Temp $\left({ }^{\circ} \mathrm{F}\right)$ & 137.6 & 100.2 \\
\hline Water Inlet Temp $\left({ }^{\circ} \mathrm{F}\right)$ & 100.2 & 138.3 \\
\hline Water Outlet Temp $\left({ }^{\circ} \mathrm{F}\right)$ & 129.3 & $8 \times 10^{-3}$ \\
\hline Condensation Constant $\mathrm{C} 1$ & & $1.6 \times 10^{-3}$ \\
\hline Evaporation Constant $\mathrm{C} 2$ & & 11.4 \\
\hline Effective Conductivity $(\mathrm{W} / \mathrm{m} . \mathrm{K})$ & & $11.4 \%$ \\
\hline Inlet Mass Fraction of $\mathrm{H}_{2} \mathrm{O}$ & $11.4 \%$ & $8.86 \%$ \\
\hline Outlet Mass Fraction of $\mathrm{H}_{2} \mathrm{O}$ & $8.6 \%$ & $22.3 \%$ \\
\hline Transportation Rate & $24.4 \%$ & 134.5 \\
\hline Flue inlet dew point $\left({ }^{\circ} \mathrm{F}\right)$ & 134.75 & $21.1 \%$ \\
\hline Flue inlet relative humidity & $21.93 \%$ & 125.9 \\
\hline Flue outlet dew point $\left({ }^{\circ} \mathrm{F}\right)$ & 124.8 & $69.2 \%$ \\
\hline Flue outlet relative humidity & $71.1 \%$ & \\
\hline
\end{tabular}

Water transportation models have been used to simulate the full scale TMC unit. The results are consistent with the field testing results (Fig. 49). FLUENT is also used to provide guidance for TMC 
performance optimization, and help improving future TMC design. From Fig. 49, the lower two rows of modules are not working efficiently for the cooling water temperature coming in is already high. So a CFD simulation was done for a 3-pass TMC design (Fig. 50), which only has minimum performance drops but save $25 \%$ membrane area as well as $25 \%$ less pressure drop, compared with the previous 4 pass design.

The objective of the modeling work at the length scale of a single tube and at the microstructural length scale is to gain a better understanding of various phenomena involved in the membrane separation process, so that the performance of the membrane can be improved. For instance, one of the aspects from the experimental work that is not well understood is the difference in water transport rates in pure water vs. in the presence of flue gas. The pure water transport rate increases almost linearly with the pressure difference across the membrane, whereas the water transport rate under capillary condensation from flue gas does not increase beyond a certain pressure difference.

Simulations of heat transfer in a single tube were used to examine the role played by the effective thermal conductivity of the substrate material. A model using the finite element program ABAQUS was generated using 2-D axi-symmetric elements, considering half the cross-section of the tube, as shown in Fig. 51. Effect of water flow inside the tube was considered through the use of forced convection elements. Heat input from flue gas on the outside surface of the tube was assumed to have contributions from condensation and convection. Heat flux due to convection was modeled using an enhanced value of $20 \mathrm{~W} / \mathrm{m}^{2} \mathrm{~K}$ for the heat transfer coefficient, to reflect the contact with flue gas containing water vapor. Heat input due to condensation was computed based on Nusselt's theory, which provides a correlation for the heat flux based on the temperature difference at the tube surface: 
Case 1: 200HP with 9.3gpm makeup water

Test results:

\begin{tabular}{|c|c|c|c|c|c|c|c|c|c|}
\hline Flue FR & Flue $\mathrm{T}_{\text {in }}$ & Flue $_{\text {out }}$ & Flue $_{\text {in }}$ & Flue $_{\text {out }}$ & $\mathrm{RH}_{\text {out }}$ & Water FR & Water $\mathrm{T}_{\text {in }}$ & Water $\mathrm{T}_{\text {out }}$ & Pressure \\
\hline $\mathrm{SCFH}$ & ${ }^{\circ} \mathrm{F}$ & ${ }^{\circ} \mathrm{F}$ & & & & $\mathrm{gpm}$ & ${ }^{\circ} \mathrm{F}$ & ${ }^{\circ} \mathrm{F}$ & "WC \\
\hline 95902.7 & 155 & 118 & $11.3 \%$ & $6.8 \%$ & $97 \%$ & 9.32 & 56 & 135 & 3.7 \\
\hline
\end{tabular}

CFD results:

CFD files: (k=8e-3) TMCApr23_1_C; TMCApr23_2_C; TMCApr23_3_C; TMCApr23_4_C.

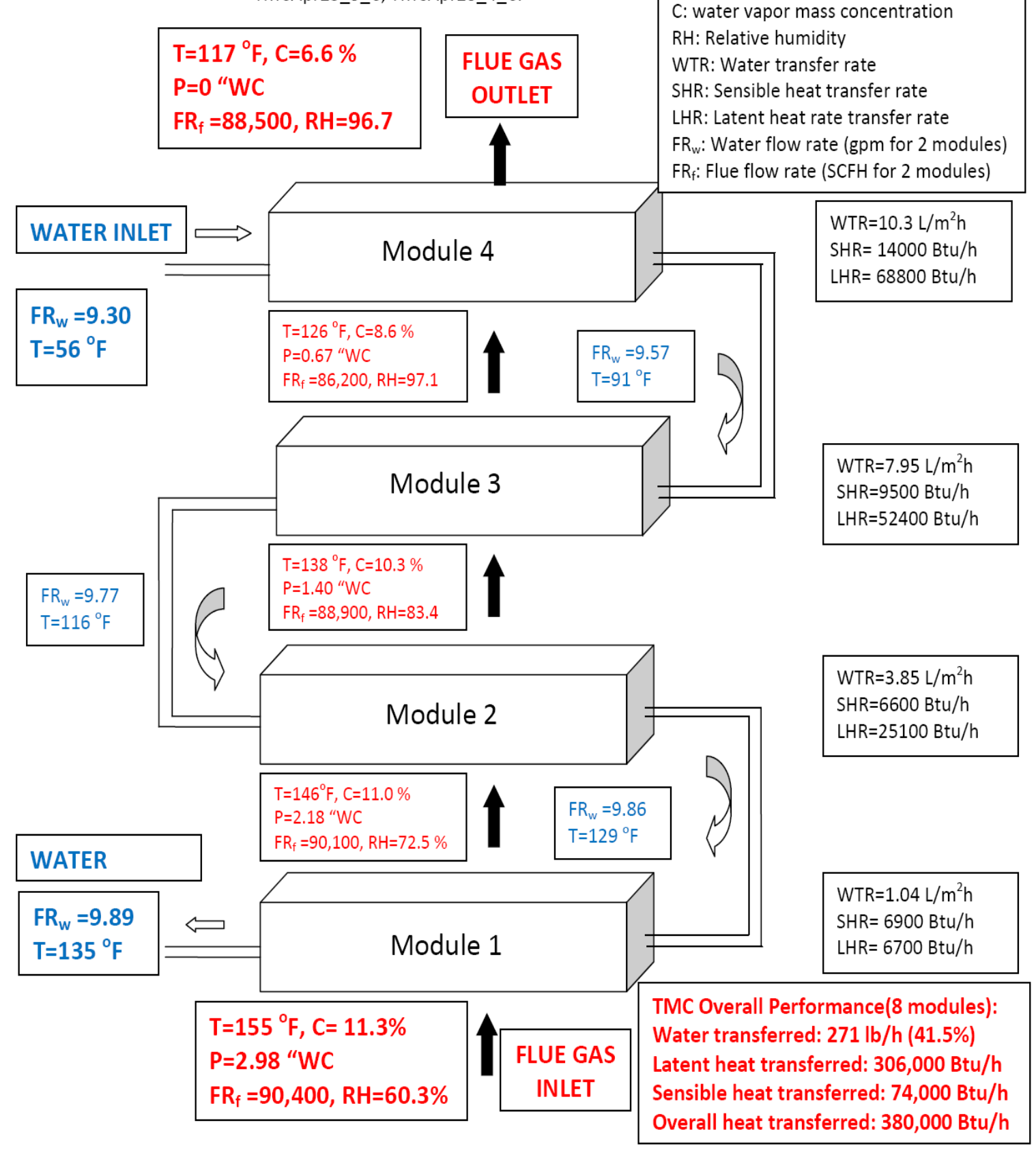

Figure 49. CFD simulation compared with test results for the 200 HP TMC. 
Case 4: New 3-pass TMC design

(Same inlet conditions as Case 1)

\begin{tabular}{|c|c|c|c|c|}
\hline Flue FR & Flue $\mathrm{T}_{\text {in }}$ & Flue $_{\text {in }}$ & Water FR & Water $\mathrm{T}_{\text {in }}$ \\
\hline SCFH & ${ }^{\circ} \mathrm{F}$ & & $\mathrm{gpm}$ & ${ }^{\circ} \mathrm{F}$ \\
\hline 95902.7 & 155 & $11.3 \%$ & 9.32 & 56 \\
\hline
\end{tabular}

CFD results:

CFD files: TMCApr23_1_TC; TMCApr23_2_TC; TMCApr23_3_TC.

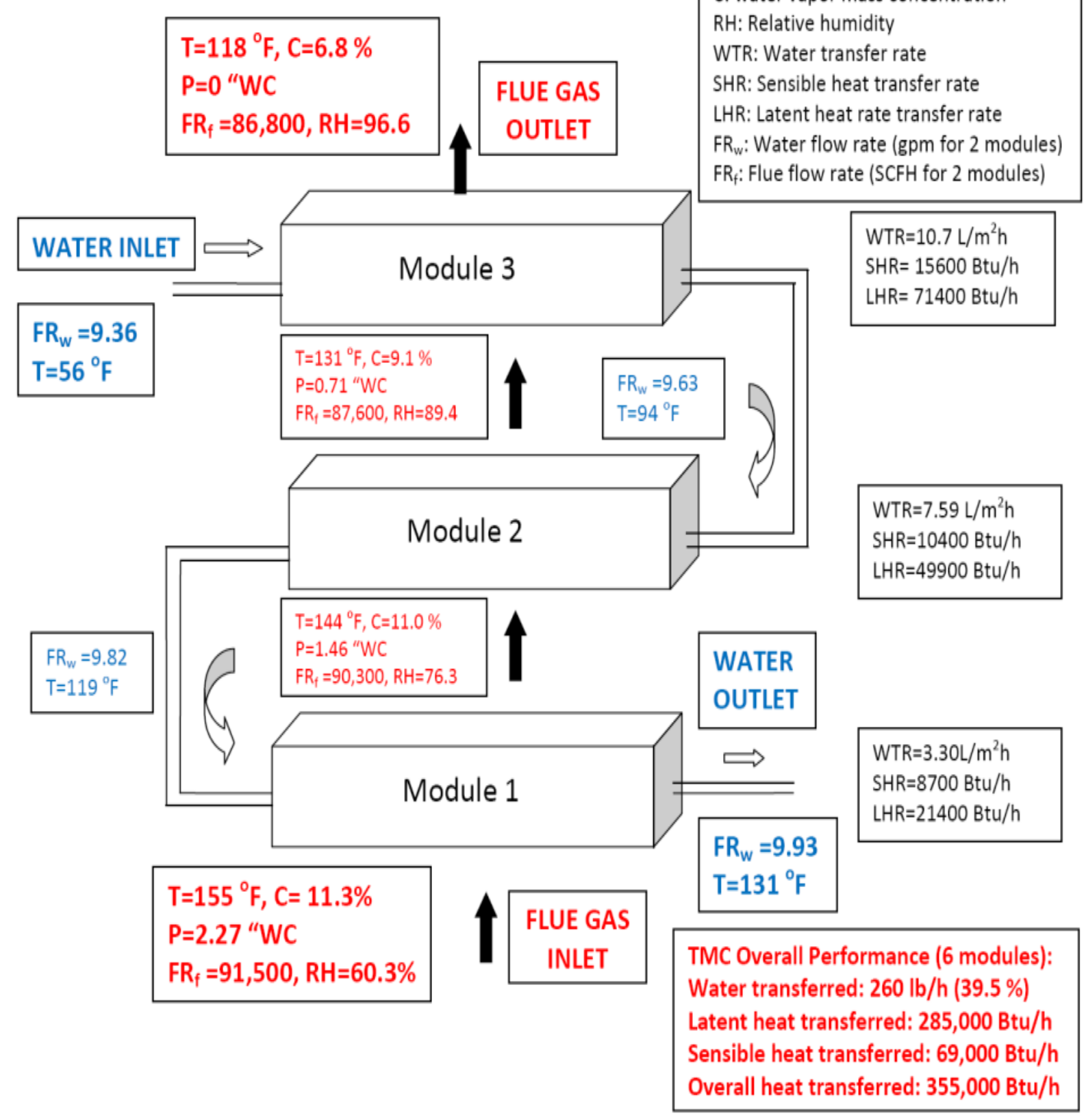

Figure 50. CFD simulation suggests a 3-pass TMC new design. 
$Q_{\text {cond }}=f^{*}\left(t_{\text {gas }}-t_{\text {surface }}\right)^{0.75}$

The factor $f$ in the above equation depends on the properties of the vapor and the condensate.

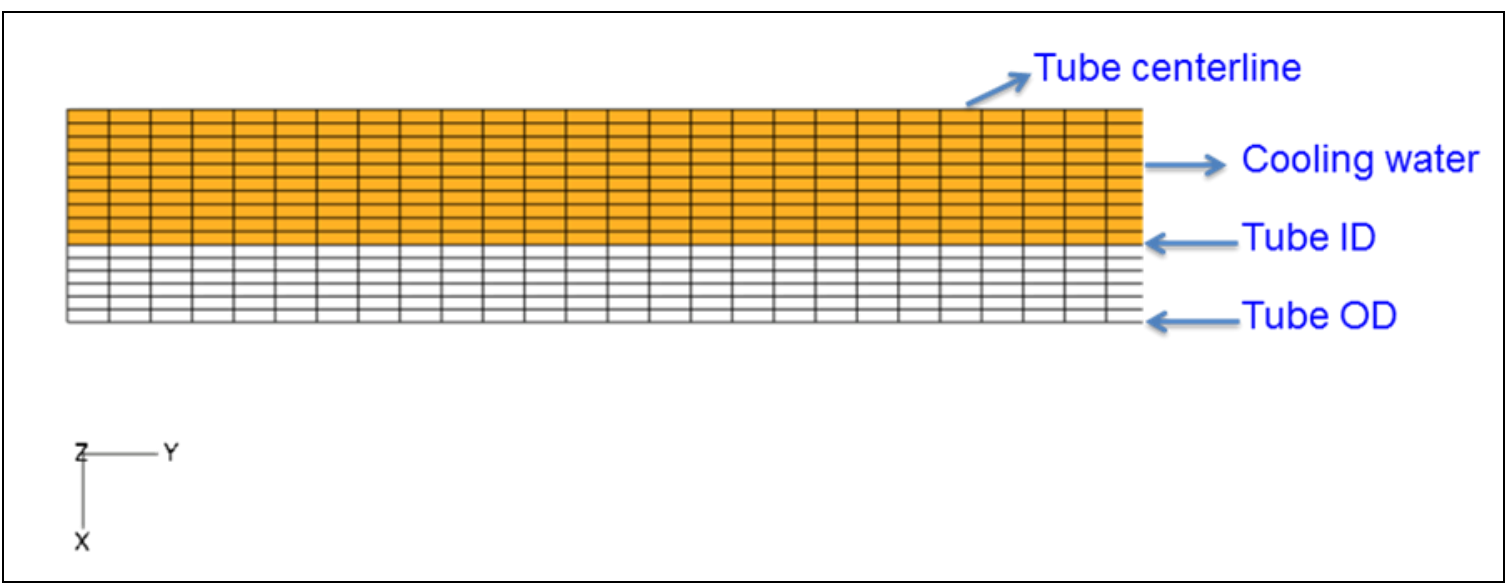

Figure 51. Mesh for the finite element model to study heat transfer in a single tube showing a section of the tube near the inlet.

Effect of changing the thermal conductivity of the tube material was examined using the heat transfer model of the single tube. Starting with a baseline case to determine the factor $f$ that gave reasonable values for the outlet water temperature (Fig. 52), the effective thermal conductivity of the tube was increased by up to a factor of 5 , but this led to less than $1 \%$ change in tube surface temperature or water outlet temperature. This result suggests that the effective thermal conductivity of the substrate has negligible impact on the heat transfer, and other factors are more important in controlling the heat transfer and water transport rate across the membrane. This is also consistent with the results of the CFD modeling work using FLUENT at GTI.

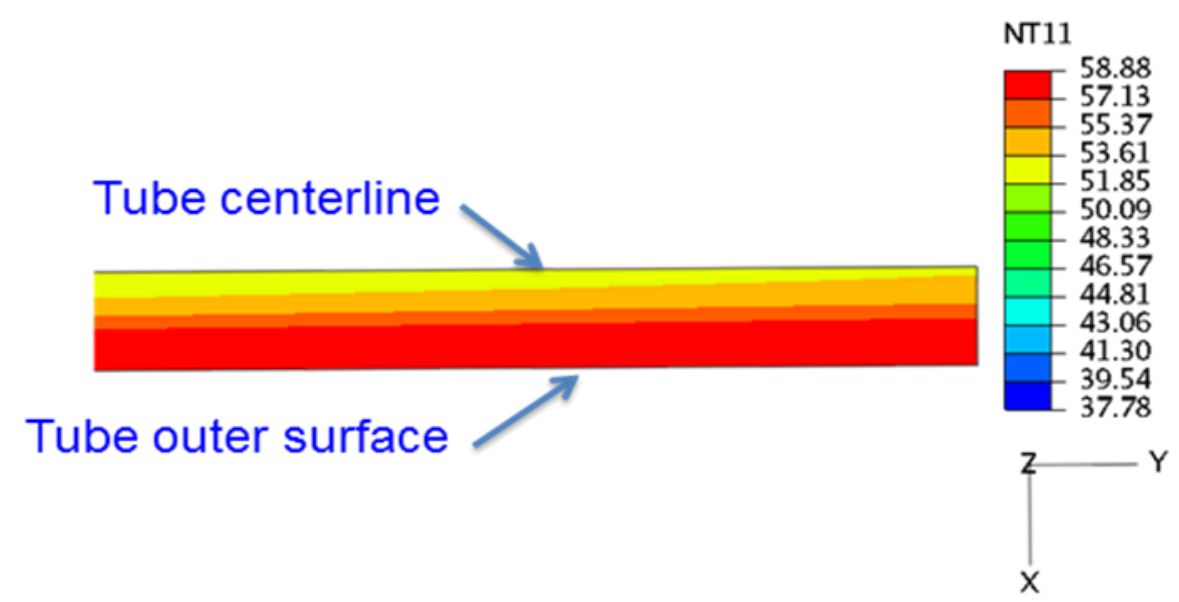

Figure 52. Temperature distribution $\left[{ }^{\circ} \mathrm{C}\right]$ from heat transfer analysis of single tube near the tube outlet.

Based on experiments at GTI, it would appear that the water transport rate is controlled mainly by the average cooling water temperature and the average pore size of the outer membrane layer. However, the pressure difference across the tube wall does not appear to have much effect beyond a certain value. It is therefore necessary to develop a better understanding of the effect of pressure difference 
and pore size on the rate of water transport. A possible scenario for the water transport may be envisioned by examining the water level at the outer surface of the membrane, as illustrated in Fig. 53. An equilibrium meniscus is established initially at the top of the membrane, due to capillary action in the porous medium. When water starts to condense at the top, the extra water could be instantaneously ejected at the bottom (tube ID) in order to maintain the equilibrium meniscus shape, provided the resistance to flow is zero. Since the membrane has a finite permeability, a pressure difference has to be applied across the tube wall to remove the water out of the capillary. In this case, if the condensation rate is greater than the water transport rate, the meniscus will gradually fill up to take a non equilibrium shape, and the excess water will eventually run down the side of the tube. Increasing the pressure difference will allow a higher flow rate, so that when condensation and flow rates become equal, the equilibrium meniscus shape will be regained. Further increase in the flow rate beyond this limit will require depressing the meniscus below the equilibrium profile, which requires significantly higher pressure difference than those used in the experiments.

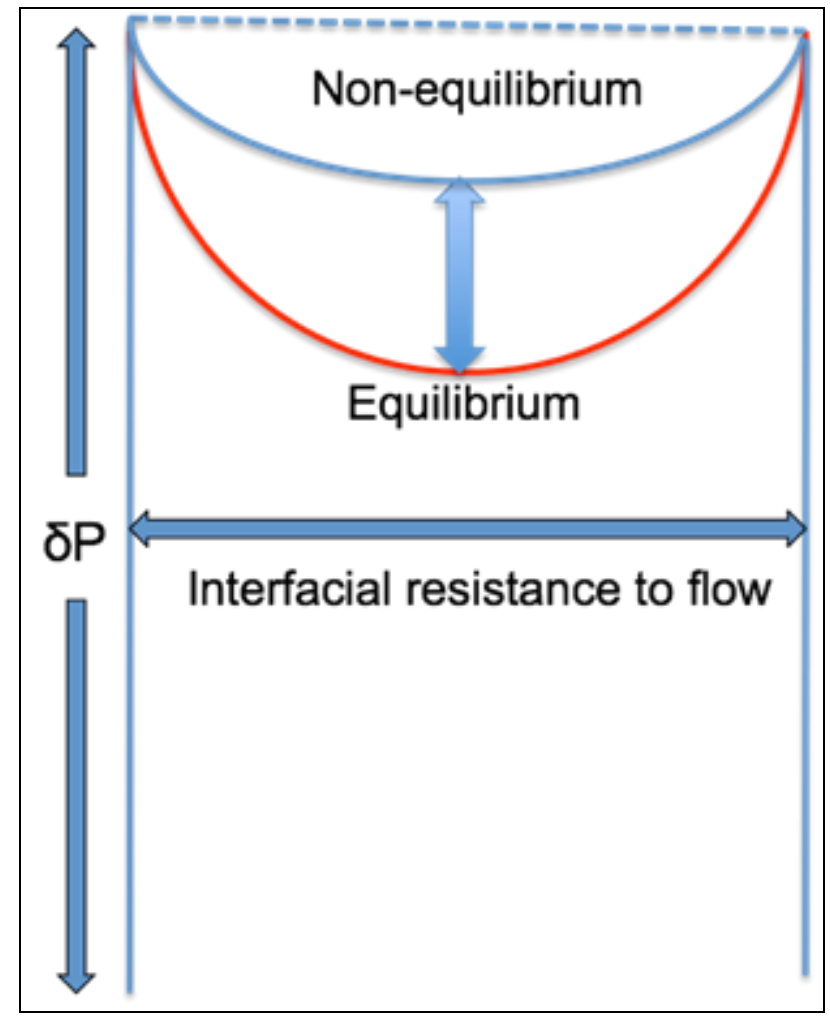

Figure 53. Schematic representation of the water meniscus at the top (outer) surface of the membrane for the case of a cylindrical pore.

Large-scale molecular dynamics simulations using the program LAMMPS were carried out to capture the adsorption of water molecules on an alumina surface. Water molecules were modeled using the TIP4P potential and the alpha alumina surface is modeled using an ab initio potential (J.D. Gale et al., Modelling and Simulation in Materials Science and Engineering, 1992, pp. 73-81).

Simulations of fouling using the molecular dynamics approach showed the interaction of water molecules with an alumina substrate containing a cylindrical hole. The preferential adsorption of water molecules to the edges of the hole and the sidewalls of the substrate was indicated. The next step was to investigate the behavior when both water and molecules of the fouling agent are present along with the substrate. Before investigating this system that contains three different species, it was first 
decided to investigate a system consisting only of water and $\mathrm{CO}_{2}$ molecules. Also, in the earlier simulations, the Noose-Hoover thermostat that was employed for temperature control did not perform satisfactorily. Therefore, one of the objectives of the study was to optimize the parameters in the thermostat to obtain good temperature control. The simulations were carried out in a $60.0 \mathrm{~nm} \times 60.0$ $\mathrm{nm} \times 60.0 \mathrm{~nm}$ volume. The simulation volume contained 173 water molecules and $52 \mathrm{CO}_{2}$ molecules consistent with the analysis of flue gas that contains typically $12 \%$ of water vapor and $9 \%$ of $\mathrm{CO}_{2}$ by weight. The temperature of the water and $\mathrm{CO}_{2}$ molecules was controlled at $350 \mathrm{~K}$ consistent with the inlet flue gas temperature of $82^{\circ} \mathrm{C}$ that was determined by earlier experiments. The presence of a large fraction of nitrogen molecules was not considered in the analysis. The objective of the analysis is to determine if the interaction between water and $\mathrm{CO}_{2}$ molecules is sufficient to trap some of the water molecules. The TIP4P potential was used for the water molecules and an Elementary Physical Model (EPM) potential with rigid bond length and a fixed bond angle of $180^{\circ}$ was used for the $\mathrm{CO}_{2}$ molecules. The interaction between the atoms belonging to different molecules was prescribed using the well known Lorenta-Berthelot mixing rules.

Figure 54 shows the temperature during the simulation for the water and $\mathrm{CO}_{2}$ molecules for a $350 \mathrm{~K}$ run. It shows initial fluctuations that reduce significantly as the simulation time increases. In the later stages of the run the temperature was controlled to within $\pm 10 \mathrm{~K}$. Figure 55 shows the initial distribution of the water and $\mathrm{CO}_{2}$ molecules within a slice of $3.0 \mathrm{~nm}$ in thickness perpendicular to the $\mathrm{z}$-direction. Several such slices perpendicular to the $\mathrm{x}$ and $\mathrm{y}$ directions were also analyzed. The results indicate that for both $300 \mathrm{~K}$ and $350 \mathrm{~K}$ runs, the water molecules show a tendency to cluster. However, there is no clear association of these clusters with the $\mathrm{CO}_{2}$ molecules. $\mathrm{H}_{2} \mathrm{O}$ clusters were observed both with and without the $\mathrm{CO}_{2}$ molecules indicating no strong interaction.

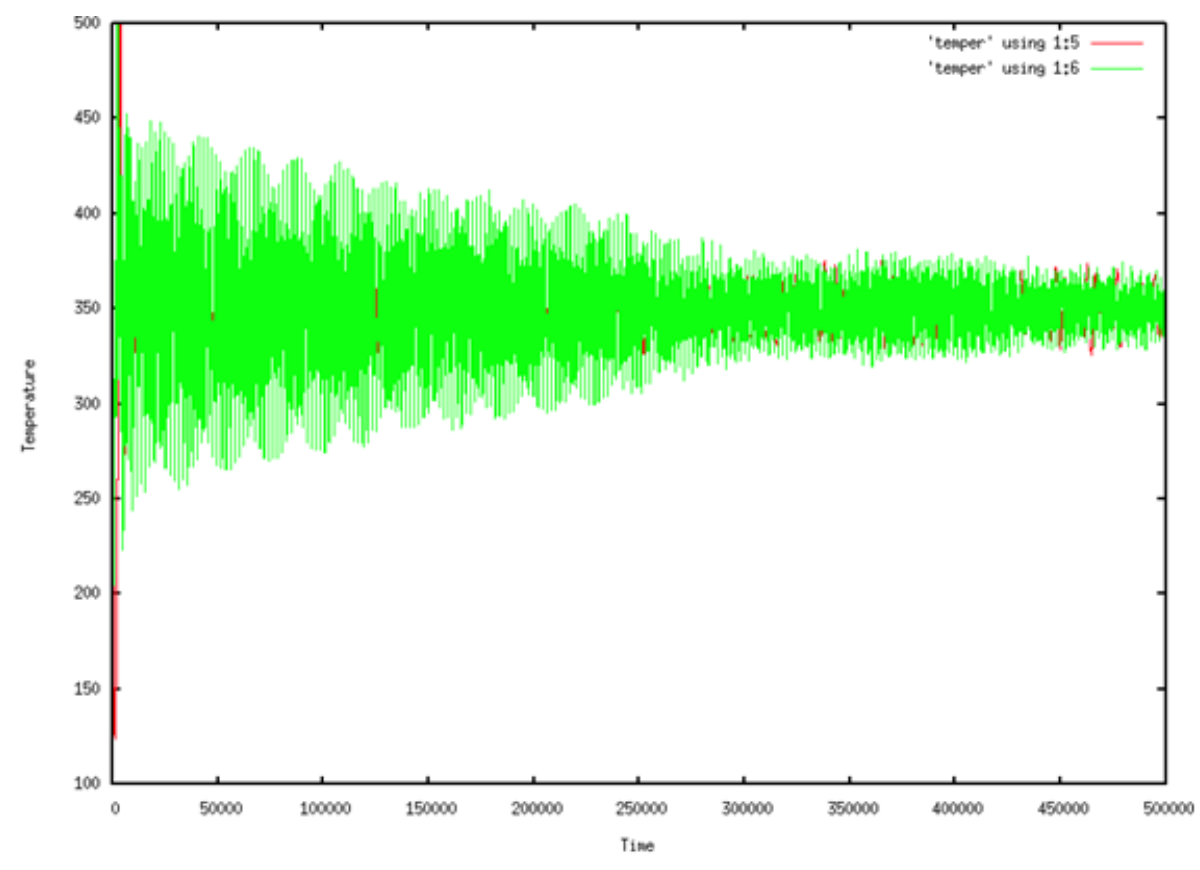

Figure 54. Temperature of the water (red) and $\mathrm{CO}_{2}$ (green) molecules during the $350 \mathrm{~K}$ run. 

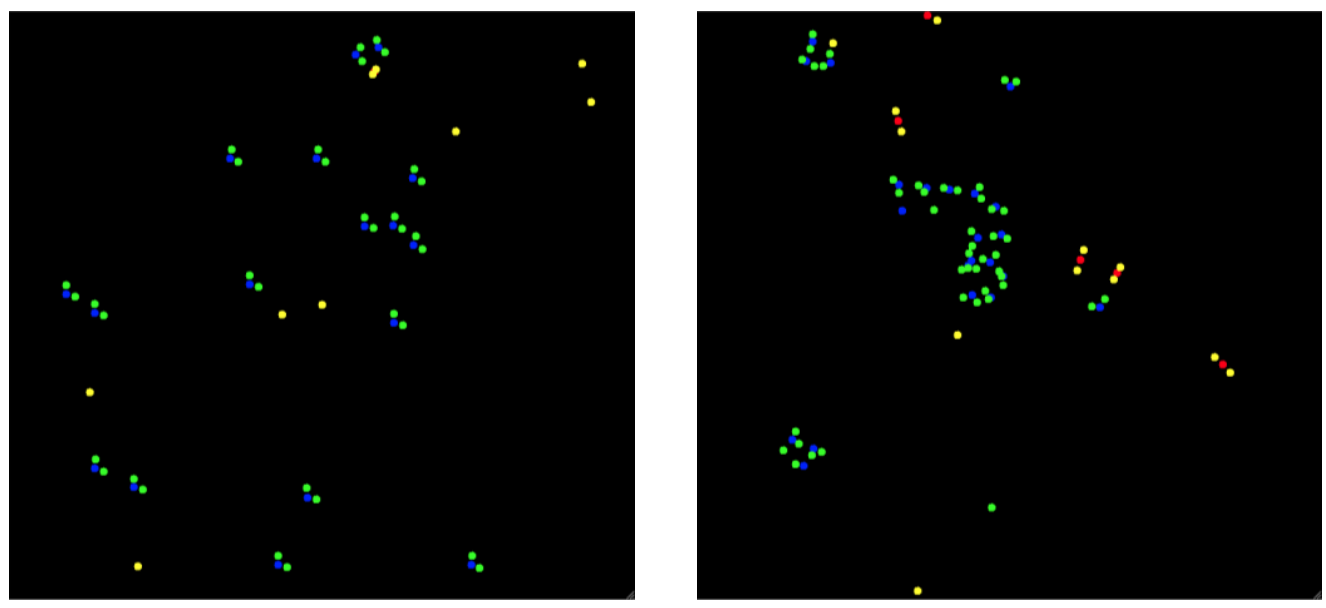

Figure 55. Initial distribution (left) and final distribution (right) of the water molecules (green and blue) and $\mathrm{CO}_{2}$ molecules (red and yellow) showing clustering of water molecules for the $300 \mathrm{~K}$ run. Similar trend was observed for the $350 \mathrm{~K}$ also.

The molecular dynamics simulations using a mixture of $\mathrm{CO}_{2}$ and $\mathrm{H}_{2} \mathrm{O}$ molecules at the flue gas temperature that was carried out in order to simulate the bonding between the different molecules provided some useful information, but it was found not to be suitable for modeling the adsorption of different molecules on the alumina substrate and the influence of impurity molecules on the adsorption of water on the alumina substrate. Consequently, it was decided to switch to Monte Carlo simulations in order to capture capillary condensation of water in nanopores with or without the presence of impurity molecules.

A Grand Canonical Monte Carlo (GCMC) simulation with constant chemical potential, temperature and volume conditions ( $\mu \mathrm{VT})$ was used to simulate the capillary condensation process. In the grand canonical simulations, the volume and temperature of the system are fixed and the number of molecules in the system is a variable that keeps the chemical potential of the system constant. At equilibrium, the chemical potential of the water molecules is the same for the condensed water and the water vapor in the system. The simulations were used to perform a parametric study of the effect of variables such as pore diameter, temperature, ratio of the water-water and water-substrate binding energies, and the chemical potential of water molecules in the system (which is proportional to the number of water molecules in the vapor form, and hence the relative humidity). The interface between condensed water and water vapor was obtained by calculating the mean residence time of the water molecules after the system evolved to an equilibrium configuration. Figure 56 shows the equilibrium configurations of the water molecules using contour plots of the mean residence time within the nanopore. From Figure 56 it can be seen that at constant temperature, chemical potential, increasing the pore size from 5.0 to 8.0 significantly reduces the fraction of condensed water. In fact, under such conditions there is just a monolayer of molecules adsorbed on the inner walls of the 8.0 size pore, while the pore of size 5.0 is almost filled with condensed water. Similarly for the same pore size of 5.0 and the same chemical potential, increasing the reduced temperature from 0.40 to 0.50 significantly reduces the fraction of capillary condensation. 


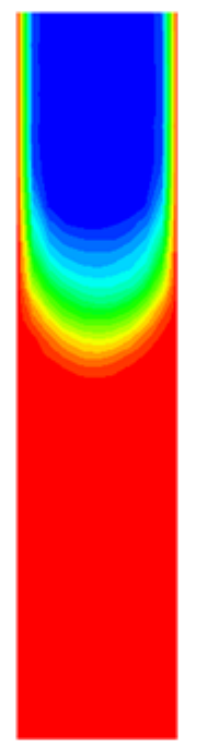

(a)

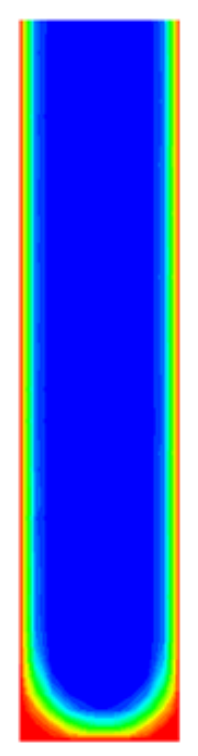

(b)

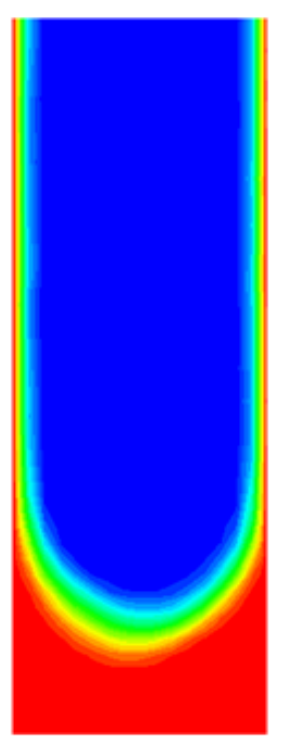

(c)

Figure 56. GCMS simulations showing capillary condensation of water in a rectangular cavity, (a) temperature $=0.4$, pore size $=5.0 ;$ (b) temperature $=0.5$, pore size $=5.0 ;$ (c) temperature $=0.4$, pore size $=8.0$. Increasing the temperature at constant pore size or increasing pore size at constant temperature lead to reduction in the amount of capillary condensation.

Simulations were also carried out in which the pore size, temperature and system volume were kept constant while the chemical potential (proportional to the relative humidity) was systematically increased. As shown in Fig. 57, the fraction of condensed water increases abruptly within a narrow interval of chemical potential which indicates the capillary condensation process occurs where a pore initially containing just a monolayer of adsorbed water molecules is completely filled with condensed water. The interface between condensed water (colored red) and water vapor (colored blue) is marked by a gradual decrease in the residence time from water to the vapor side and hence is a diffuse interface.

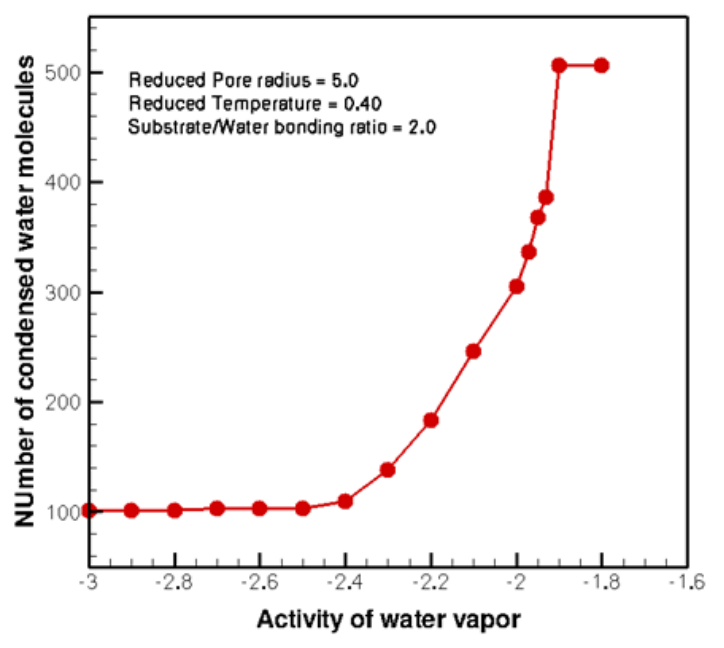

Figure 57. Variation of condensed water content in the pore as a function of chemical potential of water (proportional to the relative humidity). Sudden increase in the fraction condensed indicates filling of pores by capillary condensation. 
This GCMC simulation of capillary condensation describes the condensation of water in a periodic simulation box without any internal surfaces to simulate bulk condensation. The activity of the water molecule was varied systematically while the pore temperature was kept constant at 0.4 . Figure 58 shows the condensation curves if bulk condensation is introduced into the process. The capillary condensation in a reduced pore radius of 4.0 is the same as the one shown in Fig. 57. The condensation curve for the homogeneous case is shifted significantly to the right. The activity of water is proportional to the logarithm of the relative humidity. From the simulation results it can be see that bulk condensation requires a significantly higher relative humidity. The initial condensation fraction of 0.2 for the capillary condensation case is due to the presence of an adsorbed monolayer of water molecules even a very low level of relative humidity. The condensation curves were also obtained by keeping the relative humidity at a constant value of -1.8 and gradually reducing the temperature. The results are shown in Fig. 59, and this figure shows that the bulk condensation occurs at a reduced temperature of about $0.34-0.36$. However, for the same relative humidity, it was shown earlier that condensation with complete pore filling occurred at a higher reduced temperature of 0.4.

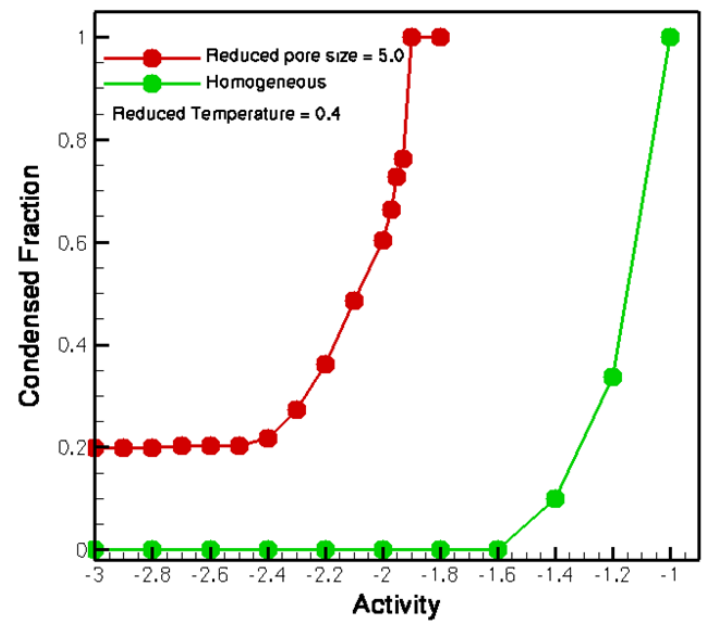

Figure 58. Comparison condensation curves for bulk and a pore of reduced radius of 4.0. The reduced temperature is 0.40 .

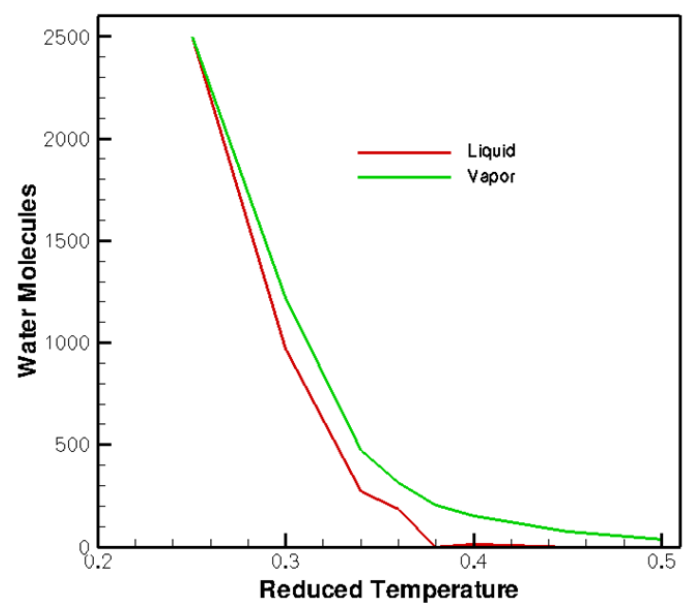

Figure 59. Bulk condensation as a function of reduced temperature with an activity level of -1.8. Condensed water appears below a reduced temperature of 0.38 and becomes significant at much lower reduced temperatures. 


\subsection{TASK 9 - CONDUCT COMMERCIAL SCALE PROTOTYPE TESTING}

The objective of this task is to evaluate the performance of the metallic substrate tubes with the modified construction (membrane on OD rather than ID) in a commercial scale test system. For this test, a sufficient number of metallic substrate tubes, pretested for their integrity by M\&PT, were shipped to GTI where they were assembled into three TMC modules. Fabrication of these tubes had to be done in ORNL and M\&PT facilities, and the tubes had to be shipped between the two facilities several times in order to apply and sinter each of the membrane layers. The quality of the finished tubes would be expected to be better if they were mass produced in one facility, but that was not an option for this first set of tubes. Consequently this first set had deficiencies that would not be expected in mass produced tubes. The first module assembled had small uniform bubbles coming from the surface of some tubes when internally pressurized with air at $3 \mathrm{psig}$, and bubbles were coming from all tubes at 6 psig. The No. 2 module had one leaking tube and No. 3 module had two leaking tubes.

The three metallic-tubed modules were installed in GTI's 3MMBTU/hr boiler test system. Figure 60 shows one of the metallic-tubed modules and the prototype TMC test system modified for the longer modules [86 cm (34 in)]. The flue gas flow rate was 30,000 standard cubic feet per hour (SCFH). Figure 61 shows the water and heat transfer rate at different average water temperatures, which is a parameter representing the combined effect of cooling water inlet temperature and flow rate. For heat recovery, $10-20 \%$ of the heat recovered was from the flue gas sensible heat while the remaining was from recovery of latent heat. Figure 61 also shows the water and heat recovery results for a test with high moisture content flue gas, and the water transfer rate increased $40-60 \%$ for flue gas with high moisture content at the same cooling water flow rate and inlet temperature.
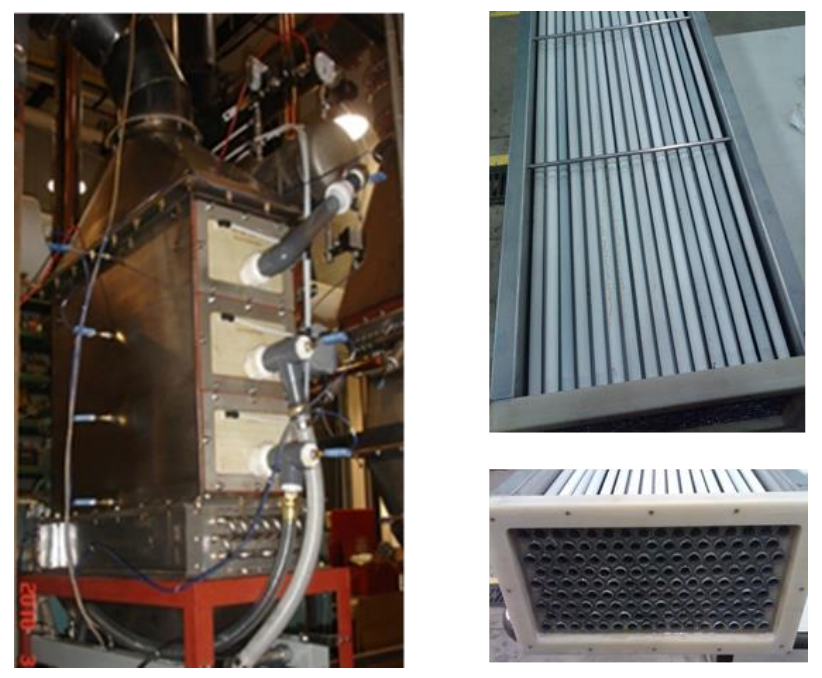

Figure 60. (left) prototype TMC test system used for evaluating metallic-substrate tubes and (right) front and top view of metallic-tubes module 

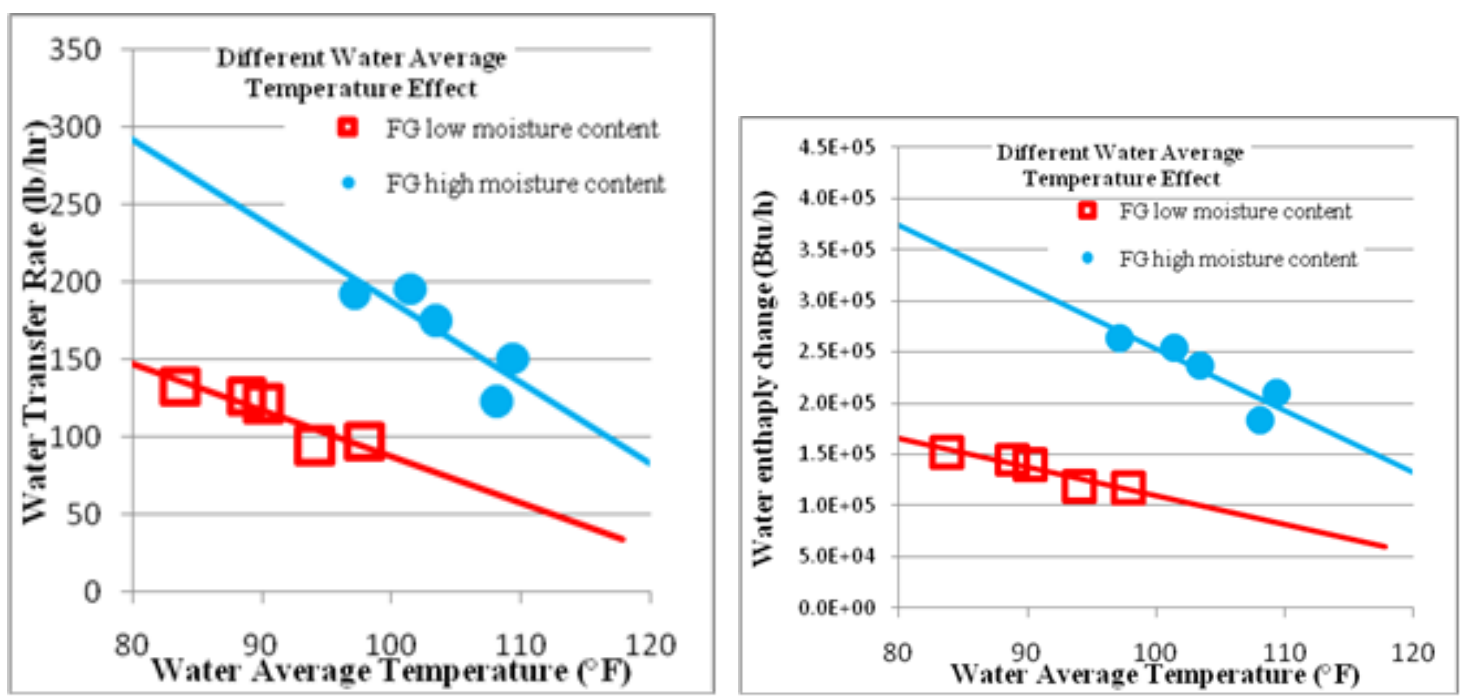

Figure 61. Effect of average water temperature on water and heat recovery

Figure 62 shows the water and heat recovery comparison of ceramic and metallic modules for flue gas. The results show somewhat less water and heat recovery for metallic modules than ceramic modules. However, the comparison between ceramic and metallic tube performance is not conclusive because there are many differences between the two kinds of modules. Although surface area are essentially the same, there are significant differences in tube diameters, which affects 1) heat transfer to the water within the tube, 2) the tube arrangement (the stagger pattern can only be used to fit into the module with the same surface area of metallic tubes), 3) the flue gas flow passages (metallic one has much smaller flow passage), and 4) the flue gas flow velocity and thus residence time and heat transfer coefficients. In general, their performances are similar and both demonstrate good water and heat recovery. These differences along with the fact that these metallic-substrate modules were the "first of a kind" means that no significant difference in performance can be deduced from these tests. However, when the robustness of the metallic-based tubes is compared to that of the ceramic-based tubes there is a definite advantage to the metallic-based tubes.
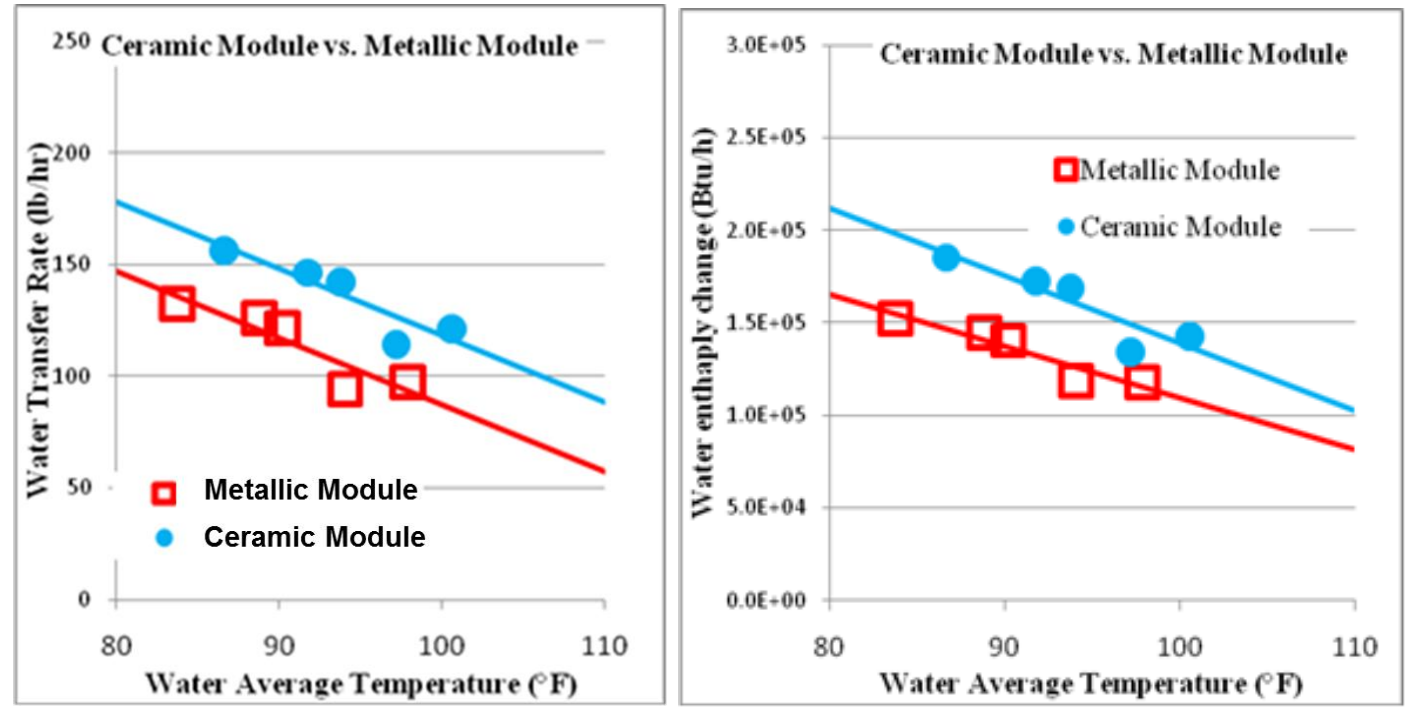

Figure 62. Water and heat recovery performance for metallic-tube modules and ceramic-tube modules. 


\subsection{TASK 10 - CONDUCT PRODUCT OPTIMIZATION STUDIES, ECONOMIC ANALYSIS AND COMMERCIALIZATION POTENTIAL}

In order to estimate the economic costs and benefits of TMCs that incorporate longer, larger diameter, metallic substrate tubes, staff members of M\&PT built on information provided by Cannon Boiler Works (CBW) for module preparation, system construction, and system installation. CBW is the licensee of the TMC technology utilizing ceramic substrate tubes, so they are a reliable source of information on TMC fabrication.

This economic analysis considered a commercial unit containing nine 400-tube (ceramic) TMC bundles (18" length, $80 \AA$ pore size, ca. $3.1 \mathrm{~m}^{2}$ of total surface area) and designed to recover heat from the flue gas of a $300 \mathrm{Hp}$ boiler burning natural gas. In addition to the TMC subsystem (TMC membranes, tube sheets, module framework, cold water pumping subsystem, vacuum pump, duct fan, etc.) other major equipment includes the low and high pressure economizers (heat exchangers) and associated pumping and flue ductwork hardware.

Based on information provided by CBW, the overall installed equipment cost for the system described above is about $\$ 196,500$. Of this total, approximately $32 \%(\sim \$ 62,800)$ is attributable to the TMC tubes, end caps, tube sheets, housing/frame and labor. Further, the tube cost in this installation is approximately $\$ 6,000$. The balance of the capital cost includes the low and high pressure economizer and components that are shared by each of these subsystems including costs such as ductwork, pump, plumbing, control, installation and labor. Hence, it is difficult to break out the cost of a standalone TMC unit, and further such a unit is generally not considered without, at minimum, including an integral low pressure economizer. However, an estimate of the installed cost of a standalone TMC would be in the range of ca. $\$ 115,000$.

CBW also provided estimates of the cost savings that can be achieved with a TMC unit (including an integral low pressure economizer) with and without a high pressure economizer. These data are shown in Table 11 and can be used to estimate the cost savings and payback period for TMCs with both ceramic and metallic tubes. As can be seen, the fully integrated TMC with low and high pressure economizer is expected to boost the efficiency of the base case $300 \mathrm{Hp}$ boiler from ca. 80 to $95 \%$. Annual fuel savings are estimated to be ca. $\$ 141,000$ per year yielding a capital payback in less than 18 months.

Table 11. Comparison of the capital cost and energy cost savings of a typical $300 \mathrm{Hp}$ steam boiler operating at a base case of $80 \%$ efficiency with a (i) standalone high pressure economizer and (ii) high pressure economizer with TMC and integral low pressure economizer. Assumes 8,400 annual operating hours and natural gas at $\$ 8.50 / \mathrm{MCF}$.

\begin{tabular}{|l|l|c|c|c|}
\hline & & High Pressure & TMC w/integral \\
System Description & Base Case & Economizer Only & LPE + HPE \\
\hline System Efficiency & $80 \%$ & $85 \%$ & $95 \%$ \\
\hline Fuel Savings / Year & $\$ 0$ & $\$ 53,550$ & $\$ 141,000$ \\
\hline Equipment Cost & $\$ 0$ & $\$ 33,000$ & $\$ 196,500$ \\
\hline Water Savings & 0 & 0 & Up to 58 gph \\
\hline
\end{tabular}

As noted above, the capital cost of the membrane tubes represents a little over $3 \%$ of the total cost of the installed equipment. For a total surface area of ca. $27 \mathrm{~m}^{2}$, the cost of ceramic substrate tubes is approximately $\$ 230 / \mathrm{m}^{2}$. At the moment, it is expected that the current cost of the stainless steel 
membrane tubes is on the order of $\$ 750$ to $\$ 1,000 / \mathrm{m}^{2}$. At this cost, the total membrane tubes cost would be on the order of $\$ 20,000$ to $\$ 27,000$ for the $300 \mathrm{Hp}$ boiler, pushing the estimated total TMC installed cost (including HPE and LPE) to about $\$ 211,000$ to $\$ 217,000$. Further, the tube cost would represent a little less than $11 \%$ of the overall unit cost for an equivalent surface area. Hence, although the stainless steel tubes are considerably more expensive, they represent only a relatively small increase in the overall system cost and increase the capital payback by only a few months. This cost payback is still likely within the target range required for this technology. Further, optimization of the stainless steel tube production would likely continue to lower the cost, providing incentive to use the stainless steel based TMC membrane element given its various advantages in heat transfer and mechanical stability.

There are other considerations that would impact the value of TMC use and the payback period. Any reduction in the price of natural gas will result in a longer payback period for recovery of the cost of installation of the TMC system. Not considered in the calculations is the value of the water that would be recovered. In some locations, this is not a significant gain, but in some water deficient areas, particularly in the southwestern U.S., there would reportedly be a substantial value to the recovered water. 


\section{COMMERCIALIZATION}

The information developed in Task 10 shows there is an economic benefit to the use of metallicsubstrate TMC modules and the payback period is within a reasonable length of time. The TMC technology using the improved TMC design with ceramic-substrate TMC modules has been licensed by GTI to CBW, but the technology using the metallic-based tubes has not been licensed to a supplier. Ceramic tube based TMCs are being successfully operated at several industrial sites in the United States. However, experience with a ceramic-tubed TMC system installed on a natural gas fired boiler at ORNL demonstrated that the brittle nature of the ceramic-based tubes presented shortcomings that would likely be avoided with a metallic-based system.

Representatives of several companies have indicated to GTI and ORNL staff members that they have an interest in the metallic-based TMCs and would be willing to serve as host sites for commercial demonstration of the technology. However, it is unlikely that companies will invest in such a system nor that a distributor will negotiate a license until there is a successful, extended-term demonstration of a full-scale system on a commercial scale.

\section{ACCOMPLISHMENTS}

No open literature journal articles resulted from this project, but quarterly reports and topical reports were produced by the project participants. Presentations were made to a variety of groups, both visitors to ORNL and at off-site locations, describing the results of the project. Organizations to whom presentations were made include the aluminum producer Alcoa, the paper company Domtar, the steel maker Arcelor Mittal and a number of other companies.

No new intellectual property was developed for this project. 


\section{CONCLUSIONS}

This project has successfully demonstrated that 34 inch long, 0.4 inch diameter tubes can be fabricated using a stainless steel substrate with a ceramic membrane applied to the outer surface. Studies of fouling and corrosion of this tube configuration were conducted to address potential issues.

Fouling studies conducted by M\&PT concluded that fouling could be avoided or controlled, and a three-pronged technical approach was introduced. To avoid irreversible fouling due to penetration or clogging of pores, use of membranes with selected pore sizes was recommended. Specifically, membranes with pores in the 4 to $10 \mathrm{~nm}$ range showed insignificant plugging in laboratory tests.

To avoid fouling by dissolved organic material, modification of the membrane surface with highly hydrophilic functional groups has been reported to have prevented, or at least minimized, interaction of the organic material with the membrane surface.

Concentration polarization $(\mathrm{CP})$ is another potential cause of fouling, but methods are being used that can disrupt or minimize the $\mathrm{CP}$ layer. Periodic backpulsing can dislodge a layer that might accumulate on the membrane surface. Another approach is to use a two-phase gas-liquid "slug" flow to create turbulence and disrupt any layer formed on the surface of the membrane.

The conclusion is that fouling can be avoided, or greatly minimized, and high fluxes maintained with the approaches that include appropriate pore size selection, use of selective surface coatings and use of techniques to prevent or minimize formation of disruptive surface layers.

The corrosion behavior of selected metallic and ceramic materials was determined in very aggressive acidic solutions. It is somewhat unlikely that the metallic components would ever encounter such solutions, but testing was initiated in these environments because it was not certain whether or not species like sulfur dioxide, carbon dioxide and hydrogen sulfide would be able to dissolve in significant quantities in the pores of the outermost membrane layer. Previous studies conducted at GTI did not indicate an increase in carbon dioxide content in the cooling water, so there is some evidence strongly acidic solutions would not be developed during normal operation. However, during periods of a reduced rate of water recovery, water might remain in the pores for an extended time, and it is not clear whether this condition would result in greater dissolution of soluble gaseous species.

Based on laboratory corrosion studies, it appears that ferritic stainless steels with at least $16 \frac{1}{2} \%$ chromium content would be required to provide sufficient corrosion resistance in the event the substrate were to encounter a fairly acidic solution. Because of their higher thermal conductivity, ferritic stainless steels would seem a better choice than the austenitic stainless steels. Consequently, if corrosion of the $16 \frac{1}{2} \% \mathrm{Cr}$ alloy were deemed to be a cause for concern, it might be appropriate to consider commercial ferritic steels with higher chromium content like $18 \mathrm{Cr}-2 \mathrm{Mo}$ or $26 \mathrm{Cr}-1 \mathrm{Mo}$.

Corrosion of the alumina layer can be an issue if $\gamma$-alumina is used for the outer membrane layer(s) and it is exposed to acidic solutions with $\mathrm{pH}<4$ or basic solutions with $\mathrm{pH}>10$. If a higher firing temperature is used, $\delta$-alumina phase is formed, and this phase has improved stability in acidic solutions, but some pore growth can be expected at $\mathrm{pH}$ extremes.

Three modules were fabricated using these metal-based tubes, and they were successfully operated as part of a TMC on a natural gas fired boiler at GTI. The new design with water flowing through the 
inside of the tubes rather than on the outside was demonstrated with the long metal-based tubes as well as with the older design, shorter alumina-based tubes. The first-of-a-kind metal-based tube modules performed favorably compared to the ceramic-based tubes, and the robustness of the metal-based tubes provided a significant advantage.

\section{RECOMMENDATIONS}

Although the demonstration conducted at GTI showed that the TMC using the updated design and metallic substrate tubes gives acceptable performance, industries are not likely to install this generation of the TMC until tube fabrication is demonstrated on a commercial scale and a system is installed and successfully operated for an extended period on a commercial system whether it be a boiler, a kiln, or the exhaust from a dryer or evaporator. Consequently, the recommendation is for a project to be fully or even partially funded to construct and install TMCs on at least two commercial systems. 


\section{REFERENCES}

1. J. Boyen, Thermal Energy Recovery, JOHN WILEY \& SONS, (1980).

2. Bend Research, Research on an Energy-Efficient Drying Process, DOE Final Report, DOE/ID/12293-1 (DE86013369), Feb.25, (1986).

3. H. Strathman, B. Bauer and J. Kerres, Polymer Membranes with Selective Gas and Vapor Permeation Properties, Makromol. Chem., Macromol. Symp., v. 33, p.161-178, (1990).

4. J. Randon, and R. Paterson, Preliminary Studies on the Potential for Gas Separation by Mesoporous Ceramic Oxide Membranes Surface Modified by Alkyl Phosphonic Acids, J. of membrane science, V.134, P.219-223, (1997).

5. R. Noble, S. Stern, Membrane Separations Technology Principles and Applications, Elsevier, (1995).

6. D. E. Fain; Membrane gas separation principles; MRS Bulletin/April, v.19(4); p.40-43,(1994).

7. S. Vercauteren and K. Keizer; Porous ceramic membranes: preparation, transport properties and applications; J. of Porous Materials, v.5, p.241-258, (1998).

8. M. Asaeda, L. Du and K Ikeda: Experimental studies of dehumidification of air by an improved ceramic membrane; J. of Chemical Engineering of Japan, v.3, p.238-240, (1986).

9. J. Falconer, R. Noble and D. Sperry, Catalytic membrane reactors, In: R. Noble and S. Stern (Eds.), Membrane Separations Technology, Elsevier, Amsterdam, (1994).

10. M. Qiu and S. Hwang, Continuous Vapor-Gas Separation with a Porous Membrane Permeation System, J. Membrane Science, v. 59, p. 53-72, (1991).

11. R. Uhlhorn, K. Keizer, and A. Burggraaf, Gas Transport and Separation with Ceramic Membranes. Part I Multilayer Diffusion and Capillary Condensation, J. Membrane Science, v. 66, p. 259-269, (1992).

12. B.V. Schlichter, H.C. Mavrov, "Study of a hybrid process combining ozonation and membrane filtration - filtration of model solutions", Desalination, 156, 257(2003)

13. E. Aoustin, etc., "Ultrafiltration of natural organic matter", Sep. Puri. Tech., 22-23, 63(2001)

14. R.J. Ciora, Jr. and P.K.T. Liu, "Ceramic membranes for environmental related applications", Fluid/Particle Sep. J., 15, 51(2003)

15. D. Vial, G. Doussau, and R. Galindo, "Comparison of three pilot studies using Microza membranes for Mediterranean seawater pre-treatment", Desalination, 156, 43(2003)

16. S. Van Hoof, J.G. Minnery, B. Mack, "Dead-end ultrafiotration as alternative pre-treatment to reverse osmosis in seawater desalination: a case study", Desalination, 139, 161(2001)

17. K. Chua, M. Hawlader, A. Malek, "Pretreatment of seawater: Results of pilot trials in Singapore", Desalination, 159, 225(2003)

18. S. Laborie, etc., "Flux enhancement by a continuous tangential gas flow in ultrafiltration hollow fibers for drinking water production: Effects of slug flow on cake structure", Filtration \& Separation, October 1997, p. 887

19. R.W. Field, etc., "Critical flux concept for microfiltration fouling”, J. Memb. Sci., 100, 259 (1995)

20. S.S. Madaeni, "An investigation of the mechanism of critical flux in membrane filtration using electron microscopy", J. Porous Materials, 4, 239(1997)

21. J.F. Hester and A.M. Mayes, "Design and performance of foul-resistant polyvinylidene fluoride membranes prepared in a single-step by surface segregation", J. Memb. Sci., 202, 119(2002).

22. D. Rana, etc., "Development and characterization of novel hydrophilic surface modifying macromolecule for polymeric membranes", J. Memb. Sci., 249, 103(2005)

23. M. Taniguchi, J.E., Kilduff, G. Belfort,'Low fouling synthetic membranes by UV-assisted graft polymerization: monomer selction to mitigate fouling by natural organic matter", J. Memb. Sci., 222, 59(2003) 
24. T. Carroll, N.A. Booker, J. Meier-Haak,'Polyelectrolyte-grafted microfiltration memrbaens to control fouling by natural organic matter in drinking water", J. Memb. Sci., 203, 3(2002)

25. Laborie, S., etc., "Fouling control by air sparging inside hollow fiber membranes - effects on energy consumption", Desalination, 118, 189(1998)

26. V.P. Cary, "Liquid-vapor Phase-change Phenomena, 1992

27. J.D. Gale et al., Modelling and Simulation in Materials Science and Engineering, 1992, pp. 73 81) 